\title{
A Two Dimensional Numerical Soot Model for Advanced Design and Control of Diesel Particulate Filters
}

Prabash E. Abeyratne

West Virginia University

Follow this and additional works at: https://researchrepository.wvu.edu/etd

\section{Recommended Citation}

Abeyratne, Prabash E., "A Two Dimensional Numerical Soot Model for Advanced Design and Control of Diesel Particulate Filters" (2011). Graduate Theses, Dissertations, and Problem Reports. 4680.

https://researchrepository.wvu.edu/etd/4680

This Thesis is protected by copyright and/or related rights. It has been brought to you by the The Research Repository @ WVU with permission from the rights-holder(s). You are free to use this Thesis in any way that is permitted by the copyright and related rights legislation that applies to your use. For other uses you must obtain permission from the rights-holder(s) directly, unless additional rights are indicated by a Creative Commons license in the record and/ or on the work itself. This Thesis has been accepted for inclusion in WVU Graduate Theses, Dissertations, and Problem Reports collection by an authorized administrator of The Research Repository @ WVU. For more information, please contact researchrepository@mail.wvu.edu. 


\title{
A Two Dimensional Numerical Soot Model for Advanced Design and Control of Diesel Particulate Filters
}

\author{
by \\ Prabash E. Abeyratne \\ Thesis submitted to the \\ College of Engineering and Mineral Resources \\ at West Virginia University \\ in partial fulfillment of the requirements \\ for the degree of \\ Master of Science \\ in \\ Mechanical Engineering \\ Vincenzo Mulone, Ph.D. \\ Gregory Thompson, Ph.D. \\ Victor Mucino, Ph.D. \\ Mridul Gautam, Ph.D., Chair
}

Department of Mechanical and Aerospace Engineering

Morgantown, West Virginia

2011

Keywords: Diesel Aftertreatment, Numerical Modeling, Emissions

Copyright 2011 Prabash E. Abeyratne 


\begin{abstract}
A Two Dimensional Numerical Soot Model for Advanced Design and Control of Diesel Particulate Filters

by
\end{abstract}

Prabash E. Abeyratne

One of the most effective methods to control diesel particulate matter (PM) emissions from heavy duty diesel engines is to use wall flow diesel particulate filters (DPF). It is still a major challenge to get an accurate estimation of soot loading, which is crucial for the engine afterteratment assembly optimization. In the recent past, several advanced computational models of DPF filtration and regeneration have been presented to assess the cost effective optimization of future particulate trap systems. They are characterized by different degree of detail and computational costs, depending on the specific application (i.e diagnostics, control, system design, component design etc)

The objective of this study is to compare in detail a two dimensional (2-D) approach with a one dimensional (1-D) approach, thus giving a better insight of the variation of properties over the DPF length. This task has been archived by extending an in-house developed 1-D numerical soot model to the next dimension to understand the impact of $2-\mathrm{D}$ representation to predict both steady state and transient behavior of a catalyzed diesel particulate filter (CDPF). Performance of the model was evaluated using three key parameters: pressure drop, filter outlet temperature and soot mass retained in the filter during both active and continuous regeneration events. Quasi-steady state conservation of mass, momentum and energy equations were solved numerically using finite difference methods adopting a spatially uniform mesh. The results obtained from the current model were compared with the 1-D code to evaluate the general validity of assumptions made in the latter, especially DPF loading status prediction.

The model was validated using the data gathered at the West Virginia University Engine and Emissions Research Laboratory (WVU-EERL) using a model year 2004 Mack MP7-355E Diesel engine coupled to a Johnson Matthey catalyzed diesel particulate filter (CDPF) exercised over a 13 mode European stationary cycle (ESC) followed by two federal transient cycles (FTP). A constant set of model tuning parameters were maintained for the sake of general validation of simplifying assumptions of the $1-\mathrm{D}$ code.

The analysis shows that the predicted pressure drop across the DPF is in good agreement with the data obtained at EERL in both steady state and transient cycles. It is also shown that the soot accumulates mainly in the frontal and rear parts across the filter length under given soot concentrations. The model is capable of tracking DPF soot mass satisfactorily with a maximum discrepancy of $3.47 \mathrm{~g}$ during steady state cycle. A $7.95 \%$ decrease in soot layer thickness can be seen in the front portion of the DPF during the transient cycle mainly due to $\mathrm{O}_{2}$ assisted regeneration at elevated temperatures. Both 1-D and 2-D models produce similar results during the loading phase. However, the current model is able to capture regeneration phase of the FTP cycle more descriptively than the 1-D model. The discrepancy of the reported total soot mass estimation between two models was $2.12 \%$. The distribution corresponding to the $1-\mathrm{D}$ model is representative of soot layer distribution given by the 2-D model at one tenth distance away from the DPF front face. 1-D model representation is effective towards PM prediction, although presenting considerable axial effects at higher DPF temperatures. 


\section{Acknowledgements}

As my graduate studies come to an end, many people come to my mind that I am grateful for. First, my deepest appreciation goes to my beloved family. Ammi, I will never be able to thank you enough for the strength and support you have given me for all my life. You are my inspiration and I'm forever in your debt for the sacrifices you have made during my road to success. Aiyya, the love and support you gave was the strength for me to stand even in difficult times in my life.

I would like to thank my academic advisor Dr. Mridul Gautam for his constant support and encouragement. His support has been invaluable to my education, academic progress and professional development. I extend my sincere thanks to Dr. Vincenzo Mulone for providing me valuable and thought-provoking ideas throughout my research. I would also like to thank other members of my committee Dr. Gergory Thompson and Dr. Victor Mucino for their support and valuable recommendations to my thesis.

I would like to extend my gratitude to my colleagues Alessandro Cozzolini, Daniele Littera, Clay Bell, Mario Velardi and Gennaro Campitelli for providing such a friendly and dynamic atmosphere in the office. I enjoyed working with you all and thank you for lending me a helping hand whenever I wanted.

Finally I would like to express my heartiest thanks to all my Sri Lankan friends Oshadha, Kaushi, Thilanka, Bhakthi, Nipuni, Saman aiyya, Sumudu aiyya and Yudheesha nangi for being such great friends and leaving numerous happy memories in the past six years of my life. 


\section{Contents}

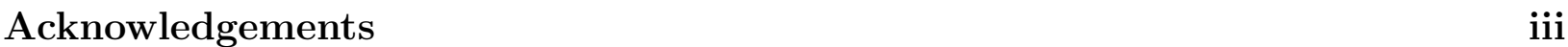

List of Figures $\quad$ vi

List of Tables $\quad$ viii

$\begin{array}{ll}\text { Notation } & \text { ix }\end{array}$

1 Introduction $\quad 1$

2 Literature Review 5

2.1 Emission Regulations . . . . . . . . . . . . . . . . . 5

2.2 Emission Formation in Diesel Engine . . . . . . . . . . . . . . . 6

2.2 .1 Hydrocarbons $(\mathrm{HC}) \ldots \ldots \ldots \ldots$

2.2.2 Carbon Monoxide $(\mathrm{CO})$. . . . . . . . . . . . . . . 7

2.2 .3 Oxides of Nitrogen $\left(\mathrm{NO}_{x}\right) \quad \ldots \ldots \ldots \ldots$. . . . . . . . . . 7

2.2 .4 Particulate matter $(\mathrm{PM}) \ldots \ldots \ldots \ldots$

2.3 Diesel Emission Control Technologies . . . . . . . . . . . . . . . . . . . . . . . . . . . . . . . . .

2.3.1 In-cylinder Control Strategies . . . . . . . . . . . . . . . . . . . 9

2.3.2 Diesel Exhaust Aftertreatment Devices . . . . . . . . . . . . . . . . 11

2.4 Numerical Modeling . . . . . . . . . . . . . . . . . . . . . . . 23

3 Model Description $\quad 26$

3.1 Model Overview . . . . . . . . . . . . . . . . . . . . . . 26

3.2 Wall Filtration Model . . . . . . . . . . . . . . . . . . . . . 28

3.3 Regeneration Model . . . . . . . . . . . . . . . . . . 35

3.3.1 Cake Regeneration Submodel . . . . . . . . . . . . . . 35

3.3.2 Washcoat Regeneration Submodel . . . . . . . . . . . . . . . . . 40

3.3.3 Wall Regeneration Submodel . . . . . . . . . . . . . . . . . . . . 42

3.3.4 Wall Energy Balance . . . . . . . . . . . . . . . . . . 43

3.3.5 Mass, Momentum and Energy Balance . . . . . . . . . . . . . 46

4 Numercal Procedure $\quad 50$

4.1 Solving the Boundary Value Problem . . . . . . . . . . . . . . . . . 50

4.2 Solving the Initial Value Problem . . . . . . . . . . . . . . . . . . . 52 
5 Experimental Setup and Procedures $\quad 56$

5.1 Instrumentation and Laboratory Setup . . . . . . . . . . . . . . 56

5.2 Experimental Procedure . . . . . . . . . . . . . . . . . 58

6 Results and Discussion $\quad 61$

6.1 Steady State Cycle Analysis . . . . . . . . . . . . . . . . . . . . . 62

6.2 Transient Cycle Analysis . . . . . . . . . . . . . . . . . . . . . . . 70

6.3 1-D and 2-D Model Comparison . . . . . . . . . . . . . . . . . . 74

6.3.1 Steady State Cycle Results Comparison . . . . . . . . . . . . . . . . 74

6.3.2 Transient Cycle Results Comparison . . . . . . . . . . . . . . . . 77

$\begin{array}{llr}7 & \text { Conclusions } & 81\end{array}$

A Model Validation Using Bissett Model $\quad 83$

$\begin{array}{ll}\text { References } & 85\end{array}$ 


\section{List of Figures}

2.1 High pressure loop EGR (left) and low pressure loop EGR (right) [17] . . . 10

2.2 Diesel oxidation catalyst (DOC) $[18] \ldots \ldots \ldots \ldots$. . . . . . . . . . 11

2.3 Selective catalytic reduction system $[20] \ldots \ldots \ldots \ldots \ldots$

2.4 Fuel burner for DPF regeneration [16] . . . . . . . . . . . . . . . . 17

2.5 Burner by-pass system for light duty application [16] . . . . . . . . . . . . . 18

2.6 Electrically regenerated DPF $[24] \ldots \ldots \ldots$

2.7 Catalyzed continuously regenerating technology (CCRT) [25] . . . . . . . . . 21

3.1 Schematic of a single channel of the diesel particulate filter . . . . . . . . . . 26

3.2 Model block diagram . . . . . . . . . . . . . . . . . . . . . . . . 28

3.3 Unit collector loading . . . . . . . . . . . . . . . . . . . . . . . . 29

3.4 Schematic of the particle deposition on filter channels . . . . . . . . . . . . 35

3.5 Sectional view of DPF with thermal resistance parameters . . . . . . . . 45

5.1 FTP reference data, exhaust flow rate, exhaust gas specie concentrations and CPF inlet temperature $[40] \ldots \ldots \ldots \ldots$. . . . . . . . . . . 59

6.1 Experimental pressure drop of the DPF during the loading cycle . . . . . . . 63

6.2 Experimental and simulated pressure drop profiles pertaining to four loading

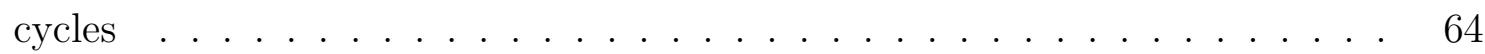

6.3 Experimental and simulated DPF outlet temperature of the $8^{\text {th }}$ loading cycle 65

6.4 Experimental and simulated DPF outlet temperature of the $8^{\text {th }}$ loading cycle 66

6.5 Model predicted filter pressure drop during 18-22 hour time duration during the loading phase . . . . . . . . . . . . . . . . . 67

6.6 Soot layer thickness evolution with time along channel length during a loading cycle . . . . . . . . . . . . . . . . . . . 68

6.7 Soot layer thickness evolution with time along channel length during a loading cycle . . . . . . . . . . . . . . . . . . . . 68

6.8 Soot layer thickness evolution with time along channel length during a loading

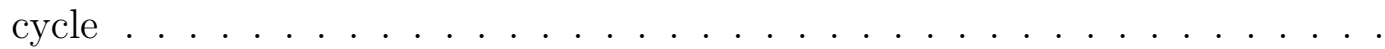

6.9 Experimental and simulated DPF soot mass comparison during the loading phase . . . . . . . . . . . . . . . . . .

6.10 Pressure drop comparison between experimental and numerical data over an FTP cycle . . . . . . . . . . . . . . . . . . 71

6.11 Experimental vs. simulated DPF pressure drop . . . . . . . . . . . . 71 
6.12 Mass balance of DPF during the FTP cycle . . . . . . . . . . . . . . . . 72

6.13 Soot layer thickness distribution along normalized CPF channel length (above); Temporal decay of soot layer thickness at different axial locations (below) . . 73

6.14 Wall velocity distribution comparison along filter length . . . . . . . . . . . . 75

6.15 1-D and 2-D DPF soot mass prediction comparison . . . . . . . . . . 76

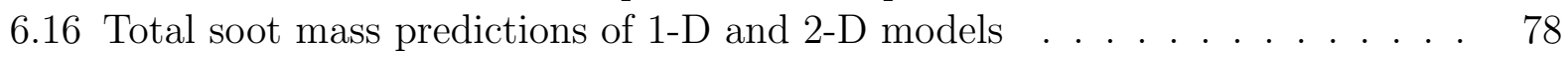

6.17 Temperature distribution variation at different axial locations . . . . . . . 78

$6.18 \mathrm{DPF}$ outlet temperature prediction comparison . . . . . . . . . . . . 79

6.19 Soot layer thickness prediction of 1-D and 2-D models . . . . . . . . . . 80

A.1 DPF pressure drop validation using Bissett model . . . . . . . . . . . . . 83

A.2 Mass retained in the DPF validation using Bissett model . . . . . . . . . . . 84 


\section{List of Tables}

2.1 Heavy-duty compression-ignition engines and urban buses exhaust emission standards $[13] \ldots \ldots \ldots \ldots \ldots \ldots$

4.1 Grid resolution comparison . . . . . . . . . . . . . . . . . . . . 50

5.1 Test engine manufacturer specifications . . . . . . . . . . . . . . . 57

5.2 Geometrical dimensions of the DOC/DPF . . . . . . . . . . 57

5.3 Test point data . . . . . . . . . . . . . . . . . . . . . 58

5.4 Exhaust gas emissions before DOC and after DPF for soot loading mode, 1800 rpm, $10 \%$ load $[40] \ldots \ldots \ldots \ldots \ldots$. . . . . . . . . . . . . . 60

5.5 Exhaust gas emissions before DOC and after DPF for soot regeneration mode,

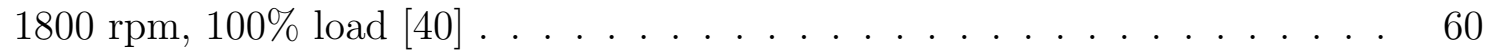

5.6 The average engine out brake specific emissions during two FTP cycles . . . 60

6.1 Model tuning parameters and constants . . . . . . . . . . . . . . . . 62

6.2 Coefficient of determination comparison relevent to 1-D and 2-D model predicted and experimental pressure drop during the 30 hour loading phase . . . 74

6.3 Coefficient of determination comparison relevent to 1-D and 2-D model predicted and experimental pressure drop during transient cycles . . . . . . . . 77 


\section{Notation}

\section{Symbols}

$A \quad:$ pre-exponential factor in Arrhenius equation, $\left[\mathrm{m} / \mathrm{s} / K^{0.21}\right]$

$A_{\text {soot }}$ : area of soot particles, $\left[\mathrm{m}^{2}\right]$

$b \quad: \quad$ unit spherical cell size, $[\mathrm{m}]$

C : PM mass concentration, $\left[\mathrm{kg} / \mathrm{m}^{3}\right.$

$c_{p g} \quad$ : gas phase heat capacity, $[\mathrm{J} / \mathrm{kg} / \mathrm{K}]$

$c_{p p}:$ particulate layer heat capacity, $[\mathrm{J} / \mathrm{kg} / \mathrm{K}]$

$c_{p s} \quad:$ substrate heat capacity, $[\mathrm{J} / \mathrm{kg} / \mathrm{K}]$

$D \quad$ : hydraulic diameter, $[\mathrm{m}]$

$d_{c} \quad:$ unit collector diameter, $[\mathrm{m}]$

$d_{c_{0}} \quad$ : inital unit collector diameter

$D_{\text {pore }}:$ pore diamter, $[\mathrm{m}]$

$E \quad:$ activation energy, $[\mathrm{J} / \mathrm{kmol}]$

$E_{\text {cake }}:$ cake filtration efficiency [-]

$F \quad:$ friction coefficient, [-]

$f_{C O}:$ thermal selectivity, [-]

$g(\varepsilon) \quad$ : Kuwabara hydrodynamic factor, [-]

$g_{C O} \quad$ : $\quad$ CO selectivity of soot oxidation by $\mathrm{NO}_{2}$

$H_{e x} \quad$ : convective heat transfer coefficient of the DPF, $\left[\mathrm{J} / \mathrm{m}^{2} / s / K\right]$

$\Delta H \quad$ : heat of reaction, $[\mathrm{J} / \mathrm{kmol}]$

$h_{i} \quad: \quad$ convective heat transfer coefficient of channel i, $\left[\mathrm{J} / \mathrm{m}^{2} / \mathrm{s} / K\right]$

$k_{\text {cat }}:$ rate of catalytic doot oxidation, $[\mathrm{m} / \mathrm{s}]$

$k_{p} \quad:$ particulate layer permeability, $\left[\mathrm{m}^{2}\right]$

$k^{\text {th }} \quad$ : rate coefficient of thermal soot oxidation, $[\mathrm{m} / \mathrm{s}]$

$L \quad$ : DPF length, $[\mathrm{m}]$

$M_{C} \quad$ : molecular weight of carbon, $[\mathrm{kg} / \mathrm{kmol}]$

$M_{i} \quad$ : molecular weight of $i^{\text {th }}$ exhaust gas specie, $[\mathrm{kg} / \mathrm{kmol}]$

$P e \quad:$ Peclet number, [-]

$P_{i} \quad:$ pressure in $i^{\text {th }}$ channel, $[\mathrm{Pa}]$

$Q_{w} \quad:$ volumetric flow rate, $\left[\mathrm{m}^{3} / \mathrm{s}\right]$

$\bar{R} \quad$ : universal gas constant, $[\mathrm{J} / \mathrm{kmol} / \mathrm{K}]$

$R a \quad:$ Rayleigh number, [-] 
$R_{i, j}: i^{t h}$ specie consumption rate in the $j^{\text {th }}$ layer, $\left[\mathrm{kmol} / \mathrm{m}^{2} / s\right]$

$R_{t}:$ thermal resistance, $[\mathrm{sK} / \mathrm{J}]$

$R$ : radius, $[\mathrm{m}]$

$S_{p} \quad$ : specific soot area of deposit layer, $[1 / \mathrm{m}]$

$T_{i} \quad$ : temperature of $i^{\text {th }}$ channel, $[\mathrm{K}]$

$T \quad$ : time, $[\mathrm{s}]$

$v_{i} \quad$ : gas velocity in the $i^{\text {th }}$ channel, $[\mathrm{m} / \mathrm{s}]$

$w_{s}:$ substrate wall thickness, $[\mathrm{m}]$

$w \quad$ : particulate layer thickness, $[\mathrm{m}]$

$x \quad$ : transverse direction (distance through the wall), [m]

$Y \quad$ : mass fraction, [-]

$y \quad:$ mole fraction, [-]

$z \quad:$ axial direction, $[\mathrm{m}]$

\section{Greek symbols}

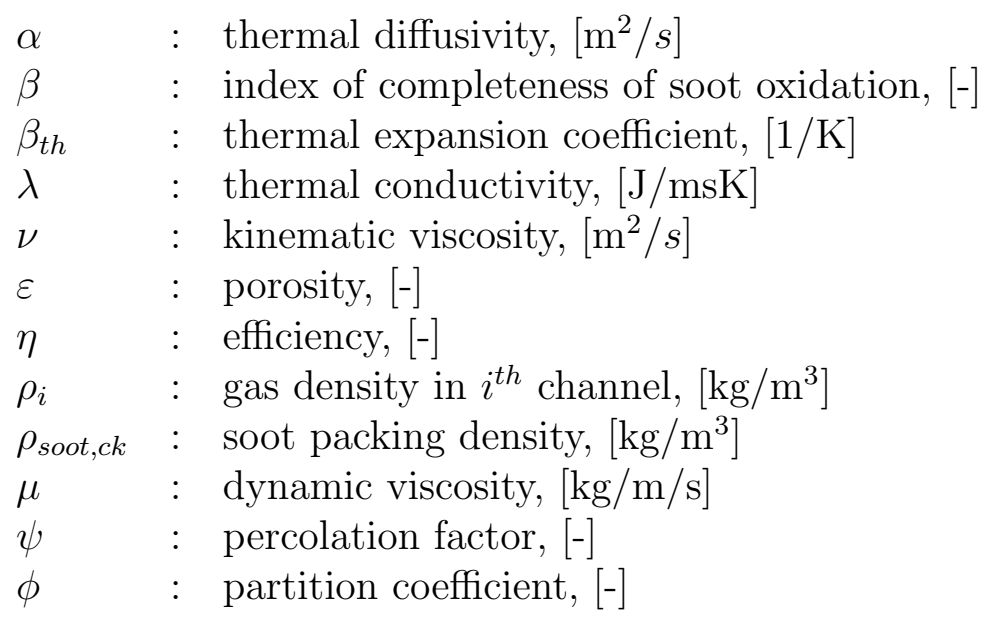

\section{Abbrevitions}

CDPF : Catalyzed Diesel Particulate Filter

$\mathrm{C}:$ Carbon

$\mathrm{CO}$ : Carbon Monoxide

$\mathrm{CO}_{2}$ : Carbon Dioxide

CVS : Constant Volume Sampling

DOC : Diesel Oxidation Catalyst

DPF : Diesel Particulate Filter

ECU : Electronic Control Unit 
EEPS : Engine Exhaust Particle Sizer

EERL : Engine and Emissions Research Laboratory

EGR : Exhaust Gas Recirculation

ESC : European Stationary Cycle

ExhAUST : Exhaust Aftertreatment Unified Simulation Tool

$\mathrm{NO}_{x} \quad$ : Oxides of Nitrogen

$\mathrm{O}_{2} \quad:$ Oxygen

PM : Particulate Matter

USLD : Ultra Low Sulfer Diesel Fuel

VGT : Variable Geometry Turbocharger

\section{Subscripts}

1 : inlet channel

$2 \quad$ : outlet channel

atm : atmospheric

cat : catalytic

cond : conduction

eng : engine

envir : environment

i : gas specie

ins : insulation

p : particulate layer

react : reaction

s : substrate

th : thermal

wall : wall 


\section{Chapter 1}

\section{Introduction}

Diesel engines have been traditionally identified in the US as the best solution for heavy duty transportation and off road applications in general terms of cost and reliability. Improved fuel economy and attainment of high torque at lower speeds have recently attracted the attention of the passenger vehicle market in the US for diesel engines, while their market share in Europe is already well established. Exhaust emissions and diesel engines comprise of a wide range of compounds. But the regulated emissions include hydrocarbons (HC), carbon monoxide (CO), oxides of nitrogen (NOx) and particulate matter (PM).

Diesel particulate filter (DPF) has earned its reputation as one of the highly effective methods to control PM emissions from diesel engines. The most commonly used DPF design is the wall flow monolith. In this design, adjacent channels are alternatively plugged at each end in order to force the diesel soot particles to flow through the substrate wall. Thus, diesel PM is deposited on the sides of the inlet channel. The deposited PM affects the flow and temperature field inside the trap, and increases the pressure drop across the trap. An excessive back pressure will raise the fuel penalty and potentially damage the engine. A regeneration process is therefore required to remove the deposited PM from the DPF. This can be performed either continuously with the use of catalyst (passive regeneration) or periodically via hydrocarbon combustion, electric heating [1] and microwave heating $[2,3]$. 
However, the optimization of DPF performance metrics whilst maintaining optimal fuel efficiency depends on extensive laboratory and on-road testing. Diesel engines operate through a wide range of operating conditions. Steady state operating conditions vary greatly from the transient operating conditions. Engine speed, torque, power output and exhaust temperature at a given engine operation condition differ and significantly impact the exhaust composition.

The application of simulation tools provides a promising alternative to traditional design of experiments approach; thereby minimizing the complex and expensive engine testing resources. These models are capable of providing insight in to local parameters such as temperature, velocity, density and pressure drop parameters opposed to spatially averaged values obtained through experiments. Thorough knowledge of each of these parameters is crucial to optimization of next generation DPF systems.

Several numerical models have been developed to globally simulate the soot loading capacity, the pressure drop evolution and regeneration behavior of wall flow filters $[4,5,6]$. These range from zero to three dimensional models. One dimensional (1-D) models are computationally efficient and can be used to get a quick estimation of the pressure drop and regeneration characteristics of the DPF. Konstandopoulos et al.[7] showed an excellent agreement between 1-D and 3-D model predictions over a variety of filter media. However, 1-D models assume constant properties along the channel length. Properties such as, soot layer thickness, wall temperature and wall velocity do vary under real world situations. There is a possibility of having local hot spots in certain parts of the monolith wall, which may not be tracked by a 1-D model, since it only provides an averaged value in the axial direction. In practice, a controlled and predictable reaction is required, considering that these filters should last through a large number of regeneration cycles. Multi scale analytical models help understanding the details of the complex processes and improving the filters and the regeneration processes. Two dimensional models facilitate tracking the aforementioned parameters, at the expense of an additional computational effort. Three dimensional (3-D) models provide the most accurate descriptions of the DPF filtration and regeneration 
parameters. However, these models are usually quite intensive in computational effort and time. Thus, 2-D models provide the means to obtain reasonable accuracy and predictability without being computationally intensive.

The primary objective of the thesis is to develop a two dimensional numerical soot model for a DPF to analyze the impact of close-to-real descriptions of filtration, regeneration process and heat transfer. The secondary objective of the thesis is to validate the developed model using both steady state and transient driving cycles. Federal test procedure (FTP) cycle is more realistic, though not exact simulation; of actual driving conditions than a steady state cycle. The author finds the numerical studies carried out in this area to be quite limited $[8,9,10]$.

The developed model uses a finite difference scheme to solve mass, momentum and energy equations. A lumped model was used to simulate the filtration process to make the code computationally efficient. Both catalytic and thermal assisted soot oxidation processes were implemented to capture regeneration behavior of modern catalyzed diesel particulate filters (CDPF). The results of the simulations include the prediction of development of temperature, pressure, channel velocity and soot layer thickness along the filter length. The developed model may be utilized as a tool to design a DPF's geometrical, physical and chemical parameters in order to optimize its performance for a given test configuration.

Differentiating from the study of transient operating conditions simulated using a smooth sinusoidal function by Rumminger [8] and Khan [9], results of the current study are based on Federal Test Procedure (FTP) cycle. During a typical driving cycle, the DPF is subjected to highly transient conditions, thus generating varying exhaust mass and volumetric flow rates, gas composition, temperature, PM content and particle size distribution. The experimental data to support validation of the DPF model was gathered at West Virginia University Engine Emissions and Research Laboratory (EERL). The model was successfully able to capture the pressure drop and temperature characteristics of the DPF during transient engine operation. 


\section{Chapter 2}

\section{Literature Review}

\subsection{Emission Regulations}

Owing to health and environmental concerns arise from various engine emissions, the Environmental Protection Agency (EPA) in the United States established regulations under the clean air act amendments (CAAA). The four main emission species $\mathrm{HC}, \mathrm{CO}, \mathrm{NO}_{x}$ and PM, were considered as the main pollutants in both the US and European union (EU). Exposure to high levels of CO concentrations could lead to fatigue and chest pain for people

with a history of heart disease [13]. Oxides of nitrogen are highly reactive gases and play a pivotal role in the formation of ozone, smog and acid rain [13]. Diesel fuel combustion has shown to produce the largest amount of particulate matter (PM) mass compared to gasoline and alternative fuels, which has been identified as a potential occupational carcinogen by the National Institute for Occupational Safety and Health (NIOSH) [15].

Table 2.1 shows that from 1998 to 2007, the emission limits for $\mathrm{NO}_{x}$ and $\mathrm{PM}$ have been tightened by $95 \%$ and $90 \%$ respectively for heavy-duty compression-ignition engines. The control of emissions has thus become one of the most prominent areas of diesel engine research. 
Table 2.1: Heavy-duty compression-ignition engines and urban buses exhaust emission standards $[13]$

\begin{tabular}{ccccccc}
\hline \hline Year & $\begin{array}{c}\mathrm{HC} \\
(\mathrm{g} / \mathrm{bhp}-\mathrm{hr})\end{array}$ & $\begin{array}{c}\mathrm{NMHC} \\
(\mathrm{g} / \mathrm{bhp}-\mathrm{hr})\end{array}$ & $\begin{array}{c}\mathrm{NO}_{x} \\
(\mathrm{~g} / \mathrm{bhp}-\mathrm{hr})\end{array}$ & $\begin{array}{c}\mathrm{NMHC}^{2} \mathrm{NO}_{x} \\
(\mathrm{~g} / \mathrm{bhp}-\mathrm{hr})\end{array}$ & $\begin{array}{c}\mathrm{PM} \\
(\mathrm{g} / \mathrm{bhp}-\mathrm{hr})\end{array}$ & $\begin{array}{c}\mathrm{CO} \\
(\mathrm{g} / \mathrm{bhp}-\mathrm{hr})\end{array}$ \\
\hline $1974-78$ & - & - & - & 16 & - & 40 \\
$1979-84$ & 1.5 & - & - & 10 & - & 25 \\
$1985-87$ & 1.3 & - & 10.7 & - & - & 15.5 \\
$1988-89$ & 1.3 & - & 10.7 & - & 0.6 & 15.5 \\
1990 & 1.3 & - & 6 & - & 0.6 & 15.5 \\
$1991-93$ & 1.3 & - & 5 & - & 0.25 & 15.5 \\
$1994-97$ & 1.3 & - & 5 & - & 0.1 & 15.5 \\
$1998-2003$ & 1.3 & - & 4 & - & 0.1 & 15.5 \\
$2004-2006$ & - & - & - & 2.4 & 0.1 & 15.5 \\
2007 & - & 0.14 & 0.2 & 2.4 & 0.01 & 15.5 \\
\hline \hline
\end{tabular}

\subsection{Emission Formation in Diesel Engine}

\subsubsection{Hydrocarbons (HC)}

In a diesel engine, fuel resides in the combustion chamber for a shorter time than in spark ignition engine. Hence the likelihood of unburned $\mathrm{HC}$ formation is much less in a diesel engine in comparison to the other. Three main mechanisms of $\mathrm{HC}$ emission formation in a diesel engine are (1) extremely lean mixtures; (2) extremely rich mixtures; and (3) flame quenching and misfire.

In an event where fuel is injected during an ignition delay, the mixtures obtained are too lean because the fuel is partially consumed in the thermal oxidation later in the expansion phase after mixing with additional air. The amount of unburned hydrocarbons originating in these lean areas depends on the quantity injected during the ignition delay, the mixing rate with air during this period and auto-ignition conditions prevailing in the cylinder.

The main cause of HC formation in rich mixtures is the nozzle sac volume. Nozzle sac is a hollow circular cavity located at the tip of the needle downstream of its seat. At the end 
of the injection event, the injector sac volume remains full of fuel. During the combustion and expansion phases, this fuel partially vaporizes and penetrates into the cylinder at low speeds. This fuel slowly mixes with air and bypasses the main combustion process. Hence, at minimum ignition delay for direct ignition engine, the HC emissions are directly proportional to the nozzle sac volume [11]. Moreover, in transient operations such as acceleration, there is a possibility of excessive injection of fuel into the combustion chamber. This may cause high local fuel/air ratios during expansion and exhaust phases.

Flame quenching at the walls is another source of $\mathrm{HC}$ emissions. Ignition deficiencies which give rise to high $\mathrm{HC}$ emissions typically occur at low compression rates and abnormally delayed injection. These ignition events occur during cold starts and can be visually identified from the formation of white smoke, a mist of microdroplets of unburned fuel.

\subsubsection{Carbon Monoxide (CO)}

Carbon monoxide is formed mainly due to incomplete combustion due to lack of $\mathrm{O}_{2}$ and is a function of temperature and residence time. Combustion of fuel rich mixtures usually produces high CO emissions. Since diesel engines always operate on an overall lean mixture, $\mathrm{CO}$ emissions are typically lower than that of gasoline engines.

\subsubsection{Oxides of Nitrogen $\left(\mathrm{NO}_{x}\right)$}

Nitric oxide (NO) and nitrogen dioxide $\left(\mathrm{NO}_{2}\right)$ are collectively identified as oxides of nitrogen $\left(\mathrm{NO}_{x}\right)$, where $\mathrm{NO}$ accounts for the larger portion of the two. The main source of NO formation is diatomic nitrogen $\left(\mathrm{N}_{2}\right)$, which covers the most significant portion of atmospheric air per volume basis. $\mathrm{NO}_{2}$ is formed by recombination reactions between $\mathrm{NO}$ and various other oxidants. $\mathrm{NO}_{2}$ emission can only be seen prominent at engine temperatures below 1200K. At higher temperatures it will quickly revert back to NO in the presence of $\mathrm{O}_{2}$.

Extended Zeldovitch mechanism has been widely accepted as the principal cause of $\mathrm{NO}_{x}$ formation. These reactions typically occur at temperature well above 2000K. Three main chemical reactions that contribute to this mechanism can be described as follows. 


$$
\mathrm{O}_{2}+2 \mathrm{~N}_{2} \rightarrow 2 \mathrm{NO}+2 \mathrm{~N}
$$

$$
\mathrm{N}+\mathrm{O}_{2} \rightarrow \mathrm{NO}+\mathrm{O}
$$

$$
\mathrm{N}+\mathrm{OH} \rightarrow \mathrm{NO}+\mathrm{H}
$$

NO emissions produced due to this mechanism appear in significant quantities well after start of heat release phase since the aforementioned reactions are relatively slow and very sensitive to temperature. High fuel/air ratios favor $\mathrm{NO}_{x}$ formation as more fuel is burned; more heat is produced with an increase in combustion temperature. Higher nozzle opening pressures also promote $\mathrm{NO}_{x}$ formation due to improved combustion efficiency with the presence of smaller fuel particles. Retarding injection timing has a desirable effect on NO formation as it is related to the premixed portion of the fuel. Fuel cetane number, swirl and intake charge dilution also contributes to $\mathrm{NO}_{x}$ formation [12].

\subsubsection{Particulate matter (PM)}

Particulate matter is defined as all substances which under normal circumstances are present in exhaust gases in a solid (ash, carbon) or liquid state [13]. PM is generated due to incomplete combustion of diesel fuel. When diesel fuel is sprayed into the cylinder at high pressure, the sprayed fuel droplets do not mix completely with the abundant oxygen at a molecular level. This results in incomplete combustion. Dust or inorganic material in the fuel or fuel additives also contributes to diesel PM in the form of ash. Presence of sulfur in the fuel and lubrication oil contributes to sulfate formation. This material is referred to as the soluble organic fraction $(\mathrm{SOF})$.

In the burning of liquid fuels of the diesel type, the size of the droplet is extremely important because the formation of soot increases with size. The non-homogeneous nature of the mixture, duration of the injection and its overlap with combustion are parameters that 
influence the process of soot formation. The list below summarizes the main parameters that influence diesel particulate formation [16].

(1) Formation of insoluble fraction: elevated temperature, high pressure and absence of oxygen.

(2) Formation of organic compounds of particles: lean mixture zones, temperature below the flammability limit, HC layers on the walls of the cylinder, fuel droplets dribbling at the nozzle tip.

(3) Sources of particles from lubricant: surface of cylinder liners, valve stem gaskets, turbostem gaskets and recycling of crankcase ventilation gases into inlet.

\subsection{Diesel Emission Control Technologies}

\subsubsection{In-cylinder Control Strategies}

Exhaust gas recirculation (EGR) is considered as one of the most efficient methods to reduce $\mathrm{NO}_{x}$ emissions from diesel engines. The basic EGR operation is to re-circulate a portion of the exhaust gas back to the intake manifold. When exhaust gas is introduced into the combustion chamber and mixed with dilution air, total heat capacity of the mixture gets elevated. Reduction of peak combustion temperature assists abatement of $\mathrm{NO}_{x}$ formation. However, net thermal efficiency of the engine reduces due to reduction in peak combustion temperature. Consequently, the fuel consumption and the PM emissions of the engine may increase. This is the major drawback of this technology.

EGR was first introduced in 1970s and today most diesel engines use in its standard configuration [17]. If the exhaust gas is recycled to the intake manifold directly, the operation is called hot EGR. If the exhaust gas is routed via an EGR cooler, the operation is called cold EGR. Implementation of EGR for a turbocharged engine is somewhat difficult in comparison to a naturally aspirated engine. There are two common EGR configurations for turbocharged engines; (1) low pressure loop EGR and (2) high pressure loop EGR (see Figure 2.1). Low pressure loop EGR depends on the differential pressure created between turbine outlet and compressor inlet. Partial throttling also helps to increase the tailpipe pressure to drive the 
flow. However, high pressure loop EGR is the most common implementation method. In this configuration, exhaust gas is re-circulated from upstream of the turbine to downstream of compressor. This differential pressure may be controlled using intake throttling, exhaust restriction and venture device. However, this configuration leads to an increase in fuel consumption and PM emissions.
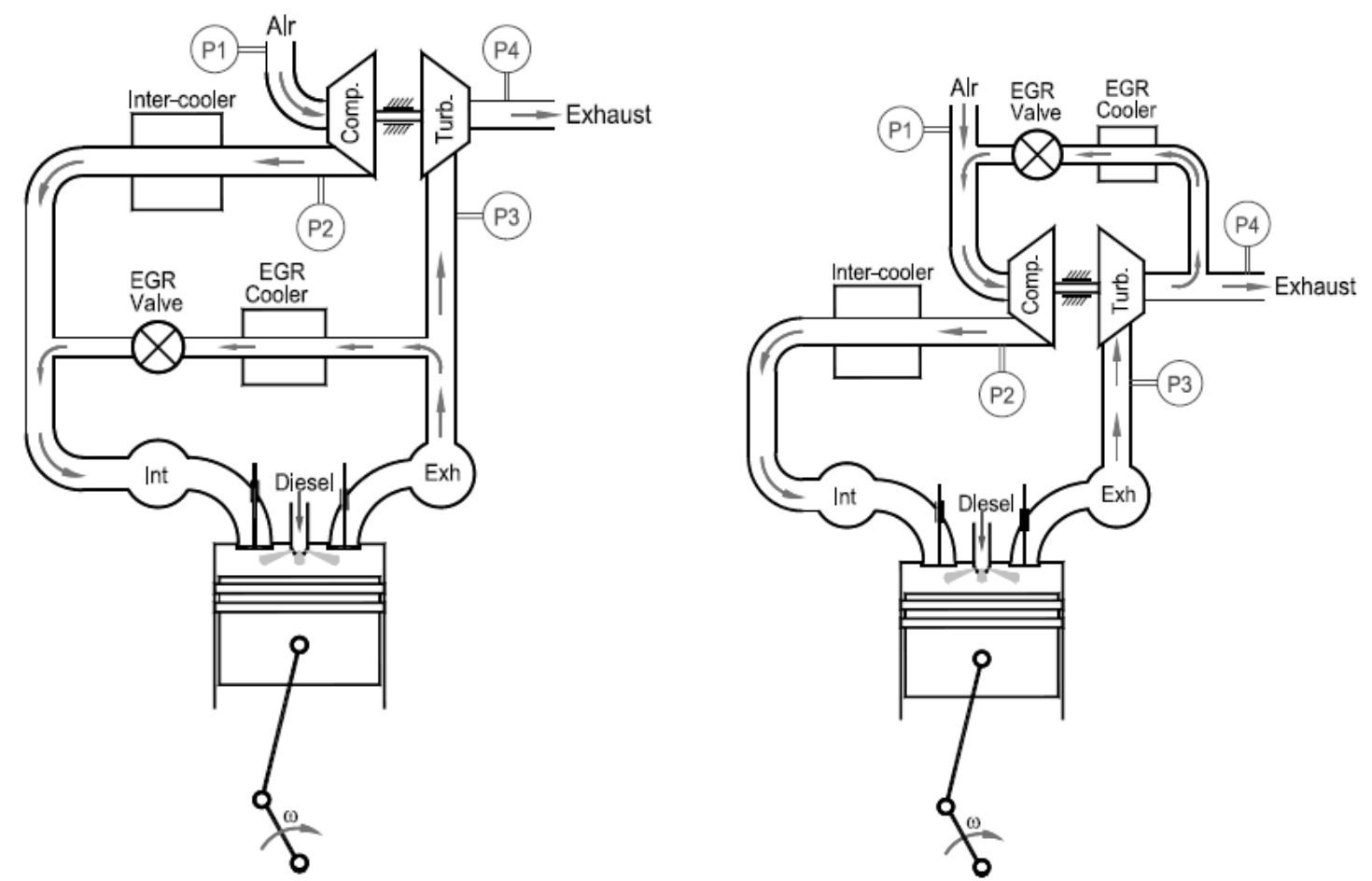

Figure 2.1: High pressure loop EGR (left) and low pressure loop EGR (right) [17]

Multiple fuel injection (MFI) strategy also helps to reduce $\mathrm{NO}_{x}$ and $\mathrm{PM}$ emissions. The idea behind this strategy is to reduce the peak combustion temperature in cylinder by spreading the fuel to be burned over a relatively longer period of time. Moreover, MFI strategy can be combined with a high pressure fuel injection system to enhance fuel atomization. This helps in archiving lower PM emissions. However, simultaneous reduction of both engine-out $\mathrm{NO}_{x}$ and $\mathrm{PM}$ emissions can be limited by the $\mathrm{NO}_{x} / \mathrm{PM}$ tradeoff.

Low temperature combustion (LTC) and premixed combustion are also promising technologies for simultaneous reduction of both $\mathrm{NO}_{x}$ and PM emissions. As discussed earlier, 
lowering combustion temperature helps in reducing $\mathrm{NO}_{x}$ emissions whilst premixing helps to reduce PM emissions. Low temperature combustion is achieved using increased levels of EGR to reduce the oxygen concentration present in the combustion chamber. Premixed combustion is accomplished by prolonging the ignition delay and dispersion of the injected fuel.

\subsubsection{Diesel Exhaust Aftertreatment Devices}

\section{Diesel Oxidation Catalyst (DOC)}

A DOC can be used across a range of exhaust temperatures and is an efficient method of reducing $\mathrm{HC}$ and $\mathrm{CO}$ in low exhaust temperature applications. The substrate is typically of honeycomb construction and each channel surface consists of a precious metal coating such as rhodium and vanadium.

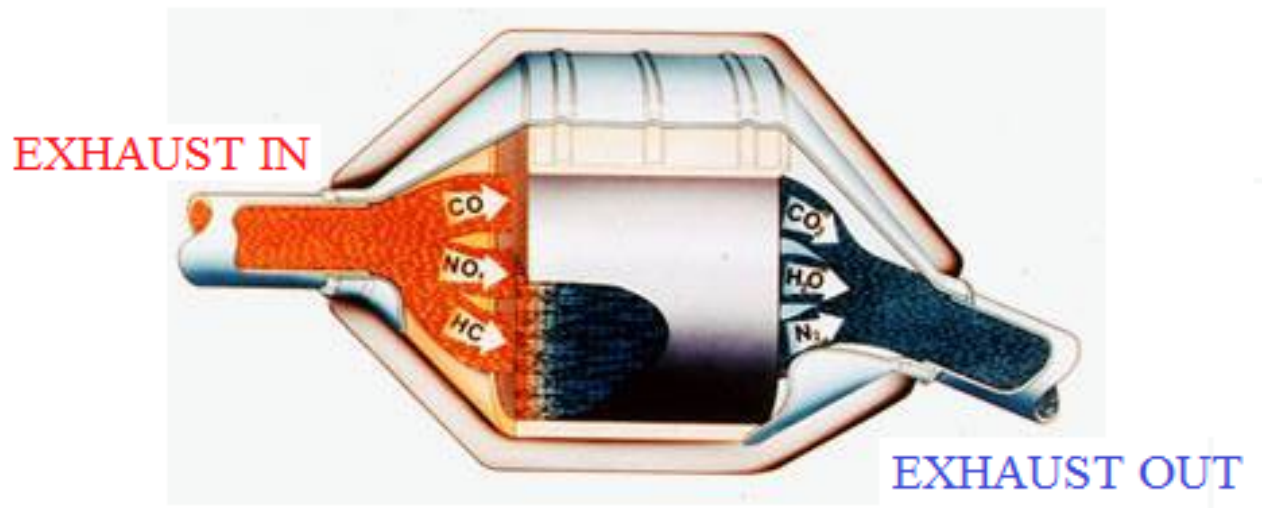

HONEYCOMB CATALYST

Figure 2.2: Diesel oxidation catalyst (DOC) [18]

DOCs are typically used to reduce the SOF component of the particulate matter as shown in the following equation.

$$
\mathrm{SOF}+\mathrm{O}_{2} \rightarrow \mathrm{CO}_{2}+\mathrm{H}_{2} \mathrm{O}
$$

DOCs can also be used to effectively reduce the amount of $\mathrm{HC}$ and $\mathrm{CO}$ emissions. Major reactions in a DOC is given in equations (2.5)-(2.7). 


$$
\begin{gathered}
\mathrm{CO}+\frac{1}{2} \mathrm{O}_{2} \rightarrow \mathrm{CO}_{2} \\
\mathrm{C}_{3} \mathrm{H}_{6}+\frac{9}{2} \mathrm{O}_{2} \rightarrow 3 \mathrm{CO}_{2}+3 \mathrm{H}_{2} \mathrm{O} \\
\mathrm{C}_{3} \mathrm{H}_{8}+5 \mathrm{O}_{2} \rightarrow 3 \mathrm{CO}_{2}+4 \mathrm{H}_{2} \mathrm{O}
\end{gathered}
$$

Typically SOF, HC and CO oxidation reactions take place in very high temperature conditions. However, the use of catalysts allows these reactions to take place at significantly lower temperatures. The reduction of CO emissions is almost entirely accomplished by noble metals, whereas HC conversion is attributed to both washcoat and noble metal loading. When the DOC reaches a certain temperature the oxidation reactions take place almost immediately. This temperature is called the "light-off temperature." Above this point, conversion efficiencies rapidly reach steady state. Extensive research efforts continues to this date, to reduce the light off temperature aiming to increase DOC performance during cold starts.

However, the catalytic performance of the DOC will gradually worsen throughout its lifetime. This is called the "Aging effect." Typical diesel fuel consists of minute percentage of sulfur at the parts per million level. Sulfates formed at high temperatures contribute to total particulates and deactivation of the catalyst through its interaction with sulfuric acid (see equations $(2.8)$ and (2.9)). The aging process can be retarded to a certain extent with the use of ultra low sulfur diesel (ULSD).

$$
\begin{gathered}
\mathrm{SO}_{2}+\frac{1}{2} \mathrm{O}_{2} \rightarrow \mathrm{SO}_{3} \\
\mathrm{SO}_{3}+\mathrm{H}_{2} \mathrm{O} \rightarrow \mathrm{H}_{2} \mathrm{SO}_{4}
\end{gathered}
$$

Exposure to high operating temperatures leads to catalyst thermal destruction, a process known as "sintering" that causes DOC efficiency to plunge due to scarcity of precious metal surface area. 


\section{Selective Catalytic Reduction}

Selective catalytic reduction (SCR) is a proven catalyst technology capable of reducing $\mathrm{NO}_{x}$ emissions to meet stringent EPA 2010 standards. Basic components of a SCR system is shown in Figure 2.3.

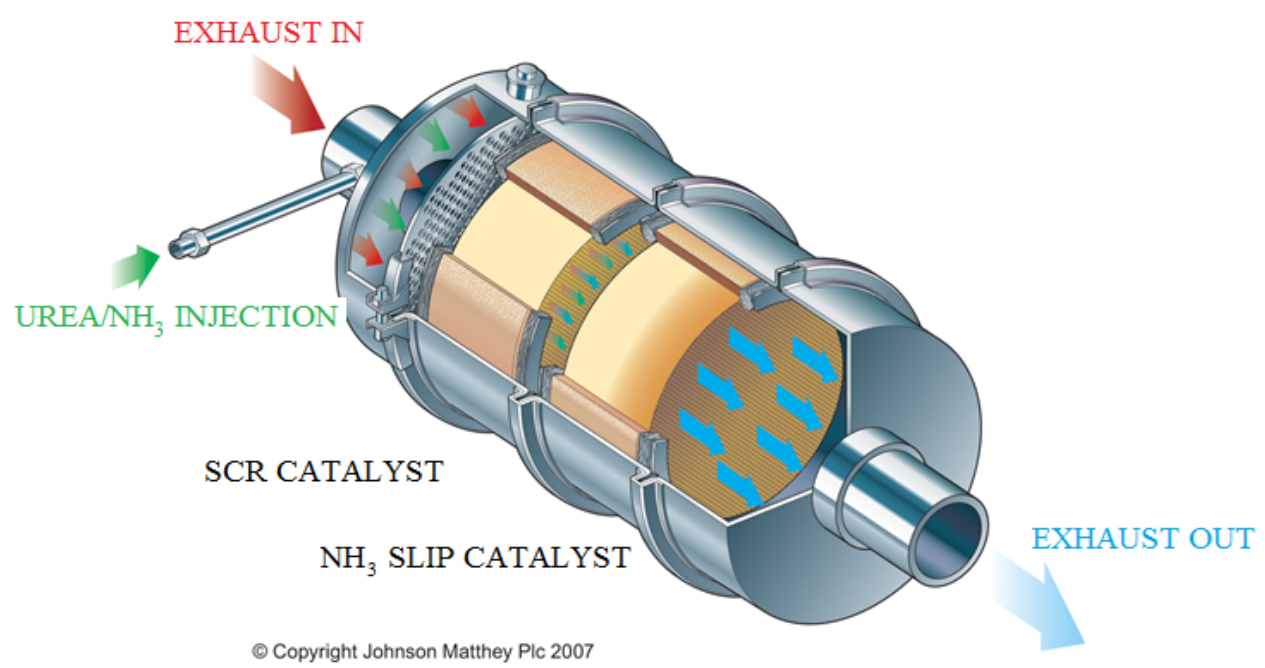

Figure 2.3: Selective catalytic reduction system [20]

SCR uses catalyst and ammonia to convert $\mathrm{NO}_{x}$ into $\mathrm{H}_{2} \mathrm{O}$ and $\mathrm{N}_{2}$ using the following hydrolysis reactions.

$$
\begin{gathered}
4 \mathrm{NO}+4 \mathrm{NH}_{3}+\mathrm{O}_{2} \rightarrow 4 \mathrm{~N}_{2}+6 \mathrm{H}_{2} \mathrm{O} \\
\mathrm{NO}+2 \mathrm{NH}_{3}+\mathrm{O}_{2}+\mathrm{NO}_{2} \rightarrow 2 \mathrm{~N}_{2}+3 \mathrm{H}_{2} \mathrm{O} \\
2 \mathrm{NO}_{2}+4 \mathrm{NH}_{3}+\mathrm{O}_{2} \rightarrow 3 \mathrm{~N}_{2}+6 \mathrm{H}_{2} \mathrm{O}
\end{gathered}
$$

The catalytic layer of the SCR consists of three main catalysts: $\mathrm{TiO}_{2}, \mathrm{~V}_{2} \mathrm{O}_{5}$ and $\mathrm{WO}_{3}$. Vanadia $\left(\mathrm{V}_{2} \mathrm{O}_{5}\right)$ is the main contributor of the $\mathrm{NO}_{x}$ abatement. However, it also promotes oxidation of sulfer and create sulfuric acid which poisons the very catalyst. Tungsten oxide $\left(\mathrm{WO}_{3}\right)$ widens the temperature window of the SCR reactions which helps improving the mechanical and structural properties of the catalyst [19].

The urea solution used for the SCR system is a mixture of $32.5 \%$ urea and $67.5 \%$ water. When urea is injected in to exhaust stream, it decomposes and creates ammonia. The SCR 
process requires precise control of urea injection rates. Insufficient injection amounts will result in unacceptably low $\mathrm{NO}_{x}$ reduction and excessive injection will result in ammonia slip. SCR can operate over a large temperature range $\left(200-600^{\circ} \mathrm{C}\right)$ [21]. However, SCR is a complex system and requires sophisticated control systems. Diesel engines typically operate in highly transient conditions. Thus the control system should constantly adjust the amount of urea injected in to the catalyst in order to reduce ammonia slip. Catalyst deactivation due to sulfur poisoning and thermal deactivation due to sintering could also hurt the SCR performance.

\section{Diesel Particulate Filter}

Perhaps most effective approach in combating PM is the DPF, which are more colloquially known as PM traps. The DPFs can be classified under two main categories depending on the respective operating principal:

(1) Deep bed filters; and

(2) Shallow bed filters.

Deep bed filters collect or trap particles throughout the whole filter (3-D), whilst shallow bed filters only accumulate soot on the wall (2-D). However, deep bed filtration can be regarded as the more generalized case since the pore diameters of most common filter materials $(\geq$ $1 \mu \mathrm{m})$ are often much larger than typical particle sizes present in diesel exhaust.

The selection of DPF materials are not based on their filtration properties, but more on their thermal and mechanical properties. Filter wall should withstand high temperatures that occur due to high exothermic reactions. Cordierite is the most commonly used DPF material [5]. This synthetic ceramic material $\left(2 \mathrm{MgO} \cdot 2 \mathrm{Al}_{2} \mathrm{O}_{3} \cdot 5 \mathrm{SiO}_{2}\right)$ has been initially developed for automotive catalytic converters. Low thermal expansion coefficient of this material resists extreme thermal cycling and high temperature gradients, increasing the mechanical integrity of the filter. Silicon carbide $(\mathrm{SiC})$ is another popular choice and has a better thermal resistivity than Cordierite. Higher thermal expansion coefficient of this material gives arise to a packaging issue. $\mathrm{SiC}$ is also more expensive than Cordierite. Ceramic DPFs are also available and is usually combined with one or more material. Ceramic DPFs provide 
greater leeway in channel geometry and better assist with filter design, geometry and shape. Metal fiber particulate traps show their advantages in electrically assisted regeneration process. Filter wall cracking due to high local temperature gradients can be avoided owing to its better thermal conductivity. However, metal DPFs are usually more expensive than the other materials discussed in this section.

The filtration mechanism in a DPF depends on filter material and design. The most commonly used filter design is the wall flow monolith. In this design, adjacent channels are alternatively plugged at each end in order to force the diesel soot particles to flow through the substrate wall. Thus, diesel PM is deposited on the sides of the inlet channel. Filter walls have a porous structure that is carefully controlled during the manufacturing process. Typical values of material porosity are between 45 and $50 \%$ whilst the pore size varies from 10 to $20 \mu \mathrm{m}$.

Deep bed filtration relies mainly on three mechanism of aerosol deposition [33]:

(1) Brownian diffusion;

(2) Inertial impaction; and

(3) Interception collection.

As the name suggest, Brownian diffusion depends on the Brownian movement exhibited by small particulates, particularly below $0.3 \mu \mathrm{m}$ in diameter.

The trajectories of these small particles do not correspond to those of the streamlines but rather diffuse from the gas to the surface of the monolith wall. Large particles suspend in the exhaust flow tend to stick in to an oncoming obstruction due to their inertial effects. This is known as the inertial impaction. The intensity of this mechanism increases with increasing particle size and flow velocity. Small, less dense particles which travel along flow streamline and flow close to the filter wall contributes to soot layer deposition without being influenced by inertia or Brownian diffusion. This mechanism is known as the interception collection. Other collection mechanism like gravitational settling, inertial deposition and thermophoresis are known to be insignificant given the conditions and particle sizes of diesel 
exhaust [33].

The deposited PM affects the flow and temperature field inside the trap, and increases the pressure drop across the trap. An excessive back pressure will raise the fuel penalty and potentially damage the engine. A regeneration process is therefore required to remove the deposited PM from the DPF by oxidizing soot particles. Soot oxidation reactions require exhaust temperatures well above $500^{\circ} \mathrm{C}$ with available oxygen concentration and flow velocities. Typical diesel engines do not produce exhaust temperatures in this magnitude. Hence, numerous regeneration techniques have been suggested over the last two decades. These can be categorized into two principal methods: (1) active regeneration and (2) passive regeneration.

Active regeneration systems trigger regeneration by raising the temperature suitable for soot oxidation with the use of an external energy source. The regeneration of the filter has to be manually initiated at pre-determined intervals. Usually it is based on the distance travelled. The three most widely used energy sources are: (1) diesel fuel combustion, (2) electrical heating and (3) microwave heating.

Diesel fuel combustion is the preferred and most commonly used method of all. It is readily available in a vehicle and is about five times energy efficient than the other active regeneration methods [22]. A proper fuel combustion based regeneration strategy is evaluated upon several guidelines [23]: (1) maximum temperature increase at minimum fuel expense; (2) minimum noise pollution; (3) minimum byproduct formation due to the regeneration event and (4) minimum dependency on the driver.

This is achieved by several ways. One method is to heat up the exhaust gas by a throttling event. Soot oxidation initiate when exhaust gas reach the desired temperature. However, this is not the most efficient method in this regard as the engine power is decreased during throttling. It also reduces the remaining oxygen content making the regeneration control difficult. However, it helps increasing the filter life as lower oxygen concentrations lead to lower filter wall temperatures due to the reduced exotherm. 
Another method is to place a diesel fueled burner in front of the DPF (see Figure 2.4) . This method is capable of carrying out the regeneration process at all engine speed and load conditions. The regeneration process is initiated when the back pressure across the filter reaches a specified level. Sudden and significant increase in DPF outlet temperature is also a good indicator of the onset of the regeneration. However, such a system requires proper control of the sophisticated electronics and a large air pump to heat up the entire exhaust gas to $540^{\circ} \mathrm{C}$. High pressure burner fuel system is also required to maintain the filter inlet temperature to a desired level. Also the system should ensure continuous air circulation through the burner nozzle to minimize fouling effects by particle deposits.

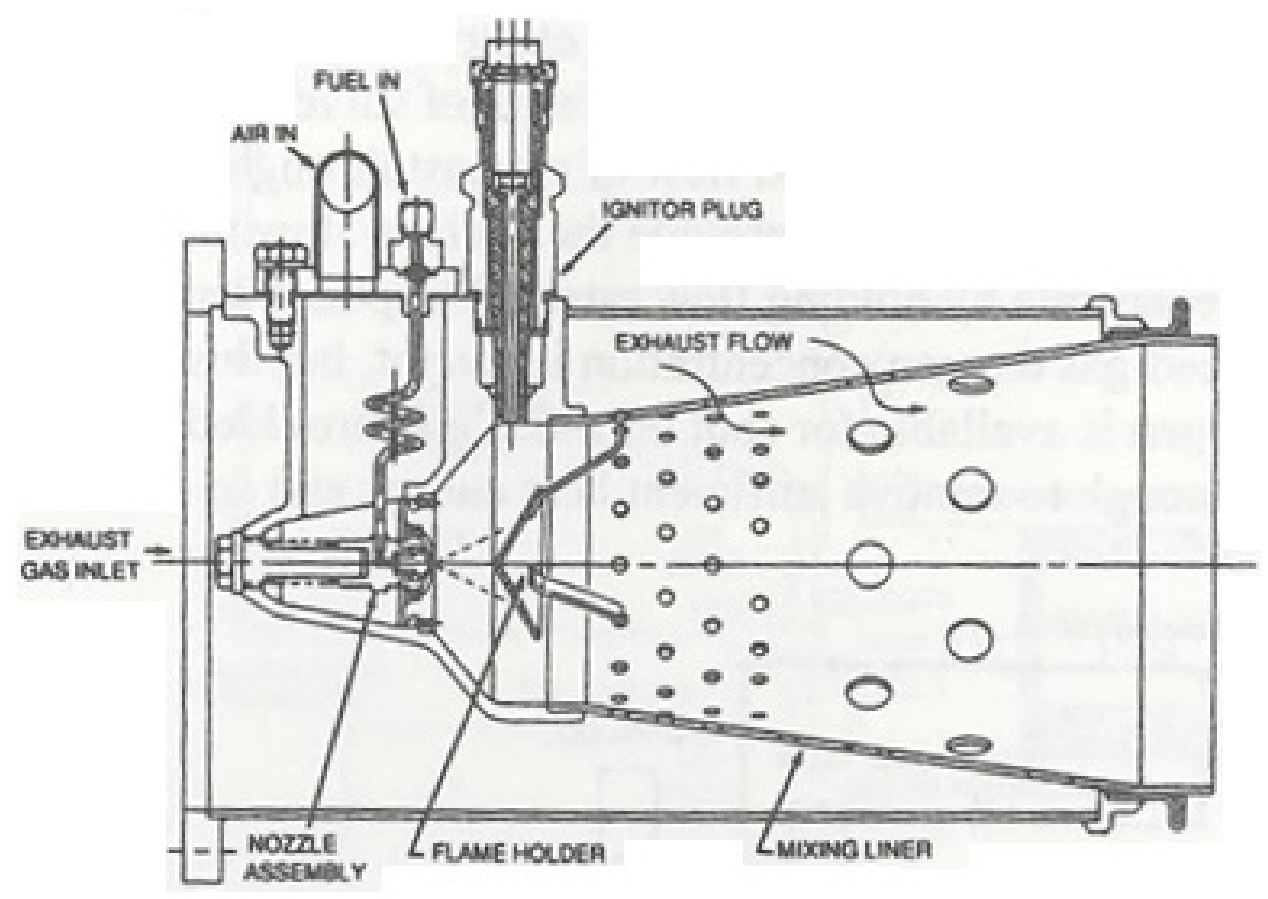

Figure 2.4: Fuel burner for DPF regeneration [16]

Newer systems overcome many of the above issues by using a bypass system, isolating the filter from the engine exhaust during the regeneration process. A schematic of such a system is given in Figure 2.5. This method requires nearly an order of magnitude less energy to heat up the filter face entirely [23]. This configuration also requires a smaller blower to route exhaust gas through the system and less complicated electronic control system for its proper operation. 


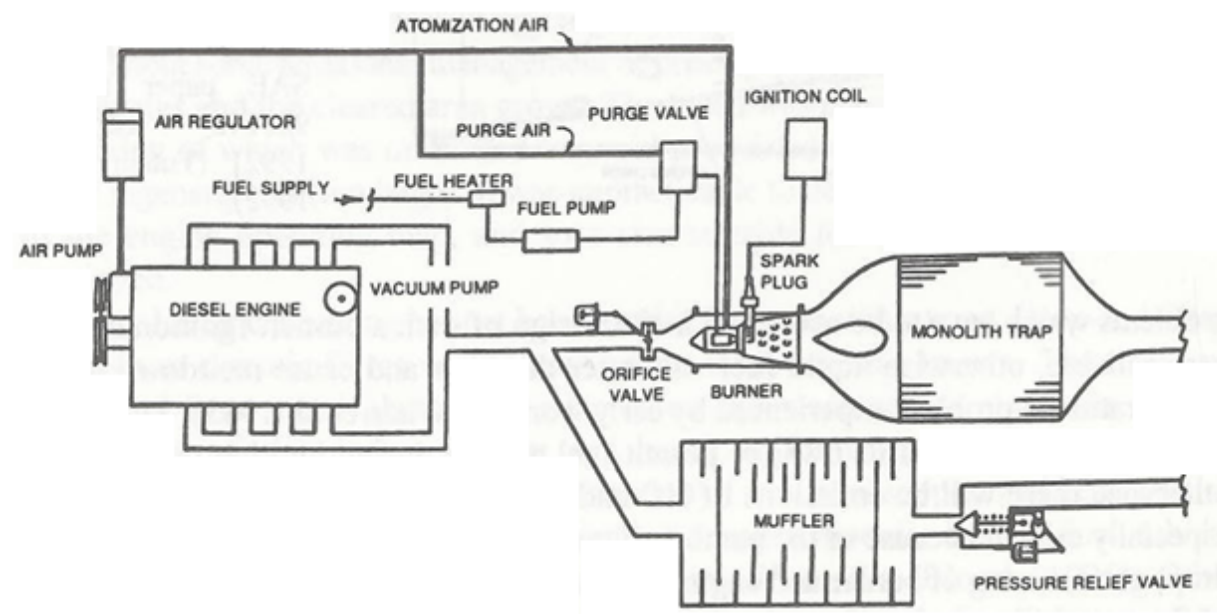

Figure 2.5: Burner by-pass system for light duty application [16]

\section{Electrical Regeneration}

Electrically assisted regeneration is also a popular choice amongst DOF regeneration techniques. The main advantage of this method is the absence of the fuel economic penalty. The necessary electrical demand is provided by the vehicle battery or off board the vehicle using an electrical outlet. During on-road regeneration, an increase in the idle speed to avoid unacceptable levels of battery discharge. The method also lets the trap to be regenerated at all speed and load conditions.

Electrical heating can be applied in a number of configurations, such as placing an electrical heater upstream of DPF (see Figure 2.6) or heating the entire DPF enclosing body. Typical heaters are fabricated from two nichrome resistance elements contained in $\mathrm{MgO}$ power insulation. A small air pump is used to transfer the heat from heater to the filter. Heating is discontinued when the trap inlet temperature reach $760^{\circ} \mathrm{C}[16]$. 


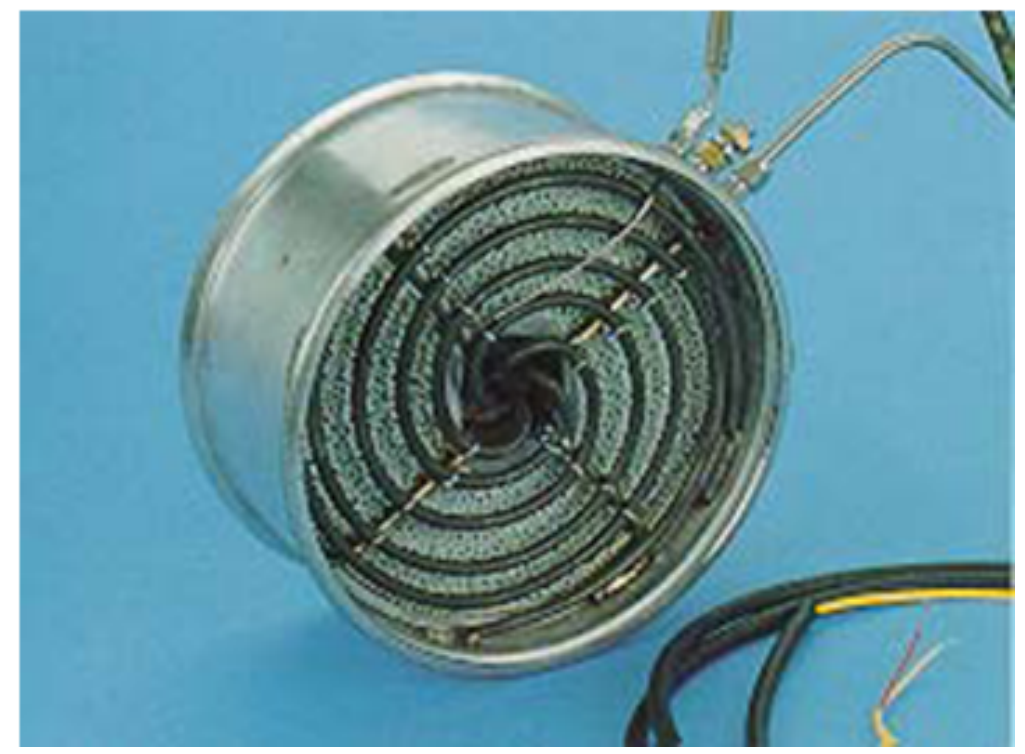

Figure 2.6: Electrically regenerated DPF [24]

Incorporating electrical heating elements in to the filter structure is another common way of employing electrically assisted filter regeneration. In this way, the soot could be ignited directly without the necessity of heating all the exhaust gas. RYPOS and MAN+HUMMEL are current manufacturers of such systems.

\section{Aerodynamic Regeneration}

Aerodynamic regeneration or compressed air regeneration method removes PM trap inside the DPF by emitting a sequence of compressed air pulses through its channels, in a direction opposite to that of the exhaust flow. The compressed air required for this operation is readily available from the compressor system used for braking. However, the system is capable of regenerating the trap even when the vehicle is in motion since the interruption to the flow is momentary. During a thermal regeneration phase, incombustible materials such as ash remain and accumulate in the filter wall over time. This leads to an irreversible plugging effect of the DPF, limiting the filter in-use service life. The compressed air pulses used in this method further helps flushing out this residual ash content. Moreover, the method averts complex sensing and control issues pertaining to the techniques described earlier in this section. 


\section{Microwave Regeneration}

Garner and Dent reported regeneration efficiencies of $40-80 \%$ with microwave regeneration. Microwave heating is accomplished by a method similar to electrical heating. In this method, soot is heated directly by the microwaves while the filter wall is heated only by conduction and convection, or in other words, no exothermic reactions occur on the filter wall. Hence, microwave regenerated DPFs have improved resistance to melting during regeneration.

\section{Plasma Regeneration}

Oxygen could be activated by applying non-thermal plasma to generate ozone, which could then be used to combust soot at low temperatures. However, this approach has not been used in commercial applications yet.

The main advantage of active regeneration is that the onset of regeneration is guaranteed regardless of the operating conditions. However, it has to embrace a significant fuel economy penalty in achieving it. Fuel needed for the burner, fuel consumed in driving the alternator for electrical heating, the energy needed for ancillary equipment such as blowers, installation of complicated systems and effectiveness of the heat energy transferred to the PM are just to name a few. Also care must be taken to limit the filter temperature to about $1400^{\circ} \mathrm{C}$ to prevent melting or cracking of the filter.

In passively regenerating DPF systems the soot oxidation happens during the normal operation of the vehicle without any action required by either the operator or the engine control system. Passive regeneration systems usually use catalyst to lower the temperature at which soot oxidizes to the temperature of exhaust stream. There are mainly two approaches for passive regeneration: (1) using a combination of DOC and DPF and (2) fuel additives.

Good catalytic reaction requires a greater catalytic surface area. To increase the surface area for a good distribution of the precious metal catalyst material so-called washcoat layer is used. The main function of the washcoat layer is to stabilize the fine dispersed catalyst material against sintering, but can also be used to enhance the catalytic activity or protect 
it against poisoning. The typical range for washcoat loading is between 3 and $300 \mathrm{~g} / \mathrm{dm}^{3}$ catalyst volume with typical metal loadings of $0.110 \mathrm{~g} / \mathrm{dm}^{3}$ catalyst [16]. Washcoat is consisted of noble metals such as platinum, palladium and rhodium. Rhodium and vanadium also help suppress the catalytic oxidation of $\mathrm{SO}_{2}$ which increases the life of the catalyst.

There are number of different washcoat based passive regeneration systems available in todays market. Continuously regenerating trap (CRT) system contains a DOC upstream of a DPF. Catalyzed soot filter (CSF) uses a catalytic coating placed inside the DPF to carry out the passive regeneration activity. The most commonly used method is the Catalyzed continuously regenerating technology (CCRT) developed by Johnson Matthey and is shown in Figure 2.7. This system contains a DOC upstream of the CSF which allows maximum use of $\mathrm{NO}_{x}$ for soot regeneration.

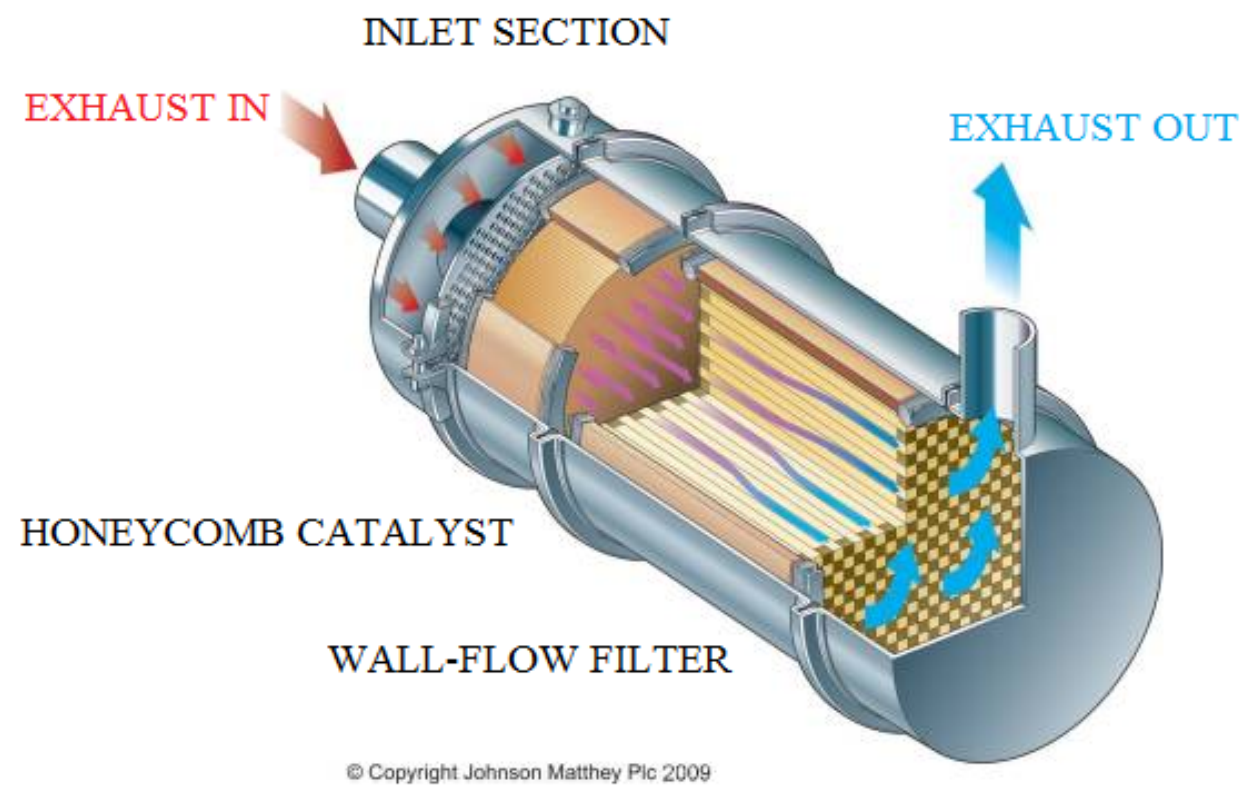

Figure 2.7: Catalyzed continuously regenerating technology (CCRT) [25]

A CSF system is more compact than a CRT system as it requires only one component instead of two. But its compactness requires compromises regarding exhaust backpressure and catalyst loading. The soot layer on top of the filter walls burns less effectively in a CSF than a CRT system. This is because in a CSF NO is oxidized to $\mathrm{NO}_{2}$ underneath the soot 
layer whereas in a CRT system $\mathrm{NO}_{2}$ is formed upstream of the DPF and has therefore a higher chance to contact the soot layer on top of the filter walls.

A CSF system requires less installation space but higher operating temperatures than a CRT system. In a CSF, $\mathrm{NO}_{x}$ can potentially be used more than once for soot oxidation. At high enough temperatures the $\mathrm{NO}_{x}$ to $\mathrm{PM}$ ratio requirements can be lower for CSFs than for CRT systems. However, due to its design a CRT system is less sensitive to ash accumulation and more robust against sintering of the precious metal components. Ash accumulation in CSF reduces efficiency due to blocking of gas pathways as the ash plug builds up. Precious metal sintering is a high temperature ageing mechanism leading to a reduced number of catalytically active sites.

In case of spontaneous thermal regenerations with oxygen the carbon burning creates heat within the DPF. Such heat would not affect an upstream DOC, like in the CRT setup, but the catalytic coating of the CSF would be fully exposed to it. If the temperature on the CSF surface becomes too high, this could potentially cause some precious metal sintering resulting in catalyst deactivation. Both systems have advantages and disadvantages. Thus, the choice of system depends on the application.

The CCRT system benefits advantages of both CRT and CSF systems. It allows a more efficient use of the $\mathrm{NO}_{x}$ emitted from the engine for carbon burning. This is especially true for low temperature applications and applications with a low $\mathrm{NO}_{x}$ to $\mathrm{PM}$ ratio.

The second approach is the use of catalyst in the form of liquid fuel additives. This liquid solution contains oxides of base metals such as barium, calcium, cerium, cobalt, chromium, lanthanum, manganese, and vanadium. In this way, the catalyst enters the engine combustion chamber with the fuel and the soot particles formed during the combustion phase contain the catalyst. Soot particles are hence able to oxidize at low temperatures.

One of the main drawbacks of these systems is the lack of pure contact between the catalytic coating and the soot particles. The particles that are in direct contact with the 
catalytic layer are only able to oxidize. Catalytic layer poisoning due to oxidation of $\mathrm{SO}_{2}$ is another drawback. When $\mathrm{SO}_{2}$ gets mixed with water, it produces sulfuric acid which immensely reduces the filter life through poisoning.

\subsection{Numerical Modeling}

As discussed in the previous chapter, in order to minimize the complex and expensive engine testing resources, a number of computational models have been presented thus far in literature, elaborating on DPFs functionality. These models are characterized by different degrees of detail in particulate transport along the channel length. Significant progress towards understanding the complicated transport and regeneration processes was gained by the pioneering work of Bissett $[4,26]$ who provided a mathematical model for the analysis of regeneration in DPF. This was a zeroth dimensional (0-D) model which performed well in cases where DPF is subjected to large flow rates. Bissett later developed a more general single layer one dimensional model to capture filtration/regeneration characteristics at sufficiently low engine speeds [27]. This model considered the conservation of mass, momentum and energy inside filters including soot oxidation reactions.

Konstandopoulos and Johnson [28] derived a one-dimensional analytical solution for the flow field and pressure drop of a clean DPF based on Bissetts model. With the assumption that the porous wall was a collection of spherical collectors, they employed diffusion and interception mechanisms to describe clean DPF filtration characteristics.

A two-layer model was later developed by Konstandopoulos and Kostoglou [29] to account for the effects of incomplete contact between the particulate layer and catalyst coated on the porous wall. Different soot oxidation rates for thermal and catalytic layers were employed in this model by evaluating oxygen depletion rates. Mass and momentum balance equations were solved using a Runge-Kutta Nystrom method opposed to the Glarkin finite element method used in Bissett model. With this approach, Konstandopoulos was able to develop a better numerical model in terms of computational efficiency. 
Haralampous and Koltsakis [30, 31] studied the oxygen diffusion and $\mathrm{NO}_{2}$ back-diffusion on DPF regeneration. The role of oxygen diffusion was shown to be important in uncontrolled regenerations, which could cause high peak temperature. The contribution of $\mathrm{NO}_{2}$ back diffusion was responsible for about one third of the total regeneration rate for CDPFs. The significance of $\mathrm{NO}_{2}$ assisted soot oxidation at lower monolith wall temperatures was discussed in a previous study [32] of the same institute.

Opris and Johnson developed [33, 34] a two-dimensional computational model to study the flow, heat transfer and regeneration behaviors of DPF. The inclusion of the viscous dissipation term is significant in this model. This study also discussed the filtration mechanisms of the monolith wall in detail. The inertial and interception effects showed greater filtration efficiencies when particle diameters become larger. The opposite effect happens when particle diameters become smaller. In this case, it was found that Brownian diffusion contributes towards better filtration efficiency. Zhang et al. [35] also presented a two-dimensional singlechannel model to simulate filter performance. An analytical approximation for the flow field was developed by simplifying the Navier-Stokes equations through an order of magnitude analysis approach. Then the flow field was employed to solve for the temperature field followed by species concentration balance.

Koltsakis et al. [10] developed a one-dimensional mathematical model to predict temperature gradient inside particulate layer and porous wall in the flow direction through the wall. It was found that significant temperature gradient existed under some operating conditions, which were associated with high flow rate and large initial particulate loading. Kladopoulou et al. [36] developed a lumped parameter model to describe the performance of particulate filter. This model assumed that the temperature of the particulate filter did not have spatial variation and was considered to be uniform over the whole control volume.

Konstandopoulos et al. [37] also developed a 3-D DPF model using commercially available computational fluid dynamics (CFD) software and compared its results with a 1-D model. The author demonstrated excellent agreement between analytical solutions of 1-D single 
channel model and 3-D CFD results.

Schejbal et al. [38] studied the ash deposition on the inlet channel of the DPF in an aged filter. The results of this study revealed that the differences between the fresh and aged filters towards filtration/regeneration characteristics to be quite small.

Recently, a model discussing advanced filtration and regeneration process treatment to the wall was presented by Mulone et. al [39] and allowed to analyze the evolution of soot layer thickness in detail. Conventionally, the soot oxidation was analyzed by descritizing the soot layer in to several parts. A 1-D fully analytical treatment was novel and unique characteristic of this model and allowed to represent with great detail key phenomena for DPF modeling, without any discretization error.

A majority of the models described so far in this section were tested and validated when the engine is operating in steady state conditions. The transient DPF model developed by Rumminger et al. [8] concluded that time varying temperature input to a soot loaded filter could cause faster regeneration with the assistance of faster reaction rates. He further identified cell density and the type of catalytic coating as parameters which could also contribute to this effect. Khan et al. [9] validated their model under transient conditions simulated using a sinusoidal modulation in the exhaust temperature and mass flow rate of the filter inlet. It was found that the modulated temperature could increase the life of the filter as it promotes low temperature regeneration process. However, these temperature fluctuations may not be easily produced by an engine in its actual driving conditions. Kandylas et al. [10] validated their model using a European Transient driving Cycle (ETC) which was representative of real road driving. The model was able to successfully predict the operation of a CRT system. 


\section{Chapter 3}

\section{Model Description}

\subsection{Model Overview}

Mathematical model presented in this chapter for DPF pressure drop and regeneration is based mainly on the works by Bissett [4] and Kostandopoulos[5]. The model assumes that the exhaust gas entering into any given inlet channel presents identical but time dependent mass flow velocities irrespective of its radial position. However, in reality, the channels closer to the walls may show different thermodynamic and fluid dynamic properties. Since, the model in the present study focused on two dimensional behavior of the DPF, aforementioned assumption is justified. This assumption leads authors to describe characteristics of all DPF channels by evaluating just one channel (unit channel approach).

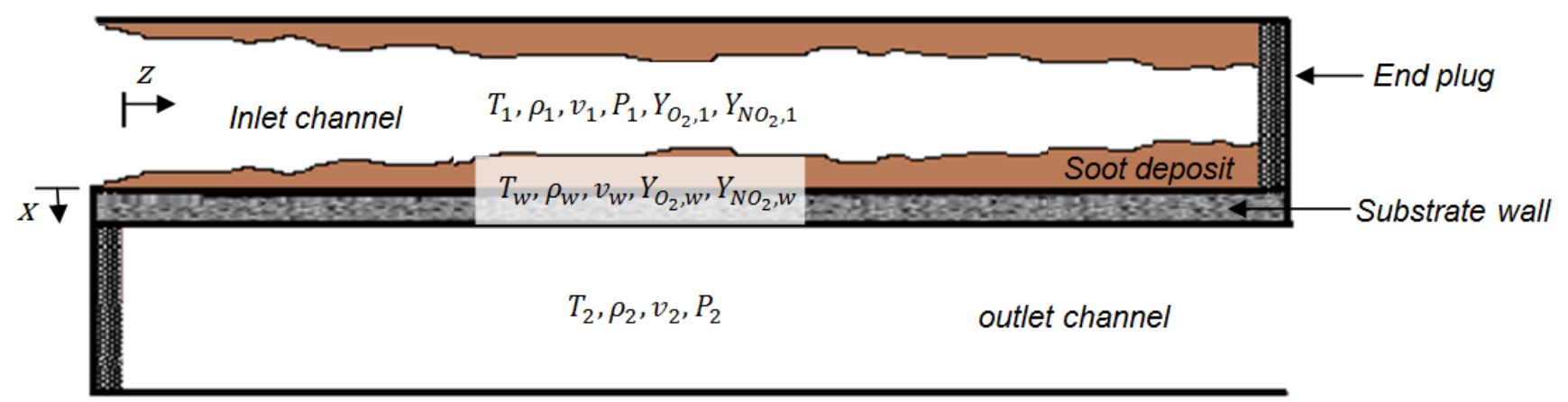

Figure 3.1: Schematic of a single channel of the diesel particulate filter 
A schematic of a single channel in the DPF is given in Figure 3.1. Axial distance along the channel is denoted by the $z$ coordinate and the transverse direction (distance through the wall) is denoted by the $\mathrm{x}$ direction.

Exhaust gas temperatures, densities, velocities and pressures are treated as cross-sectional averaged values. All these values depend only on time $t$ and $z$ direction. The oxygen mass fraction is a function of all three dimensions $(x, z$ and $t)$ due to exothermic soot oxidation in the wall. The pressure difference across the channel cross section is assumed to be negligible. Hence the mass transfer in the $z$ direction between neighboring cells and the wall is also considered to be negligible. Previous work has shown [4] that heat conduction between substrate wall and diesel particulates to be so dominant that the particulate temperature is treated the same as the substrate wall. This assumption allows treatment of the soot particle temperature only as a function of $z$ and t. Heat loss of the exhaust gas along the channel length is considered to be governed by the convection heat transfer rather than conduction heat transfer due to high Peclet numbers. Exhaust gas density was expressed in terms of temperature via the ideal gas law. The effect of ash loading in the DPF wall on the pressure drop is also considered to be negligible.

In general, the developed model is capable of simulating the DPF behavior for a variety of engine cycles. The main structure of the model is illustrated in Figure 3.2. First, the code reads the input file and defines simulation conditions such as DPF geometrical characteristics, exhaust gas property definitions, initial / boundary conditions and reaction kinetic parameters. The model then calculates the flow field and the energy balance equations along the inlet and outlet channels. Based upon these properties the model calculates soot layer evolution in the substrate wall using the filtration model and the regeneration model. The regeneration model consists of three submodels, namely cake, washcoat and wall submodels. Finally, the substrate layer energy balance is solved and results are assigned as initial conditions for the next iteration. 


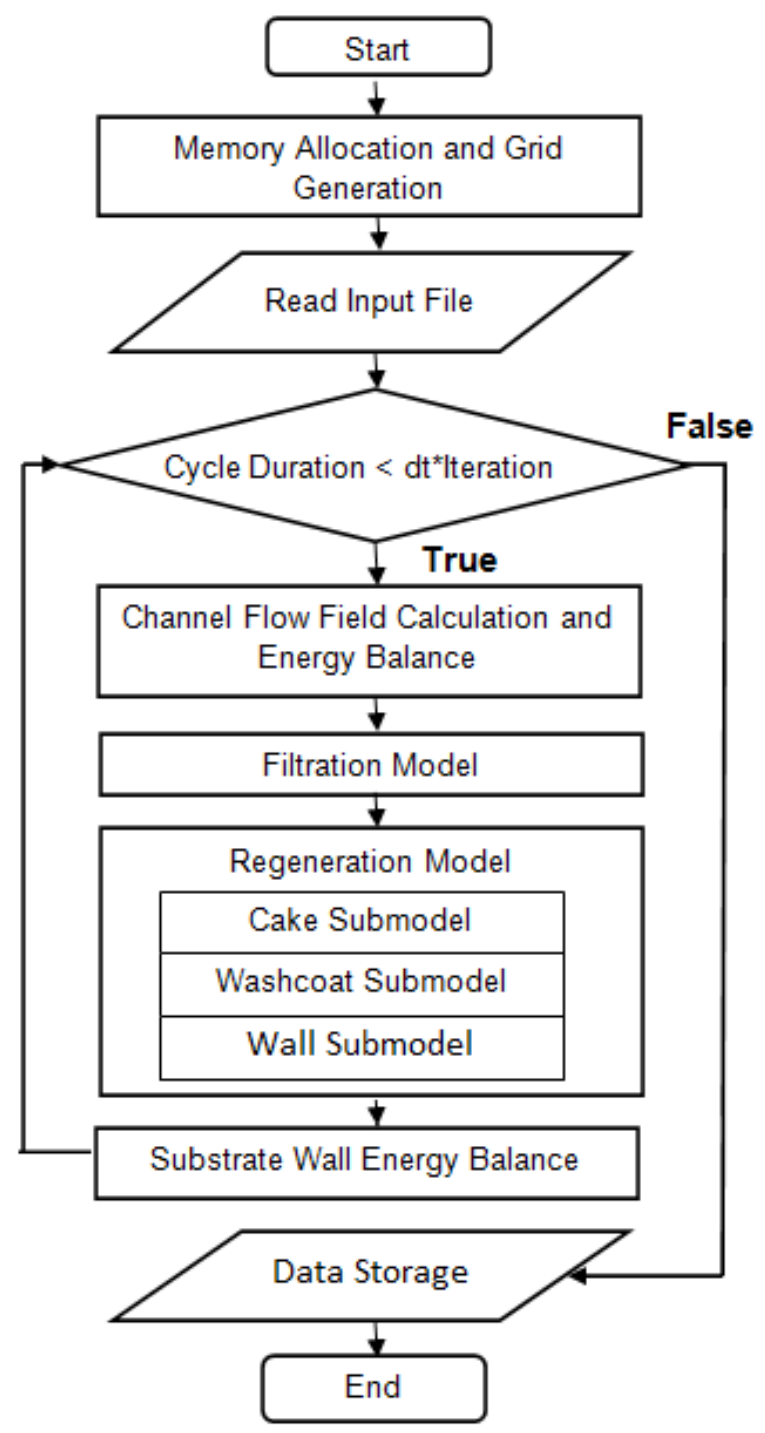

Figure 3.2: Model block diagram

\subsection{Wall Filtration Model}

The filtration model under investigation is based on the framework developed by Konstandopoulos et al. [5, 7]. Recently Mulone et al. [39] extended this work further by developing a fully analytical wall filtration model opposed to classical wall representation by slabs. The analytical approach presented in [39] was developed further by Cozzolini et al. [40] where layer collection mechanism and wall filtration have been linked together taking into account 
the soot layer thickness, similarly to what was presented by Mohammed et al. [6].

Models with such higher degree of detail level show greater complexities which in turn necessitate a greater demand in computational power. The current study uses a computationally efficient 0-D filtration model to avert such complexities.

Particulate matter filtration in particulate filters, made of extruded ceramic like cordierite, can be modeled by the theory of filtration of particles by packed beds [41]. According to this theory, the porous wall consists of numerous closely packed individual spheres known as unit collectors [41]. In reality, these unit collectors could be formed in arbitrary shapes. However, for mathematical simplicity, they were considered to be spherical in this study. Mass collection of these unit collectors solely depends on the flow around it surface. Previous studies [41] have shown the effect of the particles on the flow, and the effect of the flow inertia to be negligible at low flow rates. These conditions favor the solution to the given problem using the Kuwabara-Happel flow [41].

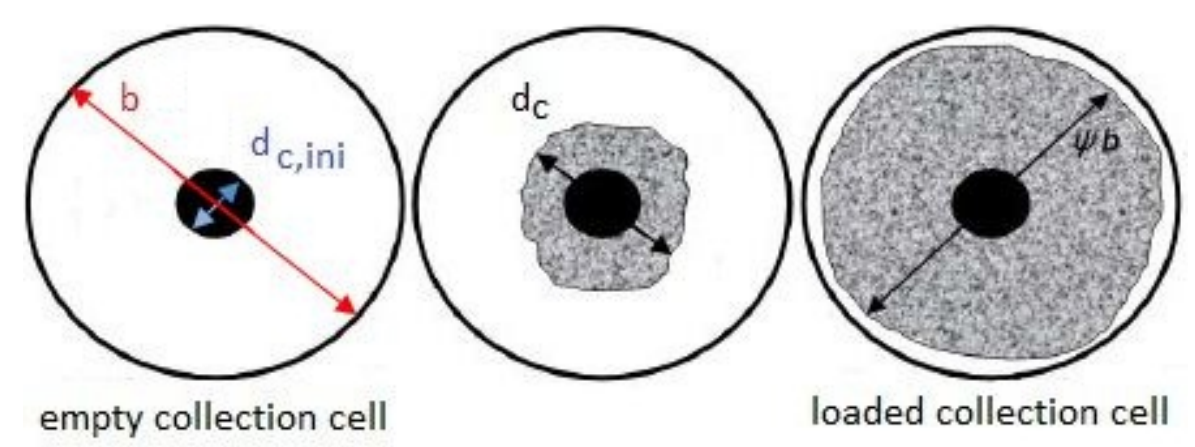

Figure 3.3: Unit collector loading

An imaginary concentric spherical boundary at a certain arbitrary distance is drawn around the collection sphere (see Figure 3.3). The radius of the spherical boundary can be calculated using the relationship between clean filter porosity, $\varepsilon_{0}$ and the unit cell diameter $d_{c, 0}[41]$.

$$
\frac{b^{3}}{d_{c, 0}{ }^{3}}=1-\varepsilon_{0}
$$


A relationship for clean filter unit cell diameter $\left(d_{c, 0}\right)$ can be derived assuming all the void fraction is distributed over cylindrical pores of diameter, $d_{\text {pore }}$ and the external area of the collectors matches the area of the surface of these pores [5].

$$
d_{c, 0}=\frac{3}{2}\left(\frac{1-\varepsilon_{0}}{\varepsilon_{0}}\right) d_{\text {pore }}
$$

As exhaust gas flows through the filter, the porosity of the bed changes as particle accumulation within the bed increases. However, not all the particles flowing into the filter get trapped inside the filter. As described in Chapter 2, particle filtration mainly depends on three aerosol deposition mechanisms: Brownian diffusion; inertial impaction and interception collection.

The single sphere efficiency due to diffusional deposition of particles is defined as the ratio of the rate at which particles diffuse to the sphere surface to that at which particles approach a surface with the cross sectional area of the sphere [41]. Therefore filtration efficiency due to diffusion could be derived incorporating the Kuwabara- Happel stream function [41].

$$
\eta_{D}=\frac{7}{2} \frac{\varepsilon}{K} P e^{-2 / 3}
$$

where $P e$ is Peclet number, $\varepsilon$ is the loaded unit cell porosity and $K$ is the Kuwabara hydrodynamic factor. Kuwabara hydrodynamic factor is given by

$$
K=2-\varepsilon-\frac{9}{5}(1-\varepsilon)^{\frac{1}{3}}-\frac{1}{5}(1-\varepsilon)^{2}
$$

Peclet number for diffusion of particles is defined as

$$
P e=\frac{U_{i} d_{c}}{D_{p}}
$$

where $U_{i}$ is undisturbed particle velocity, $d_{c}$ is unit collector diameter and $D_{p}$ is particle diffusion coefficient. The undisturbed flow rate across the channel $U_{i}$ is related to the substrate wall velocity $u_{w}$ and porosity $\varepsilon$ as follows [7]. 


$$
U_{i}=\frac{u_{w}}{\varepsilon}
$$

Diffusion coefficient is calculated assuming the Brownian motion of the particles and is given by:

$$
D_{p}=\frac{k_{B} T}{f}
$$

where $k_{B}$ is the Boltzmann constant, $T$ is absolute temperature of gas flowing through the substrate wall and friction coefficient $(f)$ is calculated based on Stokes law.

$$
f=3 \pi \mu d_{p}
$$

where $\mathrm{d}_{p}$ is primary soot particle diameter and $\mu$ is dynamic viscosity. However, this only applies to a rigid spherical particle which is further away from any surface. It is also a known fact that the drag force experienced by the particle for a given velocity is less than the predicted drag force estimated by the Stokes law. Cunningham slip correction factor $\left(C_{f}\right)$, is used to correct the Stokes friction factor; hence the equation (3.8) can be re-written as follows.

$$
D_{p}=\frac{k_{B} T C_{f}}{f}=\frac{k_{B} T C_{f}}{3 \pi \mu d_{p}}
$$

where $k_{B}$ is Boltzmann constant. Slip correction factor is given by [5]:

$$
C_{f}=1+K n\left(1.257+0.4 e^{\frac{-1.1}{K n}}\right)
$$

where $K n_{p}$ is the particle Knudsen number defined by:

$$
K n_{p}=\frac{2 \lambda}{d_{\text {pore }}}
$$


where $d_{\text {pore }}$ is pore diameter of the substrate wall and the mean free path $\lambda$ of exhaust gas is given by [5]:

$$
\lambda=\frac{\mu}{P} \sqrt{\frac{\pi \bar{R} T}{2 M}}
$$

where $\nu$ is kinematic viscosity of exhaust gas, $M W$ is the molecular weight of the exhaust gas, $\bar{R}$ is universal gas constant $P$ is atmospheric pressure and $T$ is absolute temperature of exhaust gas.

Single sphere interception efficiency of the particles trapped in a unit collector is modeled by Lee et al. [41] as follows.

$$
\eta_{R}=\frac{3}{2} \frac{\varepsilon}{K} \frac{R_{i}^{2}}{\left(1+R_{i}^{2}\right)^{s}}
$$

where $R_{i}$ is the interception parameter

$$
R_{i}=\frac{d_{p}}{d_{c}}
$$

where $d_{c}$ is collector diameter and $s$ is given by [41]:

$$
s=\frac{2-2 \varepsilon}{3 \varepsilon}
$$

Overall collection efficiency for the single collector can thus be calculated assuming as a combination of collection efficiencies associated with two filtration mechanisms:

$$
\eta_{D R}=\eta_{D}+\eta_{R}-\eta_{D} \eta_{R}
$$

where $\eta_{D}$ and $\eta_{R}$ represent the collection efficiencies due to diffusivity and direct interception, 
respectively [5]. The overall collection efficiency of the substrate wall is given by Lee et al. [41] as follows.

$$
E=1-\exp \left(\frac{-3(1-\varepsilon) \eta_{D R} w_{s}}{2 \varepsilon d_{c}}\right)
$$

where $w_{s}$ is substrate wall thickness.

As exhaust gases flow through the wall, soot particles are eventually trapped by the unit collectors which lead to a growth in unit collector diameter. The rate of mass trapped inside the unit collector is equal to the product of mass flow rate through the wall and the overall collection efficiency of the substrate wall. The unit collector diameter growth can thus be calculated after defining a soot packing density $\left(\rho_{\text {soot }, w}\right)$ in the substrate wall [5].

$$
d_{c}(i, t)=\left[\left(\frac{d_{c 0}}{2}\right)^{3}+\frac{3}{4 \pi} \frac{m_{c}(i, t)}{\rho_{\text {soot }, w}}\right]^{\frac{1}{3}}
$$

where $d_{c 0}$ is initial unit collector diameter, $m_{c}$ is mass in one unit collector and $\rho_{w, s o o t}$ is soot packing density of the virtual soot layer. Having calculated the updated unit collector diameter, modified porosity due to mass filtration can be calculated using equation (3.19).

$$
\varepsilon(i, t)=1-\left[\frac{d_{c}(i, t)}{d_{c, 0}}\right]^{3}\left(1-\varepsilon_{0}\right)
$$

where $\varepsilon_{0}$ is initial substrate porosity. Permeability change due to mass filtration is a function of both unit collector diameter and the filter porosity. The local permeability of a loaded filter $k$ in terms of the clean filter permeability $k_{0}$, is given by [5]:

$$
k(i, t)=k_{0}(i, t)\left[\frac{d_{c}(i, t)}{d_{c, 0}}\right]^{2} \frac{f(\varepsilon(i, t))}{f\left(\varepsilon_{0}\right)}
$$

As wall filtration progresses, the microstructure space between unit collectors decreases and eventually becomes less than the particle diameter. Under this circumstance, the filtra- 
tion mechanism changes from wall filtration to cake filtration, during which the particles are deposited on the surface and a particulate layer is formed. However, in reality, both wall and cake filtration occurs simultaneously.

A mathematical control parameter known as the "partition coefficient $(\phi)$ " is used to determine the fraction of incoming particle mass retained on the surface of the porous wall to form a particulate layer. This parameter is expressed as follows. [5].

$$
\phi(t)=\frac{\left(d_{c, 0}(0, t)\right)^{2}-d_{c, 0}^{2}}{(\psi \cdot b)^{2}-d_{c, 0}^{2}}
$$

Percolation factor $\psi$ limits the amount of soot mass collected in a single cell unit collector in its "fully loaded"state. When the local unit collector diameter reaches the ultimate unit collector diameter $(\psi \cdot b)$, the model no longer permits particles to flow through the substrate wall; hence, all the mass is trapped on the cake layer. This parameter is used as a tuning parameter in the model to control the amount of mass retained in the substrate wall.

As the cake layer grows on top of the substrate wall, the cake layer itself acts as a filter, limiting the amount of particles entering the substrate wall. The mathematical formulation of this phenomenon is extensively discussed in Mohammad et al. [6]. However, a detailed 1-D filtration code developed by Cozzolini et al. [40] based on aforementioned references showed that the cake filtration efficiency maintained at a constant value under the experimental conditions in which the current model was tested. Hence, to avert additional complexities a constant cake filtration efficiency $E_{\text {cake }}$ of 0.9998 was adopted in to this model. Hence mass separation between cake and wall layers can be further upgraded as follows.

$$
\begin{gathered}
\dot{m}_{\text {wall }}(t)=\dot{m}_{\text {eng out }}\left[1-\phi(t) \cdot E_{\text {cake }}\right] \\
\dot{m}_{\text {cake }}(t)=\dot{m}_{\text {eng out }}\left[\phi(t) \cdot E_{\text {cake }}\right]
\end{gathered}
$$

where $\dot{m}_{\text {wall }}$ and $\dot{m}_{\text {cake }}$ are mass flow rates experienced by wall and cake layer respectively. Engine out mass flow rate is given by $\dot{m}_{\text {eng out }}$. 


\subsection{Regeneration Model}

The particulate layer oxidation model under evaluation adopts the 2-layer approach developed by Konstandopoulos et al. [5] and Mohammed [6] (see Figure 3.4). Exhaust gas flows through two layers: washcoat layer $\left(w_{1}\right)$ and the layer of particles deposited on the washcoat $\left(w_{2}\right)$ or the cake layer.

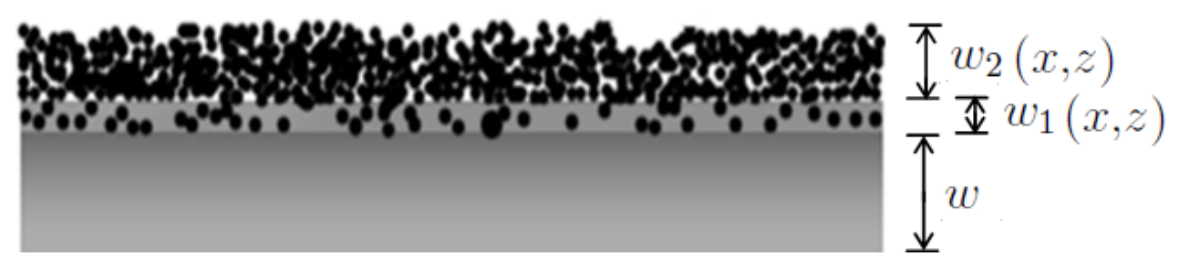

Figure 3.4: Schematic of the particle deposition on filter channels

Some change in the internal structure of the deposit layer during reactions may be expected. However, these changes have not been studied; hence, are neglected in this model. The soot particles residing in the washcoat layer are the closest to the catalytic coating of the substrate wall. Hence, the particles in this region oxidize by both catalytic and thermal means. Determining the limiting thickness $w_{\text {limit }}$ of this imaginary boundary of the washcoat layer is a strenuous task. Published literature indicates that this thickness is confined to about 10-30 $\mu \mathrm{m}$ [5]. Particles residing over this thickness are assumed to be oxidized only by thermal means and have no effect on the presence of the wall catalytic layer. Mathematical formulation of the particle separation between layer and layer 2 can be expressed as follows.

$$
\begin{gathered}
w_{1}=w_{s} ; \quad w_{2}=0 \text { if } w_{s}<w_{\text {limit }} \\
w_{1}=w_{\text {limit }} ; \quad w_{2}=w_{s}-w_{\text {limit }} \text { if } w_{s} \geq w_{\text {limit }}
\end{gathered}
$$

\subsubsection{Cake Regeneration Submodel}

Three oxidation mechanisms occur in the cake layer:

(1) Thermal oxidation; 
(2) Catalytic oxidation; and

(3) $\mathrm{NO}_{2}$ assisted thermal oxidation.

Soot oxidation due to presence of oxygen in exhaust gas at elevated temperatures $\left(500-600^{\circ} \mathrm{C}\right)$ is described by thermal oxidation [5]. Soot oxidation at lower temperatures $\left(\approx 450^{\circ} \mathrm{C}\right)$ due to presence of oxygen in exhaust gas with the assistance of Pt-doped catalytic washcoat layer is referred to catalytic oxidation. Soot oxidation at lower temperatures $\left(\approx 150^{\circ} \mathrm{C}\right)$ due to presence of $\mathrm{NO}_{2}$ in the exhaust gas is described as $\mathrm{NO}_{2}$ assisted thermal oxidation. The dominance of each of these mechanisms depends heavily on the mass fractions of $\mathrm{O}_{2}$ and $\mathrm{NO}_{2}$, and temperature at a given location in the DPF.

Reactions that occur in one phase are referred to as homogeneous reactions while reactions that occur at interfaces between phases are heterogeneous reactions. Heterogeneous kinetic reactions have to be considered since the transport process in the DPF occur between both solid and gas phases. In the current model, chemical reactions in the gas phase are neglected due to its short residence time in a DPF channel. The molar concentration of the reactant species like $\mathrm{O}_{2}$ and $\mathrm{NO}_{2}$ inside a DPF channel is assumed to be constant throughout the channel length for simplicity of calculation. It is a well understood fact that Diesel exhaust particles are composed of carbon and many other hydrocarbon / hydrocarbon derived materials. In this model, as a general simplifying assumption, diesel soot particles are assumed to be purely carbonaceous. Under this assumption, governing equations of soot oxidation reactions can be expressed as follows.

$$
\begin{aligned}
& \mathrm{C}+\mathrm{O}_{2} \rightarrow \mathrm{CO}_{2} \\
& \mathrm{C}+\frac{1}{2} \mathrm{O}_{2} \rightarrow \mathrm{CO}
\end{aligned}
$$

Aforementioned two reactions can be written as a global one step heterogeneous oxidation reaction using a selectivity parameter as follows [29].

$$
C+\left(1-\frac{f_{C O}}{2}\right) O_{2} \rightarrow f_{C O} C O+\left(1-f_{C O}\right) C O_{2}
$$


Carbon monoxide selectivity $f_{C O}$ in the equation (3.28) depends on the oxygen mole fraction in the exhaust gas $y_{O_{2}}$, thermal oxidation reaction rate constant $k_{t h}$, activation temperature of carbon oxidation due thermal oxidation reaction $\frac{E_{f 1}}{R}$, and the gas temperature in the wall $T_{w}$ [29]. The mole fraction exponent $n 1$ functions as a tuning parameter of the model to control the amount of oxygen reacting with carbon particles to match up with the experimental results. However, this value used in the model is coherent with the published literature [29].

$$
f_{C O}=\frac{1}{1+k_{t h} y_{O_{2}}^{n 1} \exp \left(\frac{-E_{f 1}}{\bar{R} T_{w}}\right)}
$$

The reaction rate constant $k_{t h}$ follows the Arrhenius relationship.

$$
k_{t h}=A_{t h} T_{w}^{n} \exp \left(\frac{-E_{t h}}{\bar{R} T_{w}}\right)
$$

where $E_{t h}$ is activation energy of thermal oxidation and $\bar{R}$ is universal gas constant. In equation (3.30), $A_{t h}$ is the pre-exponential factor of Diesel soot particle oxidation due to thermal means and $\frac{E_{t h, O 2}}{R}$ is the activation temperature of diesel exhaust oxidation due thermal oxidation reaction. As described in the previous equation, temperature exponent $n$ serves as a tuning parameter to control the rate coefficient of the reaction.

Diesel particulate matter oxidation by $\mathrm{NO}_{2}$ primarily consists of two simultaneous reactions: direct and cooperative oxidation in which one produces $C O$ and the other produce $\mathrm{CO}_{2}[42]$.

$$
\begin{gathered}
\mathrm{C}+2 \mathrm{NO}_{2} \rightarrow \mathrm{CO}_{2}+2 \mathrm{NO} \\
\mathrm{C}+\mathrm{NO}_{2} \rightarrow \mathrm{CO}+\mathrm{NO}
\end{gathered}
$$

However, a one step global heterogeneous form of soot oxidation due to $\mathrm{NO}_{2}$ can be expressed as thermal oxidation due to $\mathrm{O}_{2}$ incorporating a selectivity coefficient as follows [6]. 


$$
C+\left(2-g_{C O}\right) N_{2} \rightarrow g_{C O} C O+\left(1-g_{C O}\right) C O_{2}+\left(2-g_{C O}\right) N O
$$

The $C O$ selectivity coefficient is modeled similarly to the thermal oxidation and is given by $[6]$.

$$
g_{C O}=\frac{1}{1+k_{N_{2}} y_{N_{2}}^{n 3} \exp \left(\frac{-E_{f 3}}{\bar{R} T_{w}}\right)}
$$

The reaction rate constant for oxidation by $\mathrm{NO}_{2}$ is given in equation (3.35), [6]:

$$
k_{N O_{2}}=A_{N O_{2}} T_{w}^{n} \exp \left(\frac{-E_{N O_{2}}}{\bar{R} T_{w}}\right)
$$

It is suggested by some authors that CO selectivity parameter may be neglected considering the dominance of the reaction given in equation (3.31) over the reaction given in equation (3.32) [6]. In this model, the $C O$ selectivity parameter was used in full form since it does not arise any complications in its numerical implementation.

Particulate oxidation heavily depends upon the availability of $\mathrm{O}_{2}$ and $\mathrm{NO}_{2}$ mass at given position. Assuming that the main reaction is a first order heterogeneous oxidation of carbon and that diffusion is negligible compared to convection, the oxygen mass fraction $Y_{\mathrm{O}_{2}}$ and the $\mathrm{NO}_{2}$ mass fraction $\mathrm{YNO}_{2}$ are conserved through the cake layer accordingly to equations (3.36) and (3.37) [6]:

$$
\begin{gathered}
\frac{\partial}{\partial x}\left(\rho_{w} v_{w} Y_{O_{2}}\right)=-S_{p} \rho_{w} Y_{O_{2}} k_{t h}\left(1-\frac{f_{C O}}{2}\right) \\
\frac{\partial}{\partial x}\left(\rho_{w} v_{w} Y_{N O_{2}}\right)=-S_{p} \rho_{w} Y_{N O_{2}} k_{N O_{2}}\left(2-g_{C O}\right)
\end{gathered}
$$

where $Y_{\mathrm{O}_{2}, 2}$ and $Y_{\mathrm{NO}_{2}, 2}$ denote the oxygen mass fraction and the $\mathrm{NO}_{2}$ mass fraction entering the cake layer respectively, $\rho_{w}$ is the exhaust density and $v_{w}$ denotes the gas velocity approaching the soot layer. 
The specific reactive surface area $S_{P}$ of diesel PM in the cake layer is given by Equation (3.38):

$$
S_{p}=A_{p} \rho_{\text {soot }, c k}
$$

where $A_{p}$ and $\rho_{\text {soot,ck }}$ are the area and density of diesel soot particles, respectively.

Total rate of $\mathrm{O}_{2}$ and $\mathrm{NO}_{2}$ depletion per unit wall surface area $R_{\mathrm{O}_{2}, 2}^{\text {th }}$ and $R_{\mathrm{NO}_{2}, 2}$ can be attained by integrating equations (3.39) and (3.40), respectively along the wall thickness.

$$
\begin{aligned}
R_{O_{2}, 2}^{t h} & =\int_{0}^{w_{2}} S_{p} \rho_{w} Y_{O_{2}} k_{t h}\left(1-\frac{f_{C O}}{2}\right) d x \\
R_{N O_{2}, 2} & =\int_{0}^{w_{2}} S_{p} \rho_{w} Y_{N O_{2}} k_{N O_{2}}\left(2-g_{C O}\right) d x
\end{aligned}
$$

As stated earlier in this section, the change in density and the velocity in the $x$ direction can be assumed negligible. With this assumption, $\mathrm{O}_{2}$ and $\mathrm{NO}_{2}$ depletion rates are given by equations (3.41) and (3.42) respectively.

$$
\begin{aligned}
R_{O_{2}, 2}^{t h} & =\rho_{w} v_{w} Y_{O_{2}, 2}\left[1-\exp \left(\frac{-S_{p} k_{t h}\left(1-\frac{f_{C O}}{2}\right) w_{2}}{v_{w}}\right)\right] \\
R_{N O_{2,2}} & =\rho_{w} v_{w} Y_{N O_{2,2}}\left[1-\exp \left(\frac{-S_{p} k_{N O_{2}}\left(2-g_{C O}\right) w_{2}}{v_{w}}\right)\right]
\end{aligned}
$$

The $\mathrm{O}_{2}$ and $\mathrm{NO}_{2}$ depletion rates can be attributed to the consumption of the soot layer, given by equation (3.43).

$$
\frac{\partial\left(\rho_{\text {soot }, \mathrm{ck}} w_{2}\right)}{\partial t}=-\frac{M_{c}}{M_{\mathrm{O}_{2}}}\left(\frac{R_{\mathrm{O}_{2,2}}}{1-\frac{f_{C O}}{2}}\right)-\frac{M_{c}}{M_{\mathrm{NO}_{2}}}\left(\frac{R_{\mathrm{NO}_{2,2}}}{2-g_{C O}}\right)
$$

where $M_{c}, M_{\mathrm{NO}_{2}}$ and $M_{\mathrm{O}_{2}}$ are molecular weights of carbon, nitrogen dioxide and oxygen respectively. 


\subsubsection{Washcoat Regeneration Submodel}

Diesel particulates trapped in the washcoat undergo both thermal and catalytic oxidation and thus the oxygen depletion rates of the two paths have to be separately evaluated. But first, the $\mathrm{O}_{2}$ and $\mathrm{NO}_{2}$ mass fractions leaving the cake layer and entering the washcoat layer have to be calculated and can be expressed by:

$$
\begin{gathered}
Y_{O_{2}, 1}=Y_{O_{2}} \exp \left(\frac{-S_{p} k_{t h}\left(1-\frac{f_{C O}}{2}\right) w_{2}}{v_{w}}\right) \\
Y_{N O_{2,1}}=Y_{N O_{2}} \exp \left(\frac{-S_{p} k_{N O_{2}}\left(2-g_{C O}\right) w_{2}}{v_{w}}\right)
\end{gathered}
$$

Stoichiometric equation for soot oxidation under catalytic means can be expressed similar to equation (3.33). However, the selectivity parameter $f_{C O}^{\prime}$ should be modified to account for oxidation at lower temperatures.

$$
C+\left(1-\frac{f_{C O}^{\prime}}{2}\right) O_{2} \Rightarrow f_{C O}^{\prime} C O+\left(1-f_{C O}^{\prime}\right) C O_{2}
$$

where selectivity parameter $f_{C O}^{\prime}$ is given by

$$
f_{C O}^{\prime}=\frac{1}{1+k_{c a t} y_{O_{2}}^{n 2} \exp \left(\frac{-E_{f 2}}{\bar{R} T_{w}}\right)}
$$

The reaction rate constant $k_{c a t}$ follows the Arrhenius relationship:

$$
k_{c a t}=A_{c a t} T_{w}^{n} \exp \left(\frac{-E_{c a t}}{\bar{R} T_{w}}\right)
$$

The oxidation of the aforementioned paths were formulated by Konstandopoulos [5] in his 2-layer theory, using a soot oxidation fraction $\beta$. Due to low activation energy, soot particles trapped in the washcoat layer primarily oxidize using the available $\mathrm{O}_{2}$ mass fraction and then thermally oxidize with the remaining $O_{2}$ mass fraction $(1-\beta)$. Thus, the $O_{2}$ balance equation for washcoat layer can be expressed as shown in equation (3.49). 


$$
\frac{\partial}{\partial x}\left(\rho_{w} v_{w} Y_{O_{2}, 1}\right)=-S_{p} \rho_{w} Y_{O_{2}, 1}\left[k_{t h}\left(1-\frac{1-f_{C O}}{2}\right)(1-\beta)+k_{c a t}\left(1-\frac{1-f_{C O}^{\prime}}{2}\right) \beta\right]
$$

Integration of the equation (3.49) over the washcoat thickness yields the total oxygen depletion rate, $R_{\mathrm{O}_{2}}$, total and is expressed in equation (3.50):

$$
R_{O_{2}}^{\text {total }}=\rho_{w} v_{w} Y_{O_{2,1}}\left[1-\exp \left(\frac{-S_{p} k^{\star} w_{1}}{v_{w}}\right)\right]
$$

where,

$$
k^{\star}=k_{t h}\left(1-\frac{f_{C O}}{2}\right)(1-\beta)+k_{c a t}\left(1-\frac{f_{C O}^{\prime}}{2}\right) \beta
$$

The $C O$ selectivity and the soot oxidation fraction is then used to separate the catalytic and thermal contributions from the total oxygen depletion rate.

$$
\begin{gathered}
R_{O_{2}, 1}^{\text {th }}=R_{O_{2}}^{\text {total }}\left[\frac{k_{t h}\left(1-\frac{f_{C O}}{2}\right)(1-\beta)}{k^{\star}}\right] \\
R_{O_{2}, 1}^{\text {cat }}=R_{O_{2}}^{\text {total }}\left[\frac{k_{c a t}\left(1-\frac{f_{C O}^{\prime}}{2}\right) \beta}{k^{\star}}\right]
\end{gathered}
$$

Upon integration of the $\mathrm{NO}_{2}$ balance equation, the following $\mathrm{NO}_{2}$ depletion rate in the washcoat layer is obtained:

$$
R_{N O_{2,1}}=\rho_{w} v_{w} Y_{N O_{2,1}}\left[1-\exp \left(\frac{-S_{p} k_{N O_{2}}\left(2-g_{C O}\right) w_{1}}{v_{w}}\right)\right]
$$

Considering the reaction stoichiometry, the transient change of the washcoat layer particulate thickness can then be expressed as follows.

$$
\frac{\partial\left(\rho_{\text {soot }, c k} w_{1}\right)}{\partial t}=-\frac{M_{c}}{M_{O_{2}}}\left(\frac{R_{O_{2,1}}^{t h}}{1-\frac{f_{C O}}{2}}\right)-\frac{M_{c}}{M_{O_{2}}}\left(\frac{R_{O_{2}, 1}^{c a t}}{1-\frac{f_{C O}^{\prime}}{2}}\right)-\frac{M_{c}}{M_{N_{2}}}\left(\frac{R_{N O_{2}, 1}}{2-g_{C O}}\right)
$$


The model requires a knowledge of the value of initial soot layer thickness along the channel length in order to solve the initial value problems given in equations (3.43) and (3.55). The initial soot layer thickness $w_{b}$, was also considered to be constant along the channel length even though it could be an axial space dependent value. This parameter was determined using a process called "virtual conditioning" due to the fact that an aged filter was used during experimental phase. "Virtual conditioning" will be discussed in detain in Chapter 5 .

\subsubsection{Wall Regeneration Submodel}

Wall regeneration submodel was formulated based upon the work of Mohommad et al. [6]. Several authors have pointed out the importance of wall regeneration and its significant contribution towards pressure drop, especially in CCRTs [6]. Wall regeneration modeling approach is same as in the previous two cases. Particles trapped inside the filter are formulated to resemble a virtual particulate layer thickness, $w_{\text {wall }}$. This thickness is calculated, similar to unit cell theory, by defining a particulate packing density $\rho_{\text {soot,wall }}$ inside the substrate wall.

$$
w_{\text {wall }}(z)=\frac{m_{\text {wall }}(z)}{D d z \rho_{\text {soot }, \text { wall }}}
$$

Local mass trapped inside the filter and the axial discretization length are represented by $m_{\text {wall }}(z)$ and $d z$, respectively. Soot reside in the wall oxidizes only by thermal means. This is mainly because the lack of data availability in the published literature related to the catalytic penetration.

Considering the $\mathrm{O}_{2}$ and $\mathrm{NO}_{2}$ conservation equations for the substrate wall, respective mass fractions exiting washcoat layer or entering substrate wall are given by:

$$
\begin{gathered}
Y_{\mathrm{O}_{2}, \text { wall }}=Y_{\mathrm{O}_{2}, 1} \exp \left(\frac{-S_{p} k^{*} w_{1}}{v_{w}}\right) \\
Y_{\mathrm{NO}_{2}, \text { wall }}=Y_{\mathrm{NO}_{2}, 1} \exp \left(\frac{-S_{p} k_{\mathrm{NO}_{2}}\left(2-g_{\mathrm{CO}}\right) w_{1}}{v_{w}}\right)
\end{gathered}
$$


Depletion rates relating to the two species can be attained by integrating conservation equations along the substrate wall thickness.

$$
R_{O_{2}, \text { wall }}=\rho_{w} v_{w} Y_{O_{2}, \text { wall }}\left[1-\exp \left(\frac{-S_{p} k^{\text {th }}\left(1-\frac{f_{C O}}{2}\right) w_{\text {wall }}}{v_{w}}\right)\right]
$$

Similar to previous cases, using stoichiometry, the decay of the virtual wall layer thickness can thus be expressed using the following equation.

$$
\frac{\partial\left(\rho_{\text {soot }, \text { wall }} w_{1}\right)}{\partial t}=-\frac{M_{c}}{M_{O_{2}}}\left(\frac{R_{O_{2}, \text { wall }}}{1-\frac{f_{C O}}{2}}\right)-\frac{M_{c}}{M_{N_{2}}}\left(\frac{R_{N O_{2}, \text { wall }}}{2-g_{C O}}\right)
$$

\subsubsection{Wall Energy Balance}

The one-dimensional temperature field in the monolith is described by the following assumptions/mechanisms;

(1) Convection heat transfer between the substrate wall and the exhaust gas at the inlet and the outlet channels;

(2) Conduction heat transfer through the substrate wall;

(3) Heat generation due to the exothermic soot oxidation; and

(4) Heat loss to the environment by convection.

The resulting formula can be expressed as follows:

$$
\left(\rho_{s} c_{p s} w_{s}+\rho_{\text {soot }, c k} c_{p p}\left(w_{1}+w_{2}\right)\right) \frac{\partial T_{w}}{\partial t}=h_{1}\left(T_{1}-T_{w}\right)+h_{2}\left(T_{2}-T_{w}\right)+H_{\text {react }}+H_{\text {cond }}-H_{\text {envir }}
$$

where $C_{p s}$ is the heat capacity of the substrate wall, $C_{p p}$ is the heat capacity of the particulate matter, $\rho_{s}$ and $\rho_{\text {soot }, c k}$ are the densities of the particulate matter and the substrate, $H_{\text {react }}$ is the heat flux generated by chemical reaction of soot and $H_{\text {cond }}$ heat flux losses due to conduction through the substrate wall. The contribution of exothermic chemical reactions depend on the $\mathrm{O}_{2}$ and $\mathrm{NO}_{2}$ depletion in washcoat and cake layers is given in equation (3.62): 


$$
\begin{aligned}
H_{\text {react }} & =\frac{\Delta H^{t h}}{M_{O_{2}}}\left[\left(\frac{1}{1-\frac{f_{C O}}{2}}\right)\left(R_{O_{2}, 1}^{t h}+R_{O_{2}, 2}\right)\right]+\frac{\Delta H^{c a t}}{M_{O_{2}}}\left[\left(\frac{1}{1-\frac{f_{C O}^{\prime}}{2}}\right)\left(R_{O_{2}, 1}^{c a t}\right)\right] \\
& +\frac{\Delta H^{N O_{2}}}{M_{N O_{2}}}\left[\left(\frac{1}{2-g_{C O}}\right)\left(R_{N O_{2}, 1}+R_{N O_{2,2}}\right)\right]
\end{aligned}
$$

where $\Delta H^{\text {th }}, \Delta H^{\text {cat }}$ and $\Delta H^{N O_{2}}$ are heats of reaction carbon oxidation due to thermal and catalytic oxidation and $\mathrm{NO}_{2}$ reaction respectively. These heats of reactions solely depend on their respective $C O$ selectivity.

$$
\begin{gathered}
\Delta H^{\text {th }}=f_{C O} \Delta H_{C O}+\left(1-f_{C O}\right) \Delta H_{C O_{2}} \\
\Delta H^{c a t}=f_{C O}^{\prime} \Delta H_{C O}+\left(1-f_{C O}^{\prime}\right) \Delta H_{C O_{2}} \\
\Delta H^{N O_{2}}=g_{C O} \Delta H_{C O}+\left(1-g_{C O}\right) \Delta H_{C O_{2}}+\left(2-g_{C O}\right) \Delta H_{N_{2}}
\end{gathered}
$$

Conduction heat transfer through the substrate wall is calculated using the Euken [4] formula given in equation (3.66)

$$
H_{\text {cond }}=\lambda_{s} w_{s} \frac{\partial^{2} T_{w}}{\partial z^{2}}+\lambda_{p} \frac{\partial}{\partial z}\left(w_{1} \frac{\partial T_{w}}{\partial z}\right)+\lambda_{p} \frac{\partial}{\partial z}\left(w_{2} \frac{\partial T_{w}}{\partial z}\right)
$$

where $\lambda_{s}$ and $\lambda_{p}$ are the thermal conductivity of substrate and the particulate layer respectively.

Convection heat loss from the DPF can to the environment was also incorporated into the model to re-create experimental conditions under which the model was validated. This can be formulated with the use of conduction heat loss through DPF packaging and Newtons law of cooling.

$$
H_{\text {envir }}=\frac{\left(T_{w}-T_{0}\right)}{R_{t} \pi D L}
$$




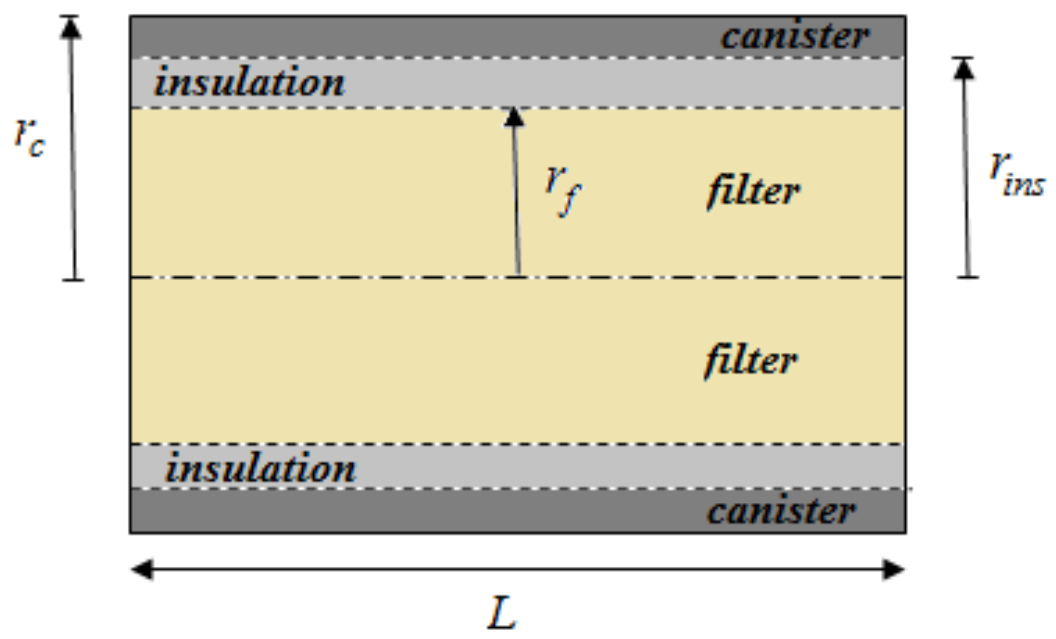

Figure 3.5: Sectional view of DPF with thermal resistance parameters

Temperature of the ambient air is denoted by $T_{0}$. The resultant thermal resistance $R_{t}$ across the DPF can be derived as follows.

$$
R_{t}=\frac{\log \left(\frac{r_{i n s}}{r_{f}}\right)}{2 \pi k_{1} L}+\frac{\log \left(\frac{r_{c}}{r_{i n s}}\right)}{2 \pi k_{2} L}+\frac{1}{2 \pi r_{c} L H_{e x}}
$$

where $r_{i n s}, r_{f}$ and $r_{c}$ are outer radius of insulation layer, filter radius and outer radius of canister respectively. The thermal conductivity between the filter and the insulation is $k_{1}$ and the thermal conductivity between the insulation and the canister is $k_{2}$.

The convective heat transfer coefficient for the DPF, $H_{e x}$ can be calculated using the thermal conductivity $k_{D}$ of the filter can and the Nusselt number $N u_{D}$ and is given in equation (3.69):

$$
H_{e x}=\frac{k_{D} N u_{D}}{d}
$$

Nusselt number for flow over a horizontal cylinder with uniform surface temperature for a wide range of Rayleigh numbers, $R a_{D}$ is given by [43]:

$$
N u_{D}=\left[0.6+\frac{0.387 R a_{d}^{\frac{1}{6}}}{\left(1+(0.559 / P r)^{9 / 16}\right)^{8 / 27}}\right]^{2}
$$


where, $\operatorname{Pr}$ is the Prandtl number and $R a_{D}$ is the Rayleigh number which can be expressed as

$$
R a_{D}=\frac{g \beta_{t h}\left(T_{w}-T_{0}\right) D^{3}}{\alpha v}
$$

In the above equation, $g, \beta, \alpha$ and $\nu$ denote gravitational acceleration, thermal expansion coefficient, thermal diffusivity and kinematic viscosity, respectively.

As described earlier, the wall temperature is calculated by solving the second order parabolic partial differential equation given in equation (3.61). Solving this equation requires two boundary conditions and an initial condition. Two boundary conditions can be attained by neglecting the heat losses from the front and rear faces of the monolith.

$$
\begin{gathered}
\frac{\partial T_{w}}{\partial z}(0, t)=0 \\
\frac{\partial T_{w}}{\partial z}(L, t)=0
\end{gathered}
$$

Initial wall temperature of the substrate, $T_{b}$, can be assumed constant throughout the channel length, and equal to the engine out exhaust gas temperature when $t=0$.

$$
T_{w}(z, 0)=T_{b}
$$

\subsubsection{Mass, Momentum and Energy Balance}

This sub-section calculates the inlet and outlet channel temperatures and velocities over channel length using conservation of momentum, mass and energy equations.

The exhaust gas mass balance states that, the change of the exhaust mass velocity is equal to the exhaust mass velocity leaving the input channel via the porous wall. The mass 
velocity in the inlet channel and the outlet channels are denoted by equations (3.75) and (3.76), respectively.

$$
\begin{gathered}
\frac{\partial\left(\rho_{1} v_{1}\right)}{\partial z}=-\frac{4}{D} \rho_{w} v_{w} \\
\frac{\partial\left(\rho_{2} v_{2}\right)}{\partial z}=\frac{4}{D} \rho_{w} v_{w}
\end{gathered}
$$

Considering the nature of the plug flow reactor following boundary conditions can be imposed for inlet/outlet channels.

$$
\begin{gathered}
\rho_{1}(0, t) v_{1}(0, t)=\rho_{\text {eng }}(0, t) v_{\text {eng }}(0, t) \\
\rho_{2}(0, t) v_{2}(0, t)=0 \\
\rho_{1}(L, t) v_{1}(L, t)=0
\end{gathered}
$$

The axial component momentum balance ( $z$-momentum) of the exhaust gas is derived using the Navier-Stokes equation considering incompressible flow of a Newtonian fluid. The viscous drag plays a vital role as the gas velocities become zero at the wall ends. The friction coefficient, $F$ has a constant value of 28.454; thus, assuming fully developed laminar flow for square cross sectional channel. The balance equation is the same for both channels.

$$
\begin{gathered}
\frac{\partial P_{1}}{\partial z}+\frac{\partial\left(\rho_{1} v_{1}^{2}\right)}{\partial z}=-\frac{F \mu\left(T_{1}\right) v_{1}}{D^{2}} \\
\frac{\partial P_{2}}{\partial z}+\frac{\partial\left(\rho_{2} v_{2}^{2}\right)}{\partial z}=-\frac{F \mu\left(T_{2}\right) v_{2}}{D^{2}}
\end{gathered}
$$

The inlet and outlet channel energy balance equations are obtained considering the convective heat transfer between exhaust gas and substrate wall. The enthalpy change due to the flow across the particulate layer and wall was also considered. Convective heat transfer of the channel dominates the conduction heat transfer hence the latter was neglected. 


$$
\begin{gathered}
c_{p g} \rho_{1} v_{1} \frac{\partial T_{1}}{\partial z}=\frac{4}{D}\left(h_{1}-c_{p g} \rho_{w} v_{w}\right)\left(T_{w}-T_{1}\right) \\
c_{p g} \rho_{2} v_{2} \frac{\partial T_{2}}{\partial z}=\frac{4}{D}\left(h_{2}+c_{p g} \rho_{w} v_{w}\right)\left(T_{w}-T_{2}\right)
\end{gathered}
$$

Inlet face of the DPF was considered to have the same temperature as the engine out temperature and the initial spatial node of the outlet channel was considered to be equal to the wall temperature [4].

$$
\begin{aligned}
& T_{1}(0, t)=T_{e n g}(0, t) \\
& T_{2}(0, t)=T_{w}(0, t)
\end{aligned}
$$

The calculation of the convective heat transfer coefficients $h_{i}$ were calculated by the relationship given by Bissett [4].

$$
h_{i}=\frac{N u}{D}\left(c_{p g}+a_{1}\right) \mu\left(T_{i}\right)
$$

The pressure difference can be described by Darcy's law. Darcy's law is a simple proportional relationship between the instantaneous discharge rate through an isotropic porous medium, viscosity of the fluid and pressure drop over a given distance. In this model, filter wall velocities are relatively low and the Forchheimer contribution to the pressure drop is considered to be negligible.

The overall pressure drop of a loaded catalyzed soot filter consists of several contributions: (1) inlet/outlet cone pressure losses; (2) contraction/expansion pressure losses; (3) inlet/outlet channel pressure losses and (4) wall and cake layer pressure losses. However, previous studies $[5,44]$ have shown that all pressure losses, other than wall and cake layer pressure losses are significant only at very high exhaust flow rates. Hence for the sake of generality, pressure losses due to wall and particulate deposition layer are accounted in this model.

$$
P_{1}-P_{2}=\frac{\mu\left(T_{w}\right) w v_{w}}{k_{p}}+\frac{\mu\left(T_{w}\right) w_{s} v_{w}}{k_{s}}
$$


Outlet face of the DPF is considered to be held at atmospheric pressure $P_{a t m}$.

$$
P_{2}(L, t)=P_{a t m}
$$




\section{Chapter 4}

\section{Numercal Procedure}

\subsection{Solving the Boundary Value Problem}

The model equations were numerically solved using finite difference methods adopting a spatially uniform mesh with a grid spacing of $0.4 \mathrm{~cm}$. The grid sensitivity was tested by checking whether the results remain the same when a finer grid resolution was employed and simulation time. Simulation time corresponding to a 200 second simulation with a given grid resolution is illustrated in Table 4.1. According to the table, seventy discretized parts, which was used in this model, gives the minimum simulation time. It is also worth noting that simulation time depends on the cycle duration as the computer exhausts computational resources to store calculated variables inside the program.

Table 4.1: Grid resolution comparison

\begin{tabular}{lc}
\hline \hline Discretized Parts & Simulation Time (sec) \\
\hline 10 & Convergance Issue \\
25 & 168.9 \\
50 & 63.6 \\
70 & 44.7 \\
100 & 79.1 \\
125 & 71.4 \\
150 & 86.3 \\
175 & 120.6 \\
200 & 145.7 \\
\hline \hline
\end{tabular}


The channel flow field and the energy balance equations [Eq:(3.75)-(3.88)] consist of two point boundary value/initial value problems. All six of the non-linear, coupled ordinary differential equations were simultaneously solved using "bvp4c", an in built boundary layer problem solver in Matlab. This solver implements a fourth order accurate Lobatto IIIa formula. This routine requires the system of equations to be written as a system of first order ODEs. Hence the aforementioned equations were re-written in the following form.

$$
\begin{gathered}
\frac{\partial G_{1}}{\partial z}=-\frac{4}{a} G_{w} \\
\frac{\partial G_{2}}{\partial z}=\frac{4}{a} G_{w} \\
\frac{\partial T_{1}}{\partial z}=\frac{4}{a} \frac{\left(h_{1}-c_{p g} G_{w}\right)\left(T_{w}-T_{1}\right)}{c_{p g} \rho_{1} v_{1}} \\
\frac{\partial T_{2}}{\partial z}=\frac{4}{a} \frac{\left(h_{1}+c_{p g} G_{w}\right)\left(T_{w}-T_{2}\right)}{c_{p g} \rho_{2} v_{2}} \\
\frac{\partial P_{1}}{\partial z}=-\frac{\partial\left(G_{1}^{2} / \rho_{1}\right)}{\partial z}-\frac{F \mu\left(T_{1}\right) v_{1}}{a^{2}} \\
\frac{\partial P_{2}}{\partial z}=-\frac{\partial\left(G_{2}^{2} / \rho_{2}\right)}{\partial z}-\frac{F \mu\left(T_{2}\right) v_{2}}{a^{2}}
\end{gathered}
$$

where

$$
\begin{gathered}
G_{w}=\frac{4}{a} \frac{\left(P_{1}-P_{2}\right)}{\left(\frac{\mu\left(T_{w}\right) w}{k_{p} \rho_{w}}+\frac{\mu\left(T_{w}\right) w_{s}}{k_{s} \rho_{s}}\right)} \\
G_{i}=\rho_{i} v_{i} \\
P_{i}=\rho R T_{i}
\end{gathered}
$$


Even though "bvp4c" is an excellent routine to solve boundary value problems, the quality of the solution heavily depends on the initial guess. A bad guess would result in inaccurate solution, no solution or a solution which makes no sense. In this model, the values obtained in the previous time step were considered as the initial guess values for the current time step. This is a widely used technique to solve boundary value problems of this nature. The relative error of the scheme was controlled to a tolerance of $10^{-3}$.

\subsection{Solving the Initial Value Problem}

A fourth order accurate Runge-Kutta method was employed to estimate the amount of particulate oxidation inside the CCRT. The governing equations and the boundary conditions related to the soot oxidation process was discussed in detail in the previous chapter. Classical method of fourth order Runge-Kutta method is given by

$$
y_{n+1}=y_{n}+h\left(\frac{k_{1}}{6}+\frac{k_{2}}{3}+\frac{k_{3}}{3}+\frac{k_{4}}{6}\right)
$$

where

$$
\begin{aligned}
k_{1} & =f\left(t_{n}, y_{n}\right) \\
k_{2} & =f\left(t_{n}+\frac{h}{2}, y_{n}+\frac{h}{2} k_{1}\right) \\
k_{3} & =f\left(t_{n}+\frac{h}{2}, y_{n}+\frac{h}{2} k_{2}\right) \\
k_{4} & =f\left(t_{n}+h, y_{n}+h k_{3}\right)
\end{aligned}
$$

The $k_{1}, k_{2}, k_{3}$ and $k_{4}$ are known as the stages of the Runge-Kutta method. These parameters correspond to different estimates for the slope of the solution. For instance, in the case of washcoat regeneration, these parameters are given by following formulae. 


$$
\begin{aligned}
& k_{1}=-\frac{d t}{\rho_{\text {soot,cake }}}\left[\alpha_{1}^{i}\left(1-e^{\alpha_{2}^{i} w_{1}}\right)+\alpha_{3}^{i}\left(1-e^{\alpha_{2}^{i} w_{1}}\right)+\alpha_{4}^{i}\left(1-e^{\alpha_{5}^{i} w_{1}}\right)\right] \\
& k_{2}=-\frac{d t}{\rho_{\text {soot,cake }}}\left[\alpha_{1}^{i}\left(1-e^{\alpha_{2}^{i}\left(w_{1}+0.5 k_{1}\right)}\right)+\alpha_{3}^{i}\left(1-e^{\alpha_{2}^{i}\left(w_{1}+0.5 k_{1}\right)}\right)+\alpha_{4}^{i}\left(1-e^{\alpha_{5}^{i}\left(w_{1}+0.5 k_{1}\right)}\right)\right] \\
& k_{3}=-\frac{d t}{\rho_{\text {soot,cake }}}\left[\alpha_{1}^{i}\left(1-e^{\alpha_{2}^{i}\left(w_{1}+0.5 k_{2}\right)}\right)+\alpha_{3}^{i}\left(1-e^{\alpha_{2}^{i}\left(w_{1}+0.5 k_{2}\right)}\right)+\alpha_{4}^{i}\left(1-e^{\alpha_{5}^{i}\left(w_{1}+0.5 k_{2}\right)}\right)\right] \\
& k_{4}=-\frac{d t}{\rho_{\text {soot }, \text { cake }}}\left[\alpha_{1}^{i}\left(1-e^{\alpha_{2}^{i}\left(w_{1}+k_{3}\right)}\right)+\alpha_{3}^{i}\left(1-e^{\alpha_{2}^{i}\left(w_{1}+k_{3}\right)}\right)+\alpha_{4}^{i}\left(1-e^{\alpha_{5}^{i}\left(w_{1}+k_{3}\right)}\right)\right]
\end{aligned}
$$

where

$$
\begin{array}{ll}
\alpha_{1}^{i}=\left(\frac{M_{c}}{M_{O_{2}}}\right) \frac{k^{t h}(i)(1-\beta) \rho_{w}(i) v_{w}(i) y^{i}}{k^{*}(i)} & \alpha_{2}^{i}=-\frac{S_{p} k^{*}(i)}{v_{w}} \\
\alpha_{3}^{i}=\left(\frac{M_{c}}{M_{O_{2}}}\right) \frac{k^{c a t}(i) \beta \rho_{w}(i) v_{w}(i) y^{i}}{k^{*}(i)} & \alpha_{4}^{i}=\left(\frac{M_{c}}{M_{N O_{2}}}\right) \frac{\rho_{w}(i) v_{w}(i) y_{N O_{2}}^{i}}{2-g_{C O}(i)} \\
\alpha_{5}^{i}=-\frac{S_{p} k_{N O_{2}}(i)\left(2-g_{C O}(i)\right)}{v_{w}(i)} &
\end{array}
$$

The filter wall energy balance was solved using a second order accurate Crank-Nicolson scheme. The implemented formulation replaces all existing derivatives by a central difference approximation, where the values of the old and new time steps are employed. Discretized transformation of the Eq:(3.61) can be given as follows.

$$
A_{1_{i}} T_{w_{i-1}}^{j+1}+A_{2_{i}} T_{w_{i}}^{j+1}+A_{3_{i}} T_{w_{i+1}}^{j+1}=B_{1_{i}} T_{w_{i-1}}^{j}+B_{2_{i}} T_{w_{i}}^{j}+B_{3_{i}} T_{w_{i+1}}^{j}+B_{4_{i}}
$$

where 


$$
\begin{gathered}
A_{1_{i}}=-\frac{\left(\lambda_{p} w_{i}^{j}+\lambda_{s} w_{s}\right) \beta}{h^{2}}+\lambda_{p}\left[\left(\frac{w_{i+1}^{j+1}-w_{i-1}^{j+1}}{2 h}\right) \beta+\left(\frac{w_{i+1}^{j}-w_{i-1}^{j}}{2 h}\right)(1-\beta)\right]\left(\frac{\beta}{2 h}\right) \\
A_{2_{i}}=\left(\frac{\rho_{p} c_{p p} w_{i}^{j}+\rho_{p} c_{p s} w_{s}}{\Delta t}\right)+2\left(\lambda_{p} w_{i}^{j}+\lambda_{s} w_{s}\right)\left(\frac{\beta}{h^{2}}\right)+\left[\rho_{p} c_{p p}\left(\frac{w_{i}^{j+1}-w_{i}^{j}}{\Delta t}\right)+h_{1_{i}}^{j}+h_{2_{i}}^{j}\right] \beta \\
A_{3_{i}}=-\frac{\left(\lambda_{p} w_{i}^{j}+\lambda_{s} w_{s}\right) \beta}{h^{2}}-\lambda_{p}\left[\left(\frac{w_{i+1}^{j+1}-w_{i-1}^{j+1}}{2 h}\right) \beta+\left(\frac{w_{i+1}^{j}-w_{i-1}^{j}}{2 h}\right)(1-\beta)\right]\left(\frac{\beta}{2 h}\right) \\
B_{1_{i}}=\frac{\left(\lambda_{p} w_{i}^{j}+\lambda_{s} w_{s}\right)(1-\beta)}{h^{2}}+\lambda_{p}\left[\left(\frac{w_{i+1}^{j+1}-w_{i-1}^{j+1}}{2 h}\right) \beta+\left(\frac{w_{i+1}^{j}-w_{i-1}^{j}}{2 h}\right)(1-\beta)\right]\left(\frac{1-\beta}{2 h}\right) \\
B_{2_{i}}=\left(\frac{\rho_{p} c_{p p} w_{i}^{j}+\rho_{p} c_{p s} w_{s}}{\Delta t}\right)-2\left(\lambda_{p} w_{i}^{j}+\lambda_{s} w_{s}\right)\left(\frac{1-\beta}{h^{2}}\right)-\left[\rho_{p} c_{p p}\left(\frac{w_{i}^{j+1}-w_{i}^{j}}{\Delta t}\right)+h_{1_{i}}^{j}++h_{2_{i}}^{j}\right](1-\beta) \\
B_{3_{i}}=\frac{\left(\lambda_{p} w_{i}^{j}+\lambda_{s} w_{s}\right) \beta}{h^{2}}-\lambda_{p}\left[\left(\frac{w_{i+1}^{j+1}-w_{i-1}^{j+1}}{2 h}\right) \beta+\left(\frac{w_{i+1}^{j}-w_{i-1}^{j}}{2 h}\right)(1-\beta)\right]\left(\frac{1-\beta}{2 h}\right) \\
B_{4_{i}}=\left(h_{1_{i}}^{j+1} T_{1_{i}}^{j+1}+h_{2_{i}}^{j+1} T_{2_{i}}^{j+1}+H_{\text {react }}^{j+1}\right) \beta+\left(h_{1_{i}}^{j} T_{1_{i}}^{j}+h_{2_{i}}^{j} T_{2_{i}}^{j}+H_{\text {react }}^{j}\right)(1-\beta)
\end{gathered}
$$

Assuming the DPF was dicretized into " $M$ " number of nodes, the above scheme can be conveniently transformed in to a linear system with " $M$-2" or " $k$ " number of equations as follows.

$$
\left[\begin{array}{ccccc}
A_{1_{2}}+A_{2_{2}} & A_{3_{3}} & & & 0 \\
A_{1_{3}} & A_{2_{3}} & A_{3_{3}} & & \\
& A_{1_{4}} & A_{2_{4}} & \ddots & \\
& & \ddots & \ddots & A_{3_{k-1}} \\
0 & & & A_{1_{k}} & A_{2_{k}}+A_{3_{k}}
\end{array}\right]\left[\begin{array}{c}
T_{w_{2}}^{j+1} \\
T_{w_{3}}^{j+1} \\
T_{w_{4}}^{j+1} \\
\vdots \\
T_{w_{k}}^{j+1}
\end{array}\right]=\left[\begin{array}{c}
\left(B_{1_{2}}+B_{2_{2}}\right) T_{w_{2}}^{j}+B_{3_{2}} T_{w_{3}}^{j}+B_{4_{2}}^{j} \\
B_{1_{3}} T_{w_{2}}^{j}+B_{2_{3}} T_{w_{3}}^{j}+B_{3_{3}} T_{w_{4}}^{j}+B_{4_{3}}^{j} \\
\vdots \\
\vdots \\
B_{1_{k}} T_{w_{k}}^{j}+\left(B_{2_{k}}+B_{3_{k}}\right) T_{w_{k}}^{j}+B_{4_{k}}^{j}
\end{array}\right]
$$

The resulting sparse matrix was then solved using Gaussian elimination method. First a set of row operations, called the forward sweep, uses each diagonal element as a pivot to eliminate the elements of the matrix below the diagonal. Next, backward substitution was used to obtain the solution vector starting from $T_{w_{k}}^{j}$ to $T_{w_{2}}^{j}$. Wall temperature related to inlet and outlet nodes were calculated using the assumed boundary conditions at each time step. 
A time step of 0.1 seconds was employed for the time integration. During the FTP cycle, experimental data was collected at $10 \mathrm{~Hz}$ data rate. Hence the same temporal time step was selected when evaluating the simulated results even though the model is able perform calculations with much lower temporal time steps. Moreover, the reduction of temporal time step lead to an increase in simulation time. The current model took 40 minutes to simulate a typical FTP cycle under the specified grid resolution on a Pentium $43.3 \mathrm{GHz}$ machine. 


\section{Chapter 5}

\section{Experimental Setup and Procedures}

\subsection{Instrumentation and Laboratory Setup}

The experimental data $[39,40]$ that was used to validate the developed DPF model was collected at the Engine and Emissions Research Laboratory (EERL) at West Virginia University. Details of the experimental equipment and procedures are described in published papers Mulone et al. [39] and Cozzolini et al. [40]. A very brief description [39, 40] of the engine and exhaust aftertreatment system is given below.

A model year 2004 Mack MP7-355E heavy-duty diesel engine equipped with a highpressure loop exhaust gas recirculation system (EGR) and an exhaust aftertreatment system consisting a diesel oxidation catalyst upstream of a Johnson-Matthey catalyzed diesel particulate filter (CCRT) were the primary components used in this study. Detailed engine information and geometrical dimensions of the DOC/DPF is provided in Table 5.1 and Table 5.2 , respectively.

The testing procedure was based on the 40 CFR Part 1065 protocol. All diluted gaseous sampling downstream the whole aftertreatment system were analyzed using the Horiba MEXA 7200D system. Particulate matter characterization downstream the aftertreatment system was quantified using the gravimetric method as outlined in 40 CFR Part 1065. Filters were weighed in an environmentally controlled clean room (Class 1000) using a Sartorius 
Table 5.1: Test engine manufacturer specifications

\begin{tabular}{ll}
\hline \hline Model & \multicolumn{1}{c}{ MACK MP7-355E } \\
\hline Configuration & 6 Cylinders, Inline \\
Aspiration & Sliding Nozzle Variable Turbocharger/Intercooler \\
Injection system & Dual Solenoid Electronic Unit Injector (EUI) \\
Maximum Torque & $1844 \mathrm{Nm}(1360 \mathrm{ft}-1 \mathrm{bs}) @ 1200 \mathrm{RPM}$ \\
Maximum Power & $265 \mathrm{~kW}(355 \mathrm{bhp}) @ 1800 \mathrm{RPM}$ \\
Displacement, L (cu-in) & $11(659)$ \\
Compression Ratio & $16.0: 1$ \\
Bore and Stroke, mm (in) & $122.94 \times 151.89(4.84 \times 5.98)$ \\
\hline \hline
\end{tabular}

Table 5.2: Geometrical dimensions of the DOC/DPF

\begin{tabular}{lcc}
\hline \hline Parameter & DOC & DPF \\
\hline Diameter (in) & 12 & 12 \\
Length (in) & 5 & 12 \\
Cell Density (cpsi) & 400 & 100 \\
Wall Thickness (mil) & 4 & 12 \\
Clean Wall Porosity & - & 0.5 \\
\hline \hline
\end{tabular}

microbalance with an accuracy of $0.1 \mu \mathrm{g}$. The engine was connected to a General Electric motoring/absorbing dynamometer capable of $700 \mathrm{hp}$ for engine speed and load control to perform steady state and transient test cycles.

Raw emissions were measured in addition to the diluted sampling. A Validyne P55D differential pressure sensor was used to measure the differential pressure across the DPF, which is critical for determining the soot loading quantity. A scale was placed directly under the DPF-DOC system during the test. This allowed for quick determination of the soot weight after detaching exhaust pipes and removing thermocouple/pressure transducer harnessing following each test. The scale used for measuring the weight was an Ohaus CD-11 which presented a resolution of 0.5 grams while weighing the DOC/DPF system. Raw PM mass concentration entering the DOC/DPF assembly was measured by using an AVL 483 micro soot sensor thus providing the model with an accurate estimation of carbonaceous soot mass entering the filter. 
Table 5.3: Test point data

\begin{tabular}{lcc}
\hline \hline Test Mode & R 10 (Soot Loading) & R 100 (Regeneration) \\
\hline Duration [h] & 30 & 1.5 \\
Engine Load [ft-lbf] & 105 & 1018 \\
Engine Speed [rpm] & 1800 & 1800 \\
Fuel Flow Rate $[\mathrm{kg} / \mathrm{hr}]$ & 11.64 & 56.11 \\
CCRT Inlet Temp. $\left[{ }^{\circ} \mathrm{C}\right]$ & 226.5 & 483.8 \\
Intake Air Flow $[\mathrm{scfm}]$ & 256.4 & 588.1 \\
\hline \hline
\end{tabular}

\subsection{Experimental Procedure}

The testing phase consisted of a 13 mode European Stationary Cycle (ESC) followed by two FTP cycles and a regeneration cycle. The engine operated for 30 hours in the R10 mode with intermittent periods of 15 minutes every 4 hour testing to perform DPF weighing and engine refueling. Specifics of the test points is given in Table 5.3.

The engine was then operated on two FTP cycles to collect data in need to validate the model under transient operation. FTP cycle was selected as a transient cycle mainly because of the exhaust temperature observed during operation. In fact, as shown later in this work, the cycle can be divided in two main parts depending on the average exhaust temperature. In particular the first 10 minutes of the cycle correspond to an average temperature of $150^{\circ} \mathrm{C}$ while the last part of the test is characterized by high exhaust temperatures on the order of $400^{\circ} \mathrm{C}$. Hence it may be concluded that $\mathrm{NO}_{2}$ soot oxidation play a key role in the initial part of the FTP cycle while the oxidation due to $\mathrm{O}_{2}$ is likely the most significant contributor to filter regeneration rate during high temperature operation [45], thus giving an opportunity to test the calibration of modeled soot oxidation on a wide range of operating points. Engine speed and torque characteristics of the evaluated FTP cycle is illustrated in Figure 5.1 along with exhaust flow rate, PM concentration, exhaust gas species concentrations $\left(\mathrm{NO}_{x} / \mathrm{O}_{2}\right)$ and CPF inlet temperature. Table 5.6 provides the averaged engine out brake specific emissions over the two FTP cycles [40]. 

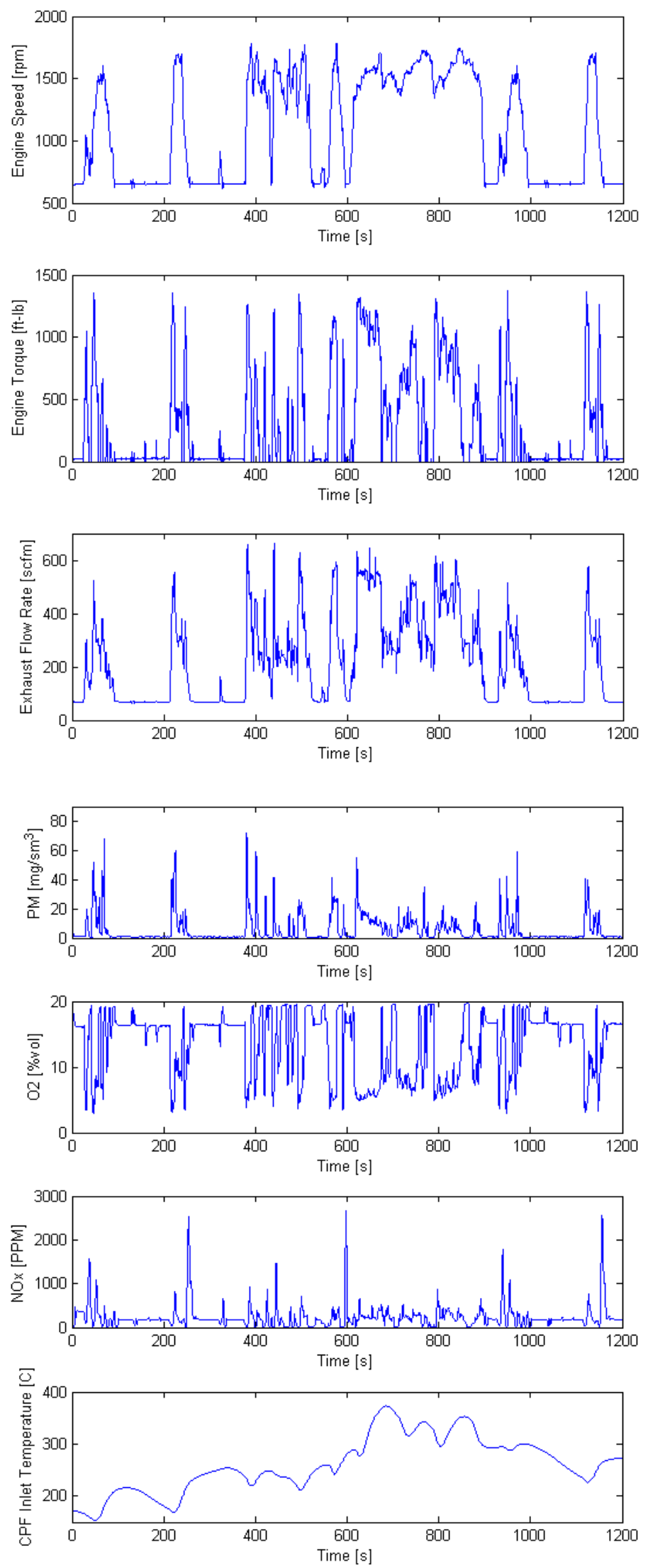

Figure 5.1: FTP reference data, exhaust flow rate, exhaust gas specie concentrations and CPF inlet temperature [40] 
Table 5.4: Exhaust gas emissions before DOC and after DPF for soot loading mode, 1800 rpm, $10 \%$ load [40]

\begin{tabular}{lcc}
\hline \hline $\mathrm{R} 10$ Mode & Pre-DOC & Post-DPF \\
\hline $\mathrm{HC}[\mathrm{ppm}]$ & 118.4 & 2.7 \\
$\mathrm{CO}[\mathrm{ppm}]$ & 197 & 2.5 \\
$\mathrm{NO}[\mathrm{ppm}]$ & 123.9 & 52.5 \\
$\mathrm{NO}_{2}[\mathrm{ppm}]$ & 40.0 & 107.4 \\
$\mathrm{NO}_{x}[\mathrm{ppm}]$ & 163.9 & 159.9 \\
$\mathrm{NO} / \mathrm{NO}_{2}$ Ratio & 3.09 & 0.49 \\
$\mathrm{PM}\left[\mathrm{mg} / \mathrm{Sm}^{3}\right]$ & 2 & - \\
\hline \hline
\end{tabular}

Table 5.5: Exhaust gas emissions before DOC and after DPF for soot regeneration mode, $1800 \mathrm{rpm}, 100 \%$ load [40]

\begin{tabular}{lcc}
\hline \hline R10 Mode & Pre-DOC & Post-DPF \\
\hline $\mathrm{HC}[\mathrm{ppm}]$ & 37.7 & 0 \\
$\mathrm{CO}[\mathrm{ppm}]$ & $\mathrm{N} / \mathrm{A}$ & 0 \\
$\mathrm{NO}[\mathrm{ppm}]$ & 361.4 & 335.0 \\
$\mathrm{NO}_{2}[\mathrm{ppm}]$ & 116.8 & 96.6 \\
$\mathrm{NO}_{x}[\mathrm{ppm}]$ & 478.2 & 431.6 \\
$\mathrm{NO} / \mathrm{NO}_{2}$ Ratio & 3.09 & 3.47 \\
$\mathrm{PM}\left[\mathrm{mg} / \mathrm{Sm}^{3}\right]$ & 13 & - \\
\hline \hline
\end{tabular}

Table 5.6: The average engine out brake specific emissions during two FTP cycles

\begin{tabular}{lc}
\hline \hline Particle/Gaseous Specie & Brake Specific Emissions \\
\hline $\mathrm{HC}$ [g/bhp-hr] & 0.098 \\
$\mathrm{CO}$ [g/bhp-hr] & 1.332 \\
$\mathrm{NO}$ [g/bhp-hr] & 2.33 \\
$\mathrm{NO}_{2}$ [g/bhp-hr] & 0.06 \\
$\mathrm{NO}_{x}$ [g/bhp-hr] & 2.39 \\
$\mathrm{PM}$ [g/bhp-hr] & 0.0648 \\
\hline \hline
\end{tabular}




\section{Chapter 6}

\section{Results and Discussion}

The experimental results reflected in this study were obtained with an aged CPF; hence, the author did not have access to some key initial DPF parameters such as wall permeability and existing soot layer thickness along the channel before running the first test cycle. Thus, the previously validated 1-D model [40] was used to determine these parameters using a process called virtual conditioning.

Virtual conditioning procedure creates a loading condition representative of the given physical state of the filter using a random sequence of loading and regeneration events [14]. Assuming the properties of a clean DPF, the conditioning procedure starts with a certain selected tuning parameters and applies a random sequence of loading cycles until it reaches the pressure drop value of the first experimental cycle. Then, the model is virtually exposed to the same physical conditions that existed during the experimental phase. If the conditioned filter is capable of mimicking the results of first loading cycle, then the simulation is moved to the next loading cycle. If the discrepancy of the pressure drop results between the simulated and the experimental values are out of $\pm 0.1 \mathrm{kPa}$, the tuning parameters are adjusted and the validation procedure is started again from the beginning.

The decision of using the 1-D model to provide the loading cycle under investigation was based mainly on required computational timings. As described in Chapter 4, the simulation time of the current model is approximately twice that of the actual cycle duration. The 
Table 6.1: Model tuning parameters and constants

\begin{tabular}{lccc}
\hline \hline Symbol & Description & Value & Units \\
\hline$E_{t h, \mathrm{O}_{2}} / R$ & $\mathrm{O}_{2}$ Thermal Activation Temperature & $1.55 \mathrm{E}+4$ & $\mathrm{~K}$ \\
$E_{c a t, \mathrm{O}_{2}} / R$ & $\mathrm{O}_{2}$ Catalytic Activation Temperature & $1.42 \mathrm{E}+4$ & $\mathrm{~K}$ \\
$E_{\mathrm{NO}_{2}} / R$ & $\mathrm{NO}_{2}$ Activation Temperature & $1.03 \mathrm{E}+4$ & $\mathrm{~K}$ \\
$A_{t h}$ & $\mathrm{O}_{2}$ Thermal Rate Constant & 25.08 & $\mathrm{~m} / \mathrm{sK}$ \\
$A_{\text {cat }}$ & $\mathrm{O}_{2}$ Catalytic Rate Constant & 2.84 & $\mathrm{~m} / \mathrm{sK}$ \\
$A_{N O_{2}}$ & $\mathrm{NO}_{2}$ Rate Constant & 2.9 & $\mathrm{~m} / \mathrm{sK}$ \\
$S_{p}$ & Soot Specific Area & $5.5 \mathrm{E}+7$ & $1 / \mathrm{m}$ \\
$\rho_{\text {soot }, w}$ & Wall Soot Packing Density & 6.8 & $\mathrm{~kg} / \mathrm{m}^{3}$ \\
$\rho_{\text {soot }, \text { cake }}$ & Cake Soot Packing Density & 35 & $\mathrm{~kg} / \mathrm{m}^{3}$ \\
$k_{0}$ & Soot Wall Clean Permeability & $3.4 \mathrm{E}-13$ & $\mathrm{~m}{ }^{2}$ \\
$k_{\text {soot }}$ & Cake Layer Permeability & $3.6 \mathrm{E}-14$ & $\mathrm{~m}^{2}$ \\
$\psi$ & Wall Filtration Filing Parameter & 0.83 & - \\
$w_{0}$ & Initial Deposit Thickness & $1.718 \mathrm{E}-5$ & $\mathrm{~m}$ \\
\hline \hline
\end{tabular}

numerical conditioning procedure requires application of numerous loading cycles each lasting 4 hours. The use of 1-D model could drastically reduce this computational burden as it could simulate the same cycle in approximately $1 / 5^{\text {th }}$ of the actual cycle duration. The reliability of the 1-D code was validated elsewhere $[39,40]$. Once the 1-D model produces satisfactory pressure drop values relevant to the first loading cycle, the 2-D model assigns those flow conditions, wall filtration characteristics and temperature profiles as its initial conditions, and runs the succeeding loading cycles.

The tuning parameters used in the current model are shown in Table 6.1. It is noteworthy that same tuning parameters used in the 1-D model are assumed to catch possible deviations between results. These parameters fall in the ranges specified in similar models available in the published literature [5],[29].

\subsection{Steady State Cycle Analysis}

The steady state particle loading experiments at different loading conditions were summarized in Table 5.3. The collected CPF data include engine exhaust volumetric flow rate, inlet and outlet temperatures, pressure drop, PM concentration, gaseous emission concentrations 
and inlet particle size distribution. The accumulated mass inside the DPF was measured by pre-weighing and post weighing the DPF after each cycle.

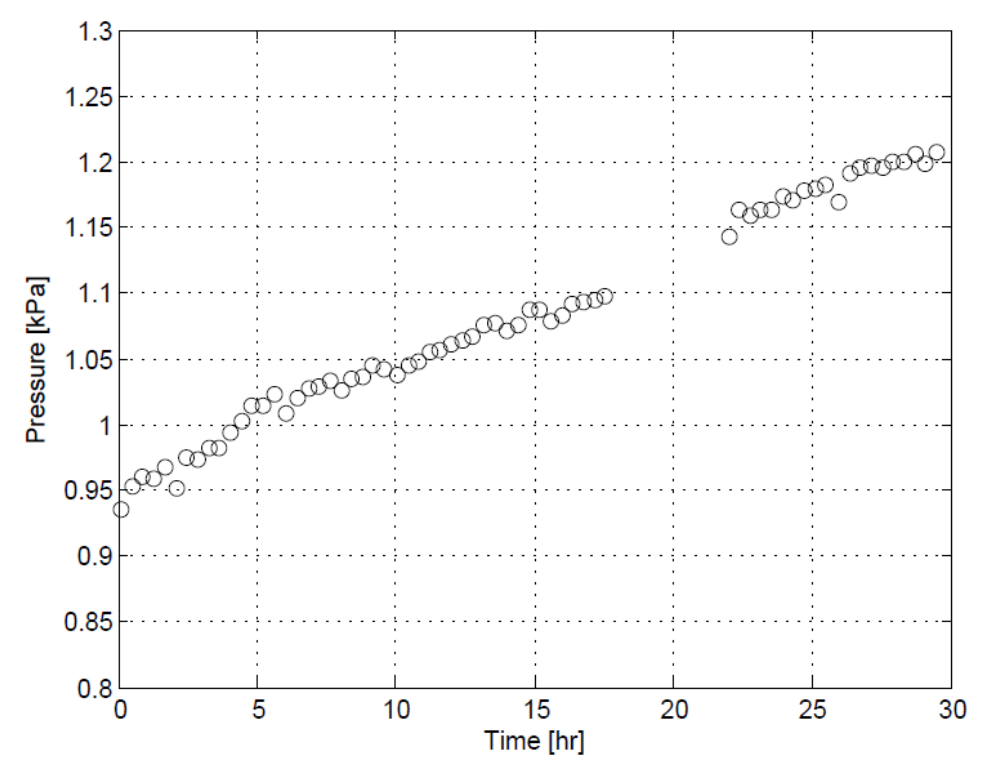

Figure 6.1: Experimental pressure drop of the DPF during the loading cycle

Pressure drop profile acquired during the loading phase is illustrated in Figure 6.1. Pressure drop data collected between 18-22 hours were not available for analysis due to an error in the data acquisition system. Typical pressure drop characteristics related to a clean DPF shows a more gradual and rounded profile during the initial phase of loading. The rounded profile results in initial deposition of soot particles which leads to a gradual increase in unit collector diameters inside the porous wall. Even a small amount of mass could lead to a sudden increase of pressure drop across the filter wall. However, this characteristic behavior is not present in Figure 6.1 due to the use of an aged filter. In the given scenario, pressure drop is determined mostly by the growth of the particulate layer thickness; thus linearly increase with time. 

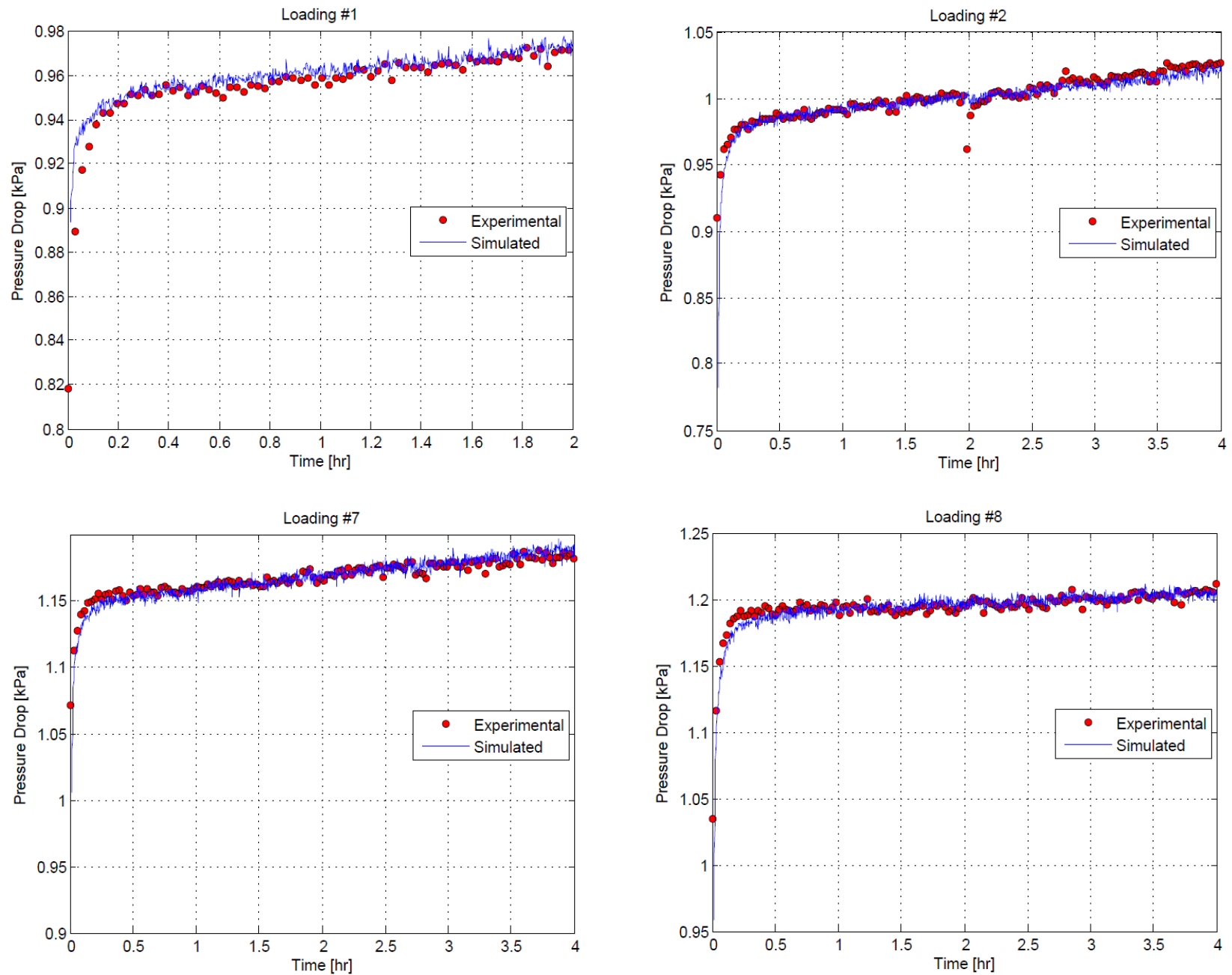

Figure 6.2: Experimental and simulated pressure drop profiles pertaining to four loading cycles

The model was tested at each of the aforementioned loading cycles using the initial conditions attained from the virtual conditioning phase. Satisfactory agreement of experimental and simulated pressure drop pertaining to four loading cycles (initial six hours and final eight hours) are shown in Figure 6.2. The maximum deviation between experimental and simulated results were less than $0.1 \mathrm{kPa}$.

During the loading phase, the filter wall temperature increases mainly due to convection heat transfer from exhaust gas stream. As time progresses, this increase leads to the filter wall reaching activation temperatures of catalytic and thermal regeneration, and effects a 
reduction in soot layer thickness. According to Darcy's law, soot layer thickness is directly proportional to filter pressure drop which leads to a decrease in the rate of pressure drop. This effect can be seen in Figure 6.2. The gradients of the pressure drop curve during the initial two cycles are considerably higher than that of the last two loading cycles. Furthermore, the non-linear behavior seen in the initial part of each loading cycle should not be misunderstood as deep bed filtration, but as an effect due to transient increment of filter temperature.

Figure 6.3 represents this transient temperature increment and testifies to the model capability in tracking exit temperature of the DPF. The maximum deviation between experimental and simulated temperature data was $\pm 3 \mathrm{~K}$. As shown in Figure 6.4, highest wall temperature values occur near the filter inlet face. It is impossible to attain a constant temperature profile along filter length other than in the initial time step due to environmental heat loss.

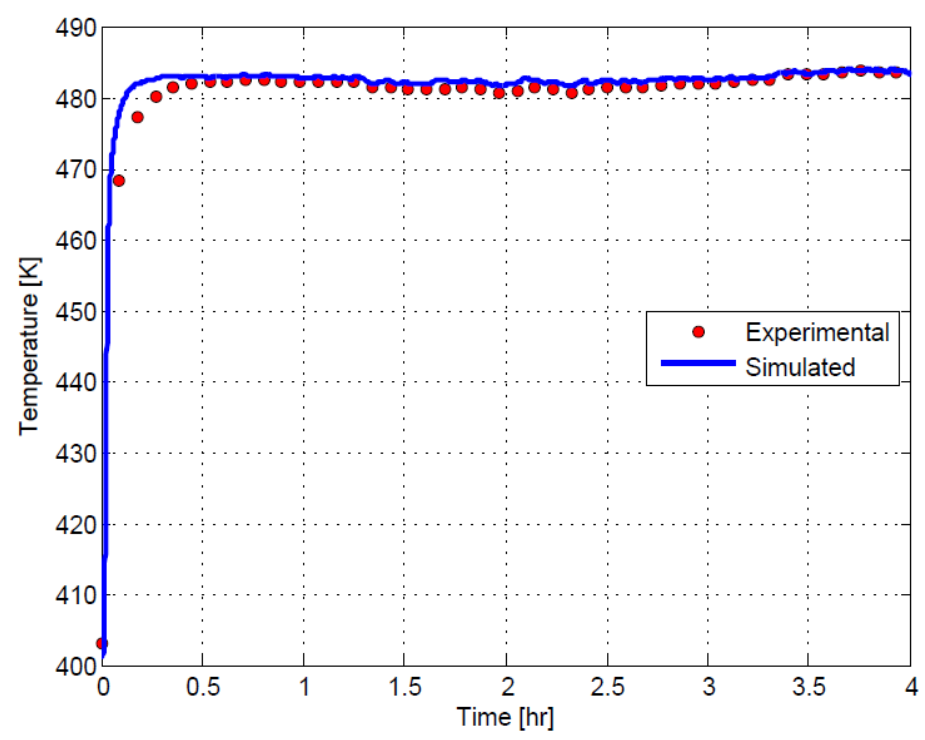

Figure 6.3: Experimental and simulated DPF outlet temperature of the $8^{\text {th }}$ loading cycle 


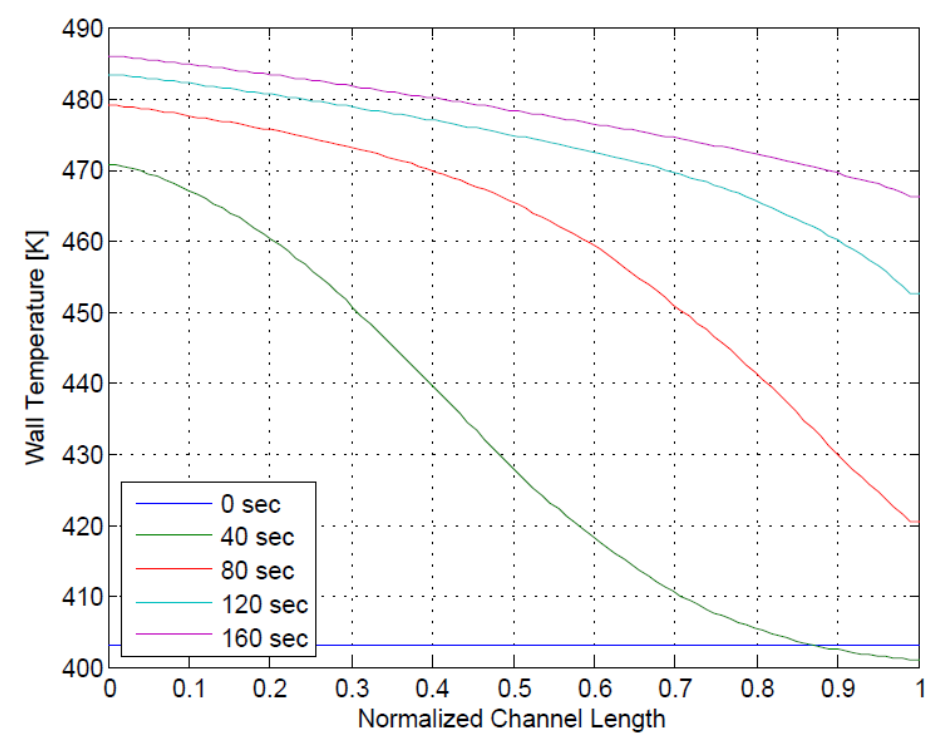

Figure 6.4: Experimental and simulated DPF outlet temperature of the $8^{\text {th }}$ loading cycle

Having validated performance over a range of loading cycles, the model was then used to predict missing filter pressure drop data during 18-22 hour time duration (6 $6^{\text {th }}$ loading cycle). Engine volumetric flow rate, engine out temperature, PM concentration and exhaust gas specie concentrations were assumed same as in the previous loading cycle. This is a valid assumption considering the steady state engine operation. Changing filter properties such as initial soot layer thickness and initial filter wall temperature were determined from the data acquired in the last time step of the previous loading cycle. The predicted pressure drop values from the model produced satisfactory results and is given by Figure 6.5. It is interesting to note that the initial pressure drop value of the $6^{\text {th }}$ loading cycle is in agreement with the final pressure drop value of the $5^{\text {th }}$ loading cycle and final pressure drop value of the $6^{\text {th }}$ loading cycle is in agreement with the initial pressure drop value of the $7^{\text {th }}$ loading cycle. Moreover, the gradient of the pressure drop curve is lower than that of the $5^{\text {th }}$ loading cycle which is in agreement with the effect of pressure drop on regeneration. 


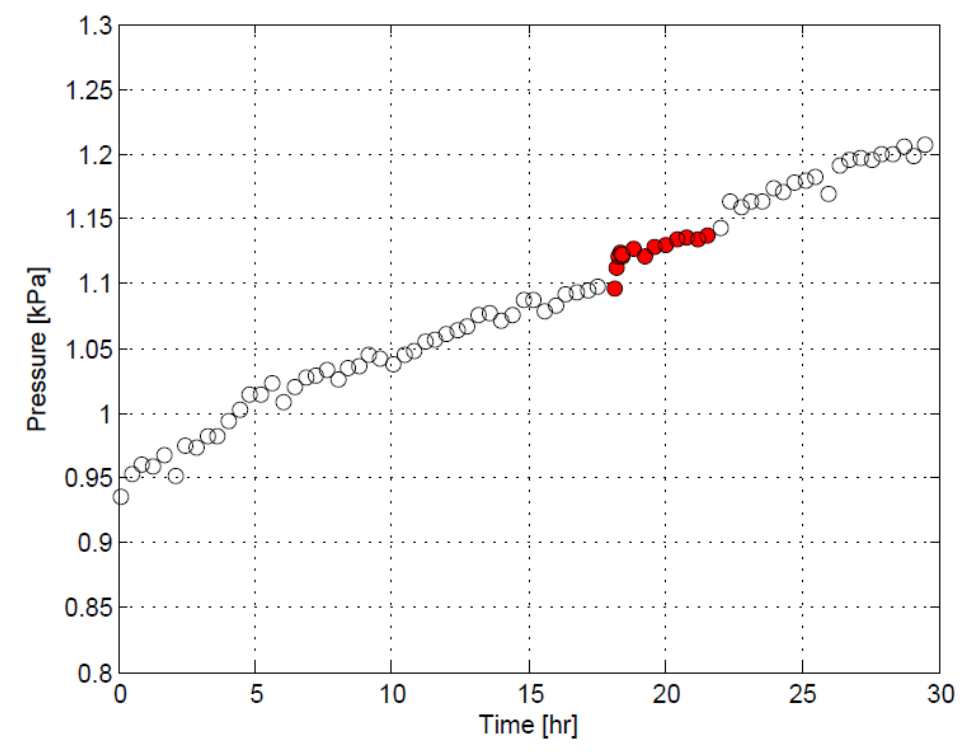

Figure 6.5: Model predicted filter pressure drop during 18-22 hour time duration during the loading phase

Figure 6.6 depicts the simulated evolution of the mean cake thickness on the filter wall surface over a four hour loading cycle. As seen in the figure, the soot layer thickness evolution is noteworthy at the two ends of the filter close to the inlet and the outlet of the channel. This is a consequence of the profiles of the filter wall velocity. Higher soot layer thicknesses at the ends of the filter provide higher resistance for exhaust gas to flow through the wall in comparison to mid-regions of the filter. Consequently, over time, an increase in wall flow velocity magnitude in the mid region can be observed as illustrated in Figure 6.7. This trend may transform the wall velocity to a more uniform profile after several hours of engine operation. 


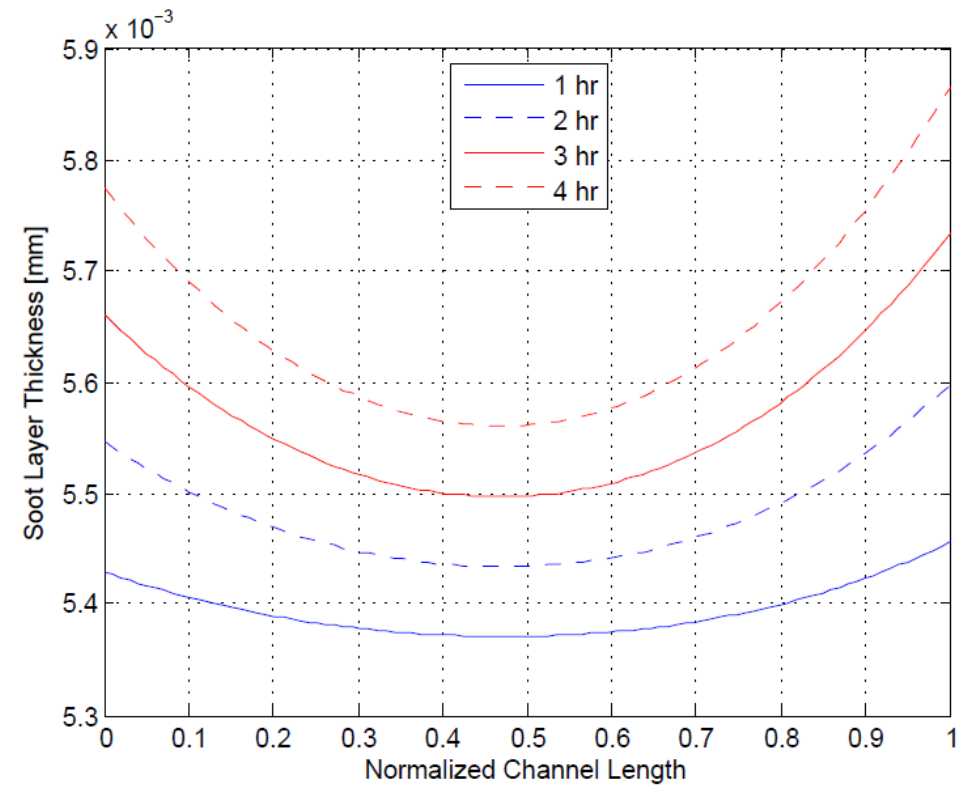

Figure 6.6: Soot layer thickness evolution with time along channel length during a loading cycle

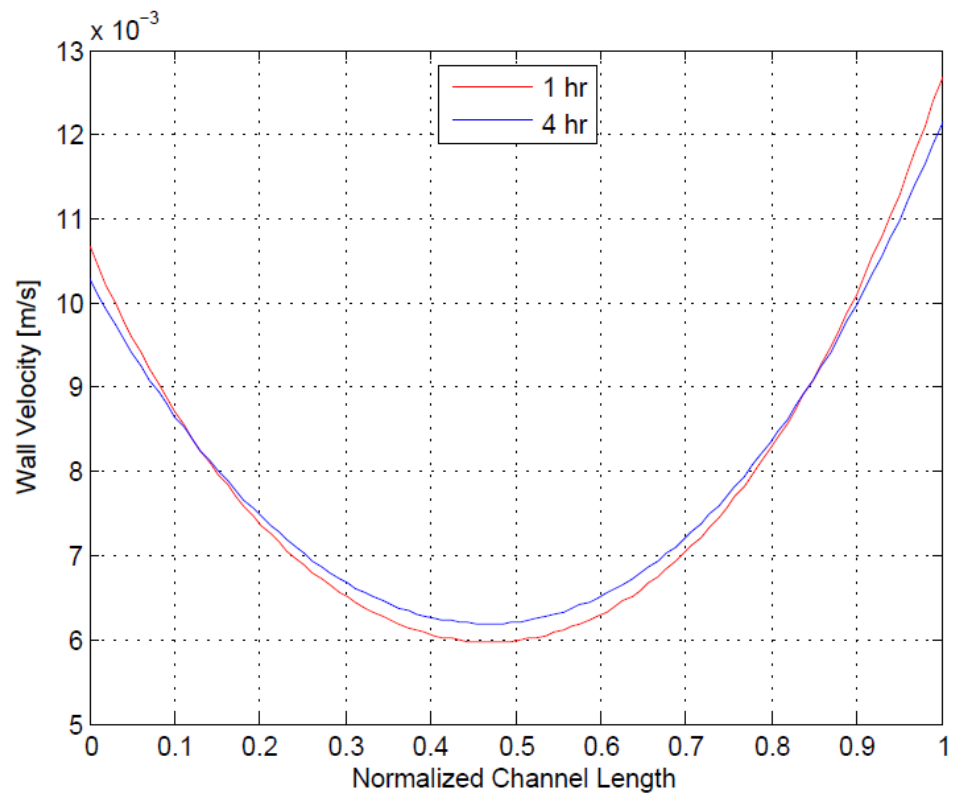

Figure 6.7: Soot layer thickness evolution with time along channel length during a loading cycle 
Figure 6.8 presents inlet and outlet channel velocity profiles during a loading cycle. The inlet channel velocity reaches maximum at the entrance of the channel and it is reduced to zero at the end plug. Similarly, the outlet channel velocity gradually increases, in sympathy with the inlet velocity, across the channel length as the exhaust gas flows through the wall. The shape of these profiles change from linear to an "S" shape as the filter gets filled with more soot since the gradient of those profiles are directly proportional to wall velocity.

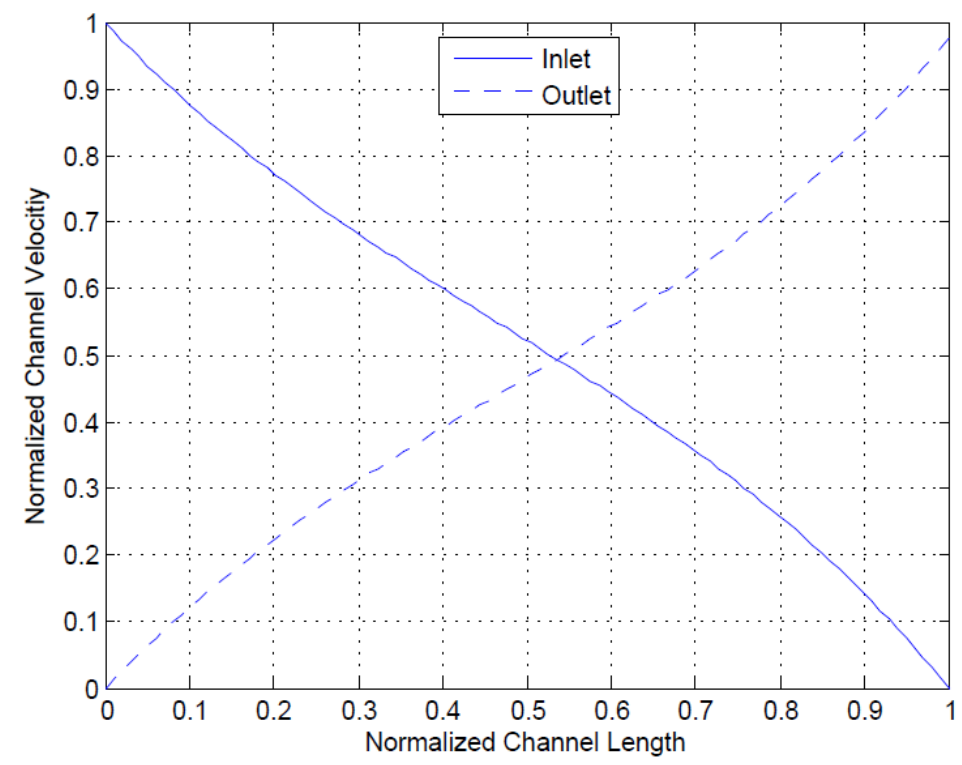

Figure 6.8: Soot layer thickness evolution with time along channel length during a loading cycle

The model predicted particulate mass evolution with time during the loading phase is illustrated in Figure 6.9. The figure shows satisfactory agreement between experimental and simulated results. The maximum deviation of the two results is $3.47 \mathrm{~g}$ which was shown during the last few loading cycles. Use of the zeroth dimensional (0D) filtration model could be one reason for this discrepancy. A 0D filtration model accounts for only one filtration efficiency considering the the whole thickness of the model. On the other hand a more advanced one dimensional (1-D) filtration model produces multiple filtration efficiencies as it divides the filter wall thickness into several slabs. This would lead the latter model to produce higher filtration efficiencies whilst retaining more mass in the filter wall than the 
0D model. However, as discussed in earlier chapters, such a model would require a strenuous computational effort. It is noteworthy to point out that even a 1-D filtration model could be subjected to an mass error tolerance of $\pm 2.83 \mathrm{~g}$ [40]. Moreover, low accuracy $( \pm 0.5 \mathrm{~g})$ of the scale used in this study could be another reason for the reported mass discrepancy.

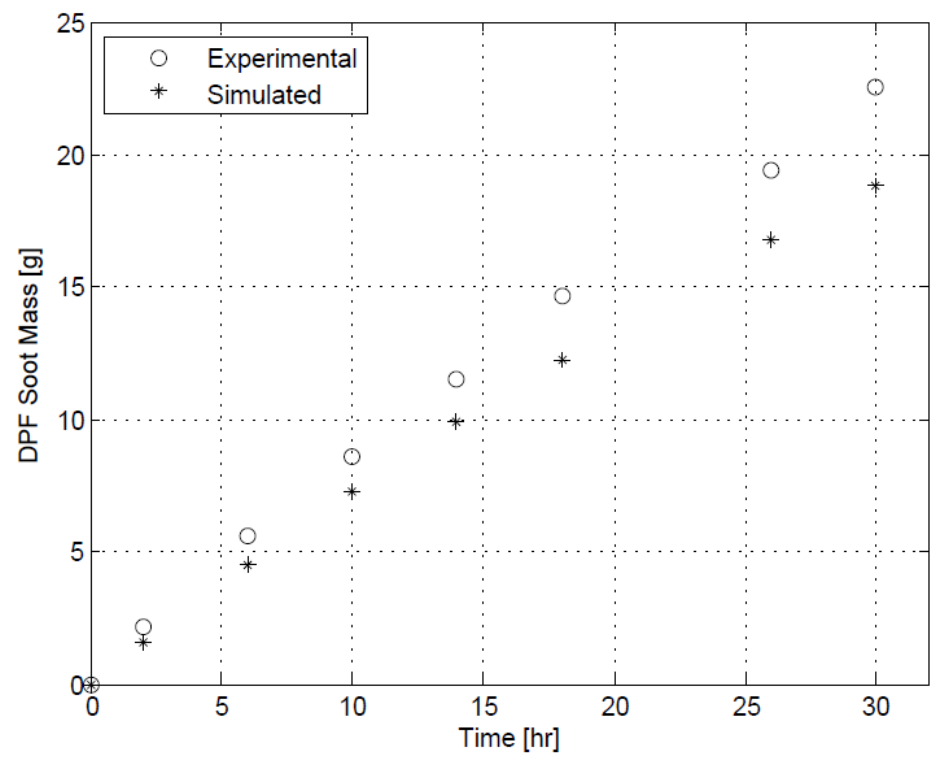

Figure 6.9: Experimental and simulated DPF soot mass comparison during the loading phase

\subsection{Transient Cycle Analysis}

Input variables related to the evaluated FTP cycles were given in Figure 5.1. The tuning parameters given in Table 6.1 were kept unchanged even during the transient cycles as the capabilities towards real time applications have to be demonstrated in this context.

Figure 6.10 shows a satisfactory agreement between the experimental and the simulated pressure drop of the DPF. The model is able to capture the pressure drop characteristics during heavily transient regimes with a high degree of detail. The accuracy of DPF pressure drop prediction by the 2-D model was further evaluated by plotting experimental pressure drop against simulated data (see Figure 6.11). The coefficient of determination corresponding to this graph was 0.9883 and is satisfactory considering the transient nature of the cycle. 


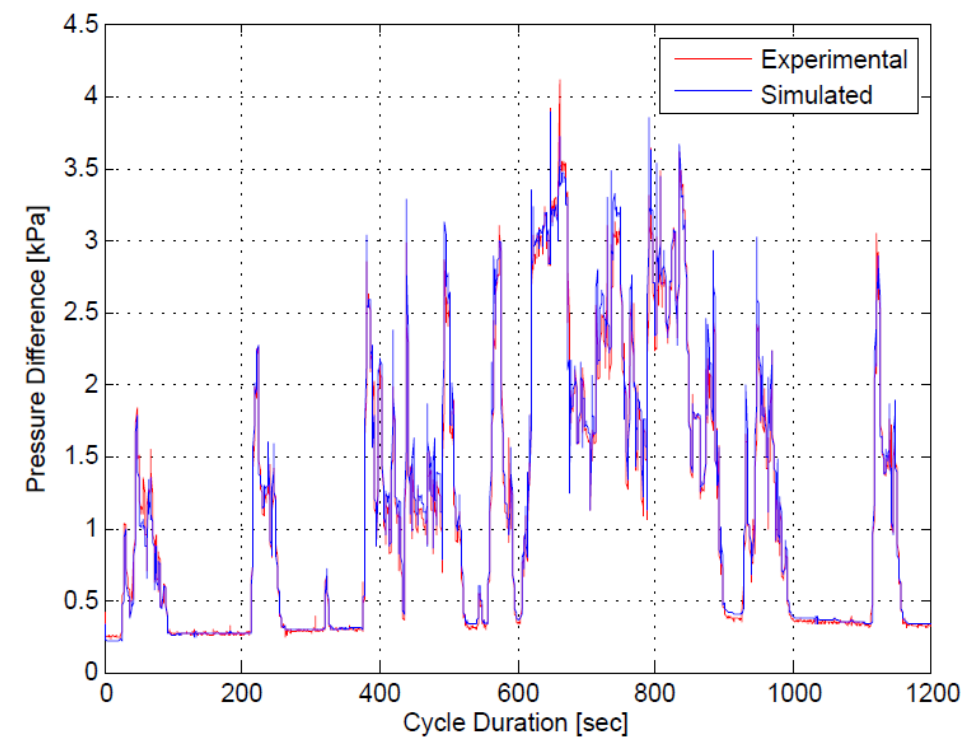

Figure 6.10: Pressure drop comparison between experimental and numerical data over an FTP cycle

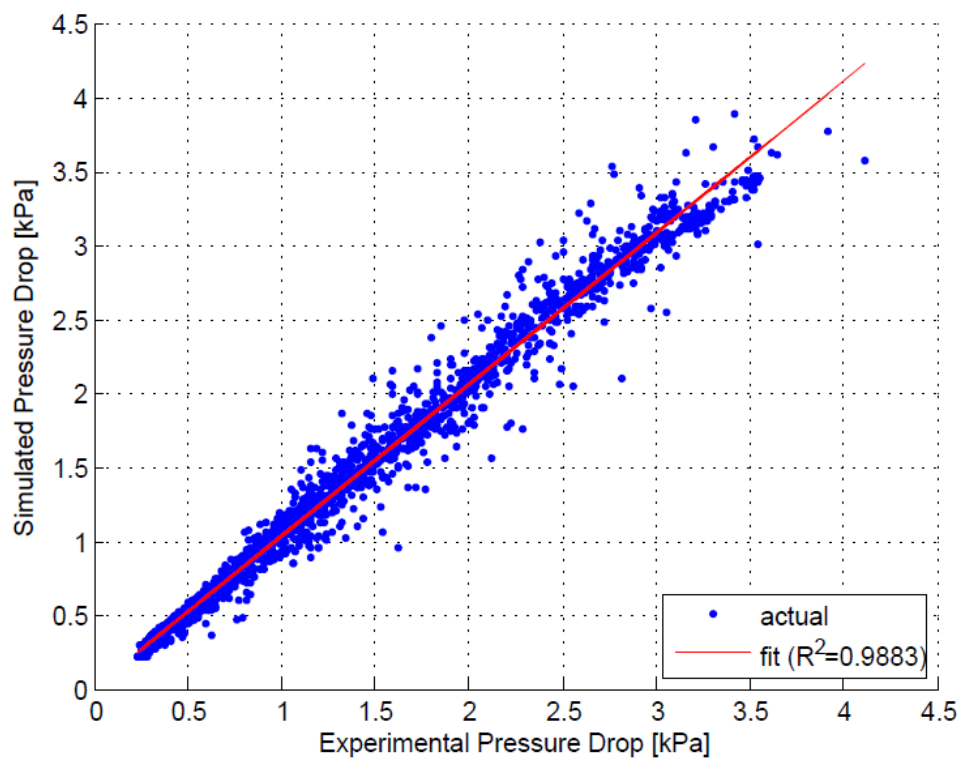

Figure 6.11: Experimental vs. simulated DPF pressure drop

Mass balance of the DPF during the FTP cycle is depicted in Figure 6.12. Even though $\mathrm{NO}_{2}$ assisted regeneration is present in the initial phase of the FTP cycle, the contribution 
towards PM oxidization is very low in comparison to $\mathrm{O}_{2}$ assisted regeneration. This is mainly due to high temperatures occurring in the latter phase of the FTP cycle which in turn triggers different soot oxidization rates described in Chapter 3 and Chapter 5.

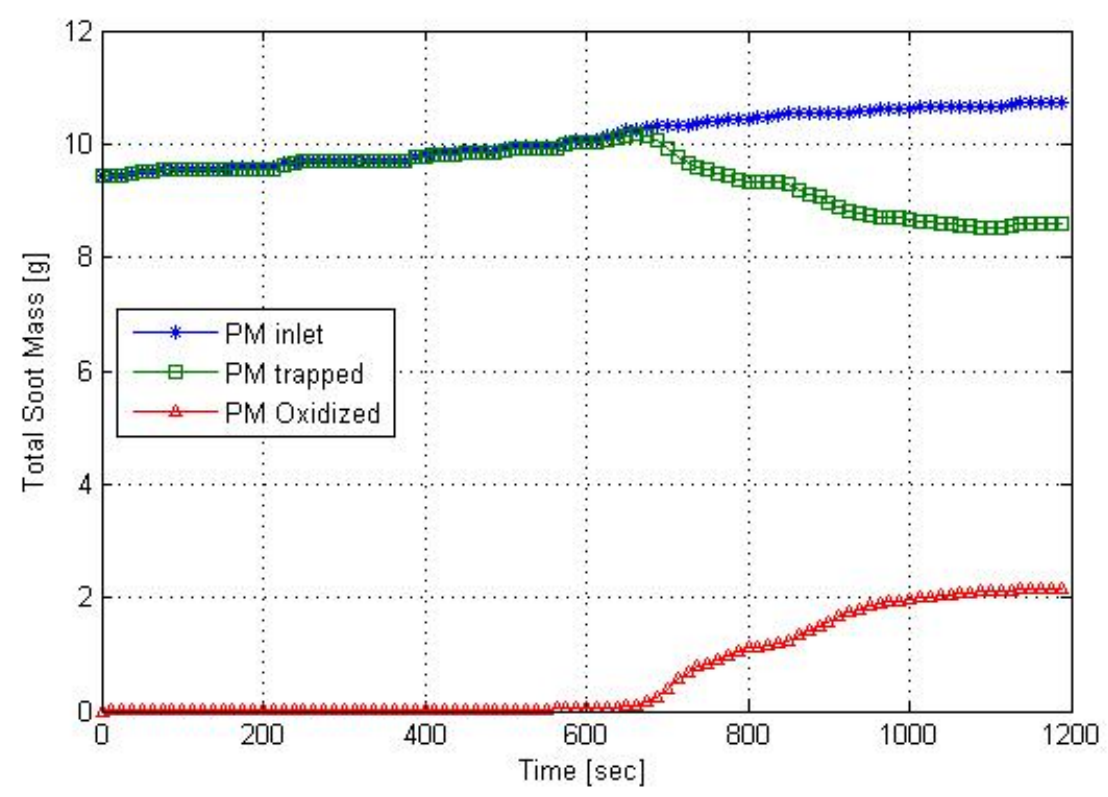

Figure 6.12: Mass balance of DPF during the FTP cycle

The particulate layer thickness distributions along the CPF channel length were plotted in Figure 6.13 with 200 second time intervals. During the New York Non-Freeway (NYNF) and Los Angeles Non-Freeway (LANF) phases of the transient cycle the engine operates mostly at idle conditions with seldom high speed transients. The low temperature conditions delay the regeneration process and assist a growth in soot layer thickness. The uneven soot layer thickness axial distribution during the first part of the loading process is attributed to the effects of wall velocity distribution through the substrate. This differential loading over the axial direction will result in an uneven permeability distribution over the channel length. During the Los Angeles Freeway (LAFY) phase, the engine operates at high speed and high load conditions increasing the inlet channel temperatures. At this point, the soot layer thickness drastically decreases due to $\mathrm{O}_{2}$ assisted regeneration. These exothermic reactions significantly increase the filter wall temperature. 

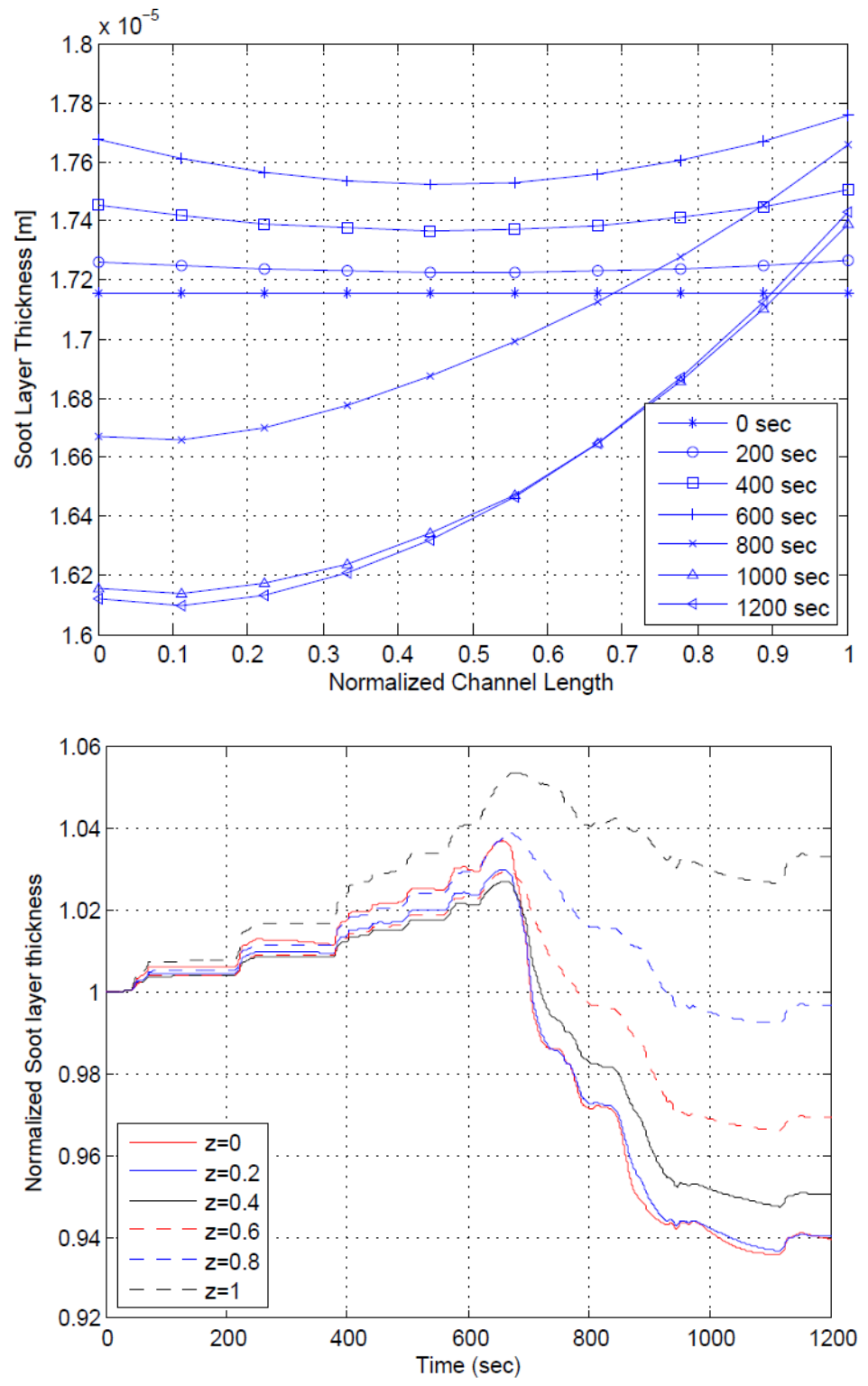

Figure 6.13: Soot layer thickness distribution along normalized CPF channel length (above); Temporal decay of soot layer thickness at different axial locations (below)

Moreover, at any given time, the front face of the CPF is exposed to the highest local temperature and gradually decreases as exhaust gases proceed to end of the channel, mainly due to convective heat loss to the filter wall. This leads to a decrease in the rate of regeneration towards the end of the channel as shown in Figure 6.13 thus collecting more soot at the end of the filter in comparison to the front end. According to Figure 6.13, FTP cycle 
can be regarded as a regenerating and loading cycle when viewing from the front section and the rear end of the DPF respectively. High temperature is generally maintained through the second NYNF phase of the transient cycle due to thermal inertia and continues to further consume the soot layer thickness.

\subsection{1-D and 2-D Model Comparison}

One of the objectives of this study was to use the model under investigation to asses the validity of the assumptions made in the 1-D model. This task will be carried out by comparing the results obtained by the two models related to both steady state and transient engine operating conditions.

\subsubsection{Steady State Cycle Results Comparison}

Pressure drop estimation is one of the main performance parameters of this model. Coefficient of determination values obtained from model predicted and experimental pressure drop values for six loading cycles are given in Table 6.2.

Table 6.2: Coefficient of determination comparison relevent to 1-D and 2-D model predicted and experimental pressure drop during the 30 hour loading phase

\begin{tabular}{lcc}
\hline \hline Cycle & Exp.vs.1-D & Exp.vs.2-D \\
\hline Loading 1 & 0.9458 & 0.9349 \\
Loading 2 & 0.9568 & 0.9631 \\
Loading 3 & 0.8015 & 0.8893 \\
Loading 5 & 0.9438 & 0.9343 \\
Loading 7 & 0.9459 & 0.9541 \\
Loading 8 & 0.7151 & 0.9139 \\
\hline \hline
\end{tabular}

As seen in the Table 6.2, both 1-D and 2-D models produce satisfactory agreements with the experimental pressure drop values during steady state engine operation conditions. One of the main parameters which control filter pressure drop are wall and soot layer permeability and soot layer thickness. The 1-D model uses a cake filtration model and a continuous wall 
soot filtration model. On the other hand, 2-D model uses a constant cake filtration efficiency and a $0-\mathrm{D}$ wall soot filtration model. However, in the given engine operating conditions, cake filtration efficiencies were almost constant and fairly close average cake filtration efficiency used in the 2-D model. Moreover, the change in wall permeability due to the use of 1D continuous filtration model and 0-D filtration model was very small due to the absence of the deep bed filtration phase. Hence, the soot layer thickness predictions given by the two models becomes to the main determination factor contributing to the discrepancy of pressure drop predictions between the two models. The evolution of the soot layer thickness is directly proportional to filter wall velocity during a loading cycle when regeneration effects are minute. Calculated filter wall velocities at four difference axial positions using 2-D model and 1-D model predicted filter wall velocity is given in Figure 6.14.

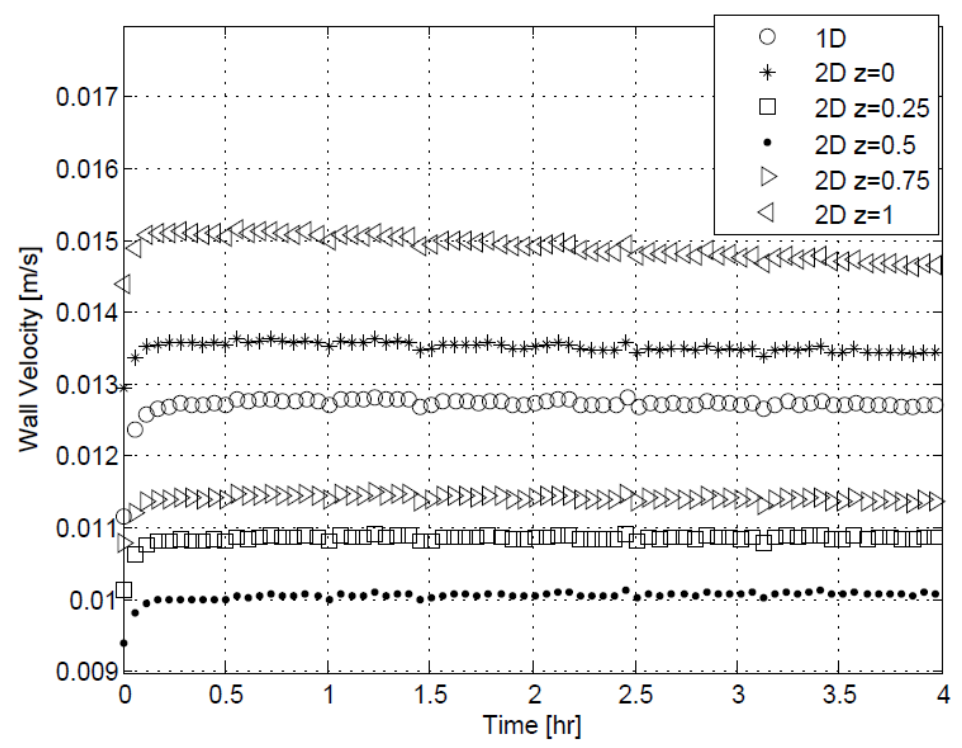

Figure 6.14: Wall velocity distribution comparison along filter length

As illustrated in Figure 6.14, length averaged filter wall velocity given by the 2-D model is approximately equal to the 1-D model predicted filter velocity. Hence one may concluded that, the average soot layer thickness given by the 2-D model is approximately equal to the soot layer thickness given by the 1-D model and thus explain similar pressure drop predictions given by the two models. 
Experimentally measured mass end of each cycle along with 1-D and 2-D model DPF mass estimations are given in Figure 6.15. Mass predictions of the two models agrees well with each other and the maximum discrepancy between mass predictions was $0.98 \mathrm{~g}$.

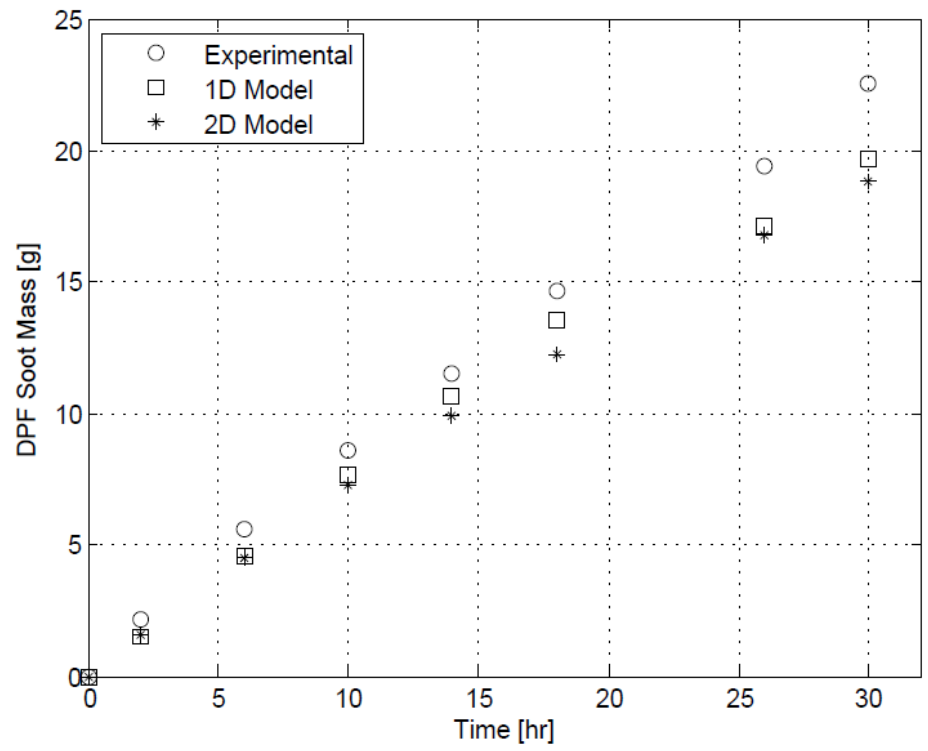

Figure 6.15: 1-D and 2-D DPF soot mass prediction comparison

The 1-D model assumes a constant filter wall temperature along the filter length. However, in reality, filter wall shows a temperature distribution along the filter length as implemented in the 2-D model. As will be shown later in the transient model comparison, treating wall temperature as a distribution becomes significant during soot layer decay due to $\mathrm{O}_{2}$ assisted thermal and catalytic regeneration. However, these regeneration mechanisms initiate typically at temperatures above 500K. The maximum wall temperature attained during the whole loading phase was $495 \mathrm{~K}$. At these temperatures soot layer decays due to $\mathrm{NO}_{2}$ assisted regeneration which is a far less powerful regeneration mechanism compared to the aforementioned. This effect describes the lower soot mass predictions from 2-D model in comparison to 1-D model during the last few loading cycles. 


\subsubsection{Transient Cycle Results Comparison}

As seen in the Table 6.3, both 1-D and 2-D models produce satisfactory agreements with the experimental pressure drop values also during transient engine operation conditions. Both models have shown exceptional ability to accurately capture pressure drop values during highly transient regions of the cycle.

Table 6.3: Coefficient of determination comparison relevent to 1-D and 2-D model predicted and experimental pressure drop during transient cycles

\begin{tabular}{lcc}
\hline \hline Cycle & Exp.vs.1-D & Exp.vs.2-D \\
\hline FTP 1 & 0.9882 & 0.9883 \\
FTP 2 & 0.9884 & 0.9878 \\
\hline \hline
\end{tabular}

During the first half period of the FTP cycle, both models report more or less the same amount of DPF PM loading. During this phase, the temperature difference between inlet and the outlet face of the DPF is small and the temperature at any given section of the DPF can be effectively represented by the 1-D model. However, during LAFY phase the DPF is subjected to high temperatures and the DPF wall temperature gradient cannot be further regarded as a constant. At this point, the front of the DPF burns much more soot mass than the back, and temperature gradient of the wall may not further be modeled by a single temperature. Hence, 1-D model reports more soot mass in comparison to the 2-D model and is reflected in Figure 6.16. 


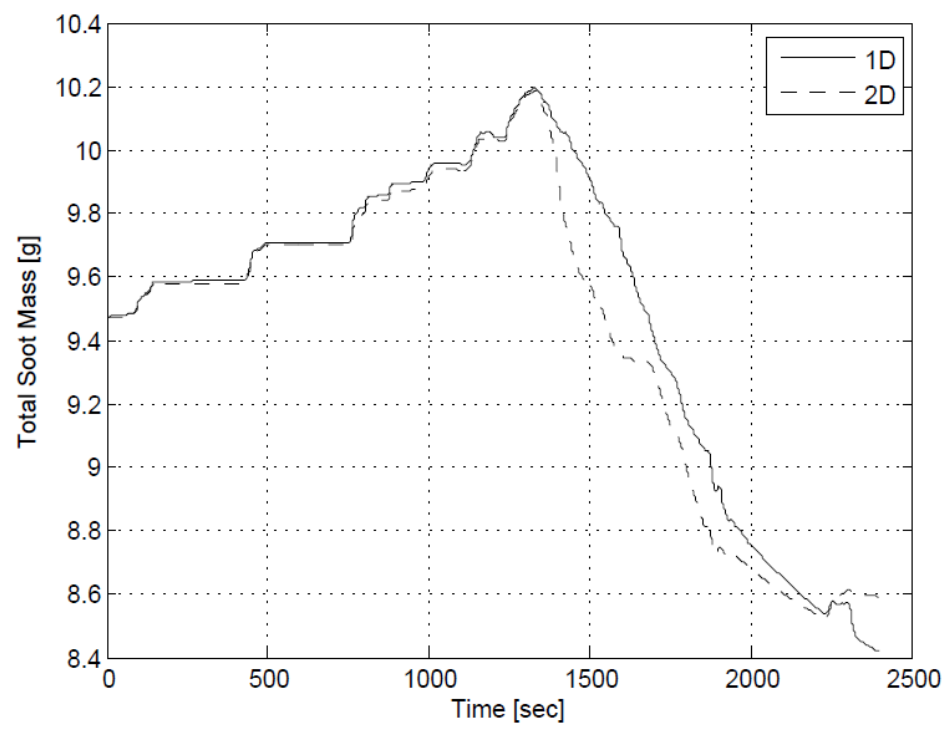

Figure 6.16: Total soot mass predictions of 1-D and 2-D models

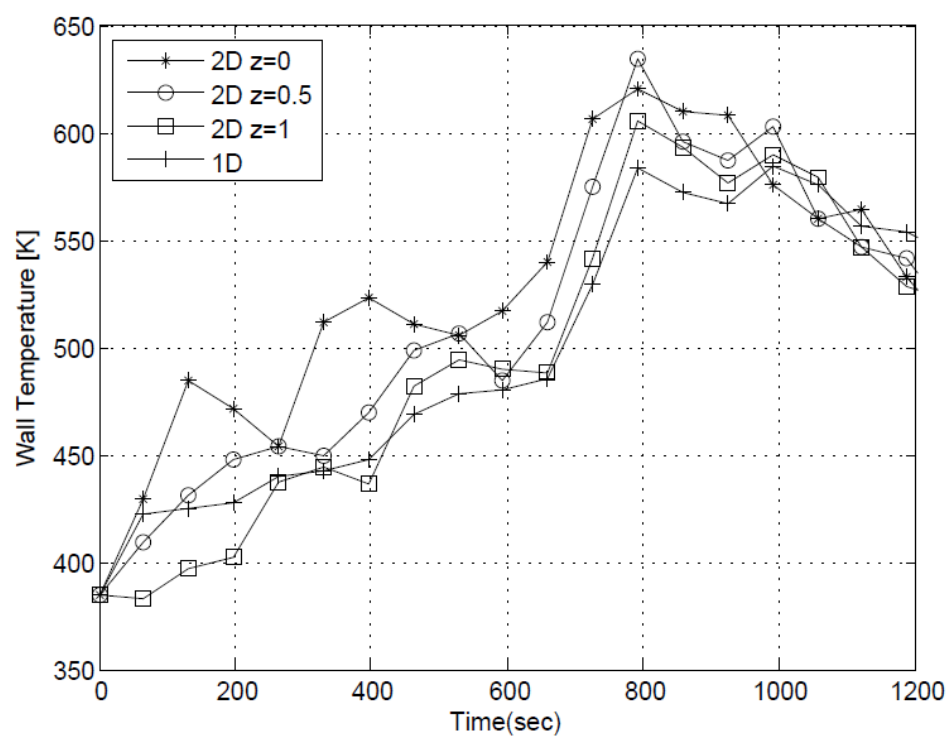

Figure 6.17: Temperature distribution variation at different axial locations

Temperature distribution variation at different axial locations further defends the effect seen in Figure 6.16. As seen in Figure 6.17, 2-D model display significantly higher wall temperature distributions in comparison to the 1-D model. Varying wall temperature distri- 
butions along the channel length and hence make soot particles to oxidize at different rates as opposed to one particular rate assumed in the 1-D model.

Figure 6.18 provides further evidence in favor of 2-D model with a DPF outlet temperature comparison. In this figure, reader could see how well the 2-D model agrees with the experimental data in comparison to the 1-D model. 1-D model does not satisfactorily capture the transient temperature variation given by the experimental data. On the other hand, 2-D model responds to all transient peaks given by experimental conditions with a very good resolution. Better temperature predictions in this high temperature range leads to more accurate regeneration behavior and thus better DPF soot mass predictions.

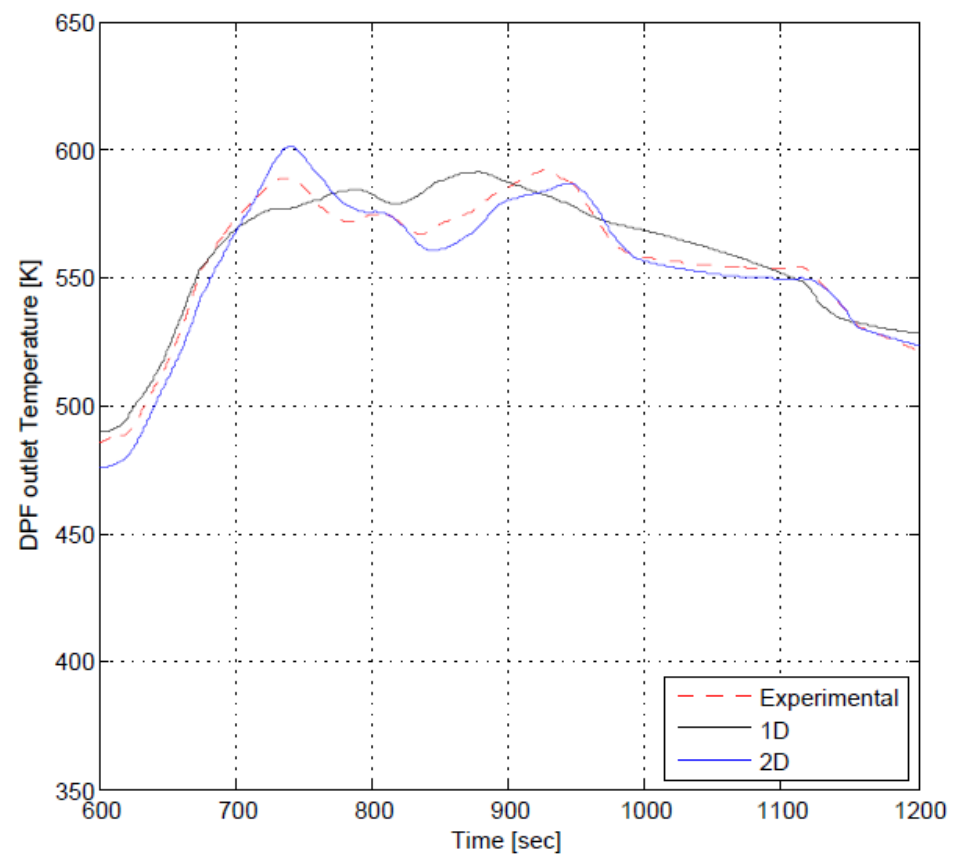

Figure 6.18: DPF outlet temperature prediction comparison

The soot layer thickness evolution in the DPF along the transient cycle is illustrated in Figure 6.19. The 2-D model produces a family of such curves, each representing a certain location of the DPF. A comparison of soot layer distributions between two models reveals that the distribution corresponding to the 1-D model is representative of soot layer distribution given by the 2-D model at one tenth distance away from the DPF front face. Hence, it can 
be concluded that the 1-D model performance is more representative of the region close to the front section of the DPF. However, the difference between the total soot mass collected by two models at the end of the cycle is $2.12 \%$.

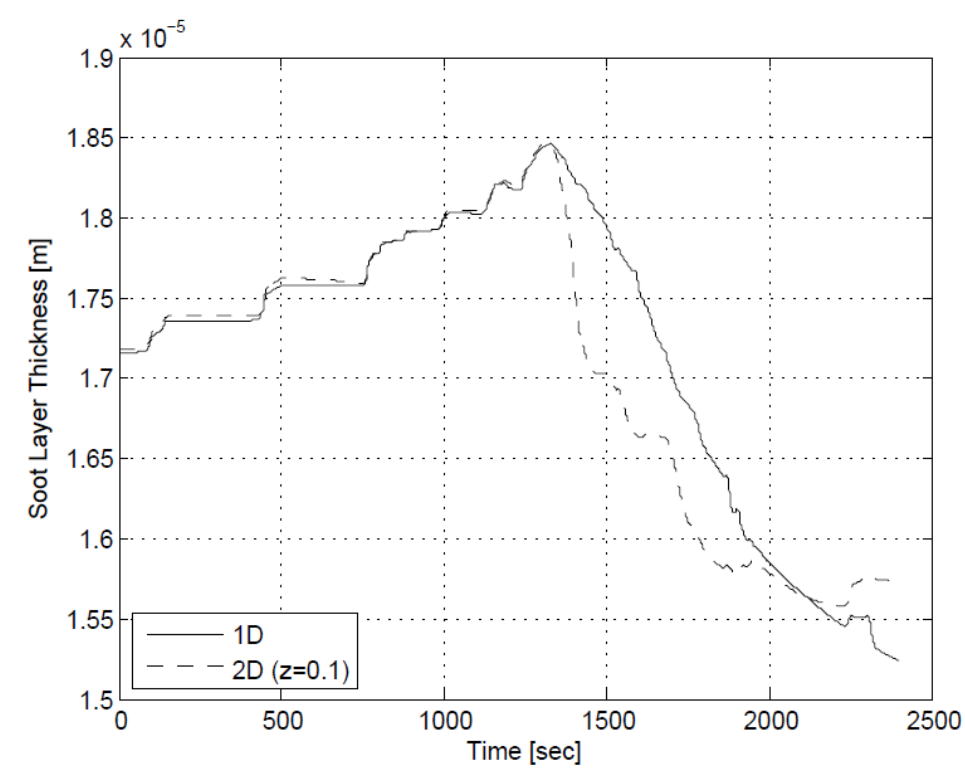

Figure 6.19: Soot layer thickness prediction of 1-D and 2-D models

Both 1-D and 2-D models have shown similar results during the steady state engine operating conditions. During transient engine operating conditions, 2-D model provide slightly better mass prediction than the 1-D model. But the error between the to mass predictions found to be $2.12 \%$. As described earlier, the key performance parameters of the numerical soot model was DPF pressure drop, outlet temperature and mass estimation. In both steady state and transient engine operating conditions, discrepancy of the results obtained by the two models related to the aforementioned performance parameters were well below $3 \%$. Hence the assumptions used to derive $1-\mathrm{D}$ model equations is validated by the $2-\mathrm{D}$ model. 


\section{Chapter 7}

\section{Conclusions}

The current study extended the previously validated 1D filtration and regeneration model in to two dimensional space with the intention analyzing the given problem in a more descriptive manner. The numerical investigation of the two dimensional numerical soot model was performed for both steady state and transient engine operating conditions and results presented here show satisfactory agreement with experimental data. The model is capable of representing the evolution of the DPF back pressure and PM content along the filter channel. According to the discussed results, following conclusions can be drawn.

- Satisfactory correlation between the experimental and simulated pressure drop was obtained $\left(R^{2}=0.88\right.$ for steady state and $R^{2}=0.98$ for transient) for both steady state and transient engine operating conditions. This is one of the key performance metrics of the current model.

- The soot layer thickness evolution is noteworthy at the two ends of the filter close to the inlet and the outlet of the channel. Hence over time wall flow velocity magnitude in the mid region increases and may eventually lead to a constant soot layer thickness distribution across filter length.

- The model is capable of tracking DPF soot mass with a satisfactorily maximum discrepancy of $3.47 \mathrm{~g}$ during steady state cycles.

- The 2D model is able to capture the regeneration phase of the FTP more descriptively 
than the 1D model. However, the reported discrepancy of the total soot mass estimated by two models was $2.12 \%$.

- The distribution corresponding to the $1 \mathrm{D}$ model is representative of soot layer distribution given by the 2D model at one tenth distance away from the DPF front face.

- 1D model representation is effective toward PM loading prediction, although presenting considerable axial effects at higher DPF temperature. 


\section{Appendix A}

\section{Model Validation Using Bissett Model}

In this Appendix, DPF pressure drop and mass retained results were compared with results published in Bissett et al. [4]. The 2-D model showed god agreement with the pressure drop data given by Bissett et al. [4]. Figure A.1 shows that the two sets of results were within \pm $0.25 \mathrm{kPa}$. The maximum difference in mass retained in the filter as calculated by the models (see Figure A.2) was less than $10 \mathrm{mg}$.

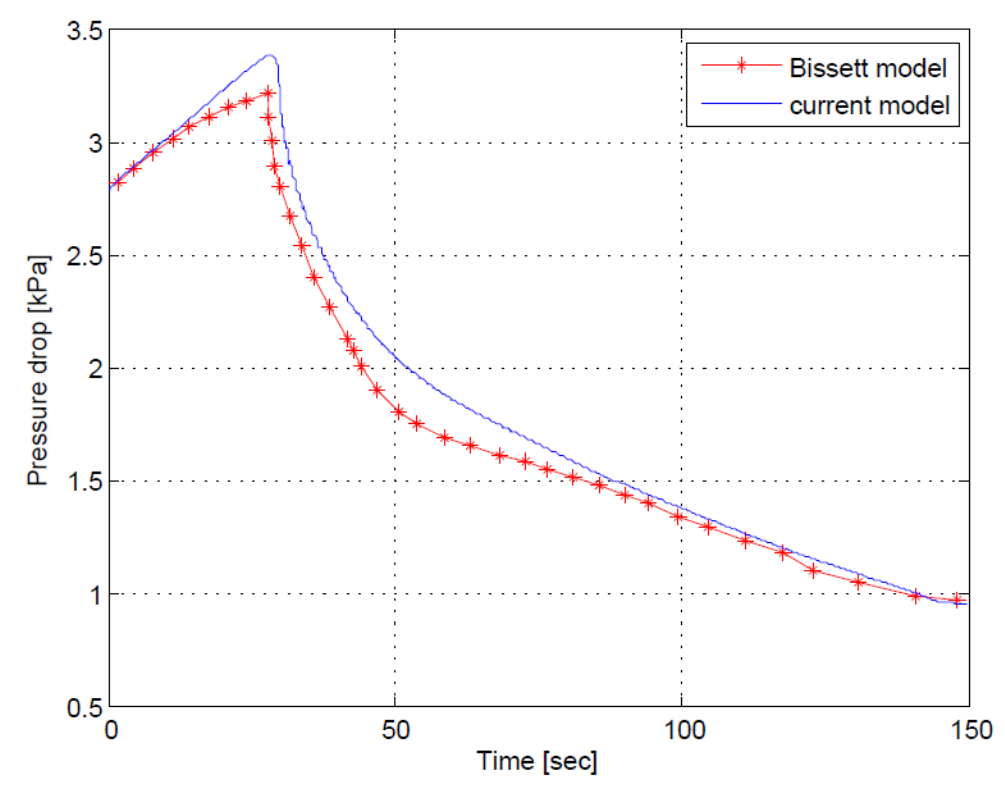

Figure A.1: DPF pressure drop validation using Bissett model 


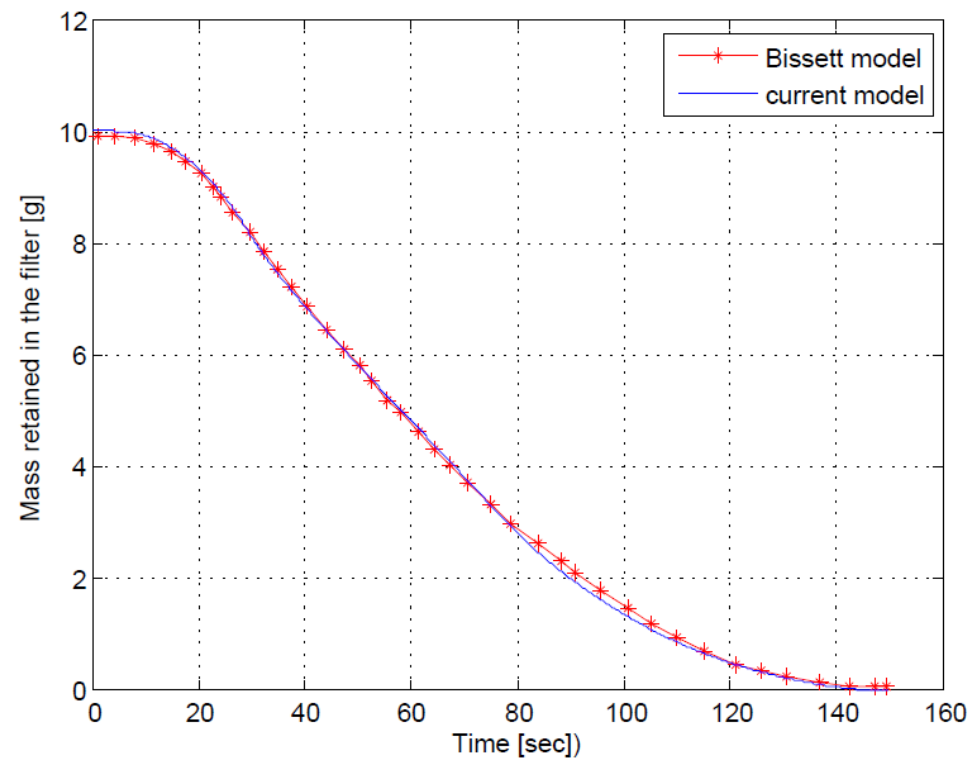

Figure A.2: Mass retained in the DPF validation using Bissett model 


\section{References}

[1] Kitagawa J., Hijikata T. and Yamada S., Electric Heating Regeneration od Large WallFlow type DPF, SAE Technical paper 910136, 1991.

[2] Walton F.B., Hayward P.J. and Wren D.J., Controlled Energy Deposition in Diesel Particulate Filters During Regeneration by Means of Microwave Irradiation, SAE Technical Paper 900327, 1990.

[3] Gautam M., Popuri S., Rankin B. and Seehra M., Development of a Microwave Assisted Regeneration System for a Ceramic Diesel Particulate System, SAE Technical Paper 1999-01-3565, 1999.

[4] Bissett E. J., Thermal Regeneration of Particle Filters with Large Conduction, Mathematical Modeling, Vol. 6, pp.1-18, 1985.

[5] Konstandopoulos A.G., A., Kostoglou, M., Skaperdas, E., Papaioannou, E., Zarvalis D. and Kladopoulou E., Fundamental Studies of Diesel Particulate Filters: Transient Loading, Regeneration and Aging, SAE Technical Paper 2000-01-1016, 2000.

[6] Mohammed H., Triana A.P., Yang S.L. and Johnson J.H., An Advanced 1D 2-Layer Catalyzed Diesel Particulate Filter Model to Simulate: Filtration by the Wall and Particulate Cake, Oxidation in the Wall and Particulate Cake by $\mathrm{NO}_{2}$ and $\mathrm{O}_{2}$ and Regeneration by Heat Addition, SAE Technical Paper 2006-01-0467, 2006.

[7] Konstandopoulos A.G., Kostoglou M., Vlachos N. and Kladopoulou E., Advances in the Science and Technology of Diesel Particulate Filter Simulation, Advances in Chemical Engineering, Vol.33, pp.213-294, 2007.

[8] Rumminger, M., Zhou, X., Balakrishnan K., Edgar, B., and Ezekoye, O., Regeneration Behavior and Transient Thermal Response of Diesel Particulate Filters, SAE Technical Paper 2001-01-1342, 2001.

[9] Khan M. R. and Shamim T. A Numerical Investigation of the Regeneration Characteristics of Diesel Particulate Filters under Simulated Transient Exhaust Conditions, Proceedings of the Institution of Mechanical Engineers, Part D: Journal of Automobile Engineering, pp.2469-2485, 2008.

[10] Kandylas I.P. and Koltsakis G.C., Simulation of Continuously Regenerating Diesel Particulate Filters in Transient Driving Cycles, 
Proceedings of the Institution of Mechanical Engineers, Part D: Journal of Automobile Engineering, pp.591-606, 2002.

[11] Bennett S., MODERN DIESEL TECHNOLOGY:DIESEL ENGINES, New York: Delmar, 2010.

[12] Heywood J.B., INTERNAL COMBUSTION ENGINE FUNDAMENTALS, New York: McGraw Hill, Inc., 1988.

[13] U.S. Environmental Protection Agency. Emission Standards Reference Guide. July 4th 2011. http://www.epa.gov/otaq/standards/heavy-duty/hdci-exhaust.htm.

[14] U.S. Environmental Protection Agency. An Introduction to Indoor Air Quality (IAQ). July 4th 2011. http://www.epa.gov/iaq/co.html.

[15] Carcinogenic Effects of Exposure to Diesel Exhaust, Current Intelligence Bulletin 50, Publication No. 88-116, pp.548-159, 1988.

[16] Eastwood P., PARTICULATE EMISSIONS FROM MOTOR VEHICLES, New Jersey: Wiley and Sons Ltd, 2008.

[17] Zheng M., Reader G.T. and Hawley J.G., Diesel Engine Exhaust Gas Recirculationa review on advanced and novel concepts, Energy Conversion and Management, Vol.45, pp.883-900, 2004.

[18] Platinum Today. Autocatalyst. 4th July 2011. http://www.platinum.matthey.com/applications /autocatalyst/

[19] Nova I., Lietti L., Tronconi E. and Forzatti P., Dynamics of SCR Reaction over a $\mathrm{TiO}_{2}$ supported Vanadia-Tungsta Commercial Catalyst, Catalysis Today, Vol.60, pp.7382,2000 .

[20] Johnson Matthey Emission Control Technologies. Ammonia-SCR. July 15th 2011. http://ect.jmcatalysts.com/emission-control -technologies-ammonia-selective-catalyticreduction-SCR.

[21] Geishoff J., Schaffer-Sindlinger A., Spurk P.C., van den Tilaart J.A.A. and Garr G., Improved SCR systems for Heavy Duty Applications, SAE Technical Paper 2000-01-0189, 2001.

[22] Rao V.D., White J.E., Wade W.R., Aimone M.G. and Cikanek H.A., Advanced Techniques for Thermal and Catalytic Regeneration of Diesel Trap Regeneration, SAE Technical Paper 830083, 1983.

[23] Salvat O., Marez P. and Belot G. Passenger Car Serial Application of a Particulate System on a Common Rail Direct Injection Diesel Engine, SAE Technical Paper 200001-0473, 2000.

[24] Kahir M.K., A Review of Diesel Particulate Filter Technologies, SAE Technical Paper 2003-01-2303, 2003. 
[25] Johnson Matthey Emission Control Technologies. Diesel Particulate Filter. July 15th 2011. http://ect.jmcatalysts. com/emission-control-technologies-diesel-particulate-filterDPF.

[26] Bissett E. J. and Shadman F., Thermal Regeneration of Diesel Particulate Monolithic Filters, AIChE Journal, Vol. 31, 753-758, 1985.

[27] Bissett E. J., Mathematical Model of the Thermal Regeneration of a Wall-Flow Monolith Diesel Particulate Filter, Chemical Engineering Science, Vol. 39, pp.1233-1244, 1984.

[28] Konstandopoulos A.G. and Johnson J.H., Wall-Flow Diesel Particulate Filters-Their Pressure Drop and Collection Efficiency, SAE Technical Paper 890405,1989.

[29] Konstandopoulos A.G. and Kostoglou M., Reciprocating Flow Regeneration of Soot Filters, Combustion and Flame, Vol. 121, pp.488-500, 2000.

[30] Haralampous O.A. and Koltsakis G.C., Oxygen Diffusion Modeling in Diesel Particulate Filter Regeneration, AIChE Journal, Vol.50, pp.2008-2019, 2004.

[31] Haralampous O.A. and Koltsakis G.C., Back Diffusion Modeling of $\mathrm{NO}_{2}$ in Catalyzed Diesel Particulate Filters, Industrial and Engineering Chemistry Research, Vol.43, pp.875-883, 2004.

[32] Kandylas I.P. and Koltsakis G.C., $\mathrm{NO}_{2}$ Assisted Regeneration of Diesel Particulate Filters, Industrial and Engineering Chemistry Research, Vol.41, pp.2115-2123, 2002.

[33] Opris C.N. and Johnson J.H., A 2-D Computational model Describing the Flow and Filtration Characteristics of a Ceramic Diesel Particulate Trap, SAE Technical Paper 980545, 1998.

[34] Opris C.N. and Johnson J.H., A 2-D Computational model Describing the Heat Transfer, Reaction Kinetics and Regeneration Characteristics of a Ceramic Diesel Particulate Trap, SAE Technical Paper 980546, 1998.

[35] Zhang Z., Yang S.L. and Johnson J.H., Modeling and Numerical Simulation of Diesel Particulate Trap Performance during Loading and Regeneration, SAE Technical Paper 2002-01-1019, 2002.

[36] Kladopoulou E.A., Yang S.L., Johnson J.H., Parker G.G and Konstandopoulos A.G., A Study Describing the Performance of Diesel Particulate Filters During Loading and Regeneration - A Lumped Parameter Model for Control Applications, SAE Technical Paper 2003-01-0842, 2003.

[37] Konstandopoulos A.G., Kostoglou M. and Vlachos N., The Multiscale Nature of Diesel Particulate Filter Simulation, International Journal of Vehicle Design, Vol.41, pp.256$284,2006$.

[38] Schejbal M., Koči P., Mareka M. and Kubiček M., Modelling of wall-flow filters for diesel particulate removal, Computer Aided Chemical Engineering, Vol.26, pp.803-808, 2009 
[39] Mulone,V., Cozzolini, A., Abeyratne, P., Littera,D., Thiagaraian,M., Besch,M. and Gautam, M., Soot Modeling for Advanced Control of Diesel Engine Aftertreatment, ASME Journal of Engineering for Gas Turbine Engine and Power, in press

[40] Cozzolini, A., Mulone, V., Abeyratne, P., Littera,D., Gautam, M., Advanced Modeling of Diesel Particulate Filters to Predict Soot Accumulation and Pressure Drop, SAE Technical Paper 2011-24-0187, 2011.

[41] Lee K.W. and Gieske J.A., Collection of Aerosol Particles by Packed Beds, Environmental Science and Technology, Vol.13, pp466-470, 1979.

[42] Harriot P, CHEMICAL REACTOR DESIGN, New York:Marcel Dekker, 2003.

[43] Bejan A., CONVECTION HEAT TRANSFER, New Jersey:Wiley, 2004.

[44] Konstandopoulos A.G., Skaperdas E. and Masoudi M., Inertial Contributions to the Pressure Drop of Diesel Particulate Filters, SAE Technical Paper 2001-01-0909, 2001.

[45] Koltsakis G.C. and Stamatelos A.M.,, Modeling Catalytic Regeneration of Wall Flow Particulate Filters, Industrial Engineering and Chemical Research, Vol.35, pp.2-13, 1996.

[46] Koltsakis, G.C., Dardiotis, C.K., Samaras, Z.C., Maunula, T., Kinnuen T. and Lundorf P., Optimization Methodologies for DPF Substrate-catalyst Combinations, SAE Technical Paper 2009-01-0291, 2009.

[47] Hyunh C.T., Johnson J.H., Yang S.L., Bagley S.T. and Warner J.R., A OneDimensional Computational Model for Studying the Filtration and Regeneration Characteristics of a Catalyzed Wall-Flow Diesel Particulate Filter, SAE Technical Paper 200301-0841, 2003. 